\title{
Home Environments and Allergen Avoidance Practices in a Hot, Humid Climate
}

\author{
Benjamas Kutintara \\ Dissertation submitted to the Faculty of the \\ Virginia Polytechnic Institute and State University \\ in partial fulfillment of the requirements for the degree of \\ Doctor of Philosophy \\ in \\ Housing, Interior Design, and Resource Management \\ and \\ Graduate Certificate in Gerontology
}

\author{
APPROVED \\ Dr. Kathleen R. Parrott, Chair \\ Dr. Julia O. Beamish \\ Dr. Karen A. Roberto \\ Dr. Lawrence H. Cross \\ Dr. Nadia Boschi
}

April 12, 2002

Blacksburg, Virginia

Key words: Allergy, Healthy House, Older People, Home design, Indoor Air Quality, Bangkok, Thailand

Copyright 2002, Benjamas Kutintara 


\title{
Home Environments and Allergen Avoidance Practices in a Hot, Humid Climate
}

\author{
Benjamas Kutintara
}

\section{(ABSTRACT)}

The purpose of the study was to examine home conditions, housing satisfactions, and allergen avoidance practices of people with allergic rhinitis, focusing on female patients who lived in an urban area in a hot, humid climate. The Morris and Winter theory of housing adjustment provides a theoretical base for this study. Nine hypotheses were tested to investigate interrelationships among home conditions, housing satisfaction in terms of health issues, allergen avoidance practices, and age. A sample of 41 female allergy patients aged 20 to 77 years completed a screening questionnaire and an in-depth survey questionnaire. The researcher visited their dwellings to conduct home observations and to take photos.

Dust mite allergens were reported as the most common allergy triggers. Presence of cockroaches, presence of furry pets outdoors, molds in bathrooms, and molds in kitchens were the most common problematic home conditions. Open shelves, bookcases, drapes, horizontal blinds, and foam rubber pillows were the most common allergy related items found in respondents' bedrooms. Concerning health issues, the majority of the respondents were satisfied with their homes. Allergen avoidance practices were not followed regularly, particularly, using allergen-proof pillowcases and sheets, washing bedding in hot water, wearing a particle mask when vacuuming, using an exhaust fan, an air cleaner, a dehumidifier, and cockroach traps. The respondents who received suggestions from doctors were more likely to follow allergen avoidance practices than those who did not receive suggestions.

The result shows a significant negative relationship between problematic home conditions and housing satisfaction in terms of health issues. A significant negative relationship between age and allergen avoidance practices was found. Older sufferers were less likely to use allergen-proof products. They also lived in older homes that were more likely to have allergy related conditions. The most common obstacles that prevented respondents from improving their homes in order to avoid allergens were cost of products, emotional attachment to pets, not having time to improve homes, and procrastination. Based on these findings, design recommendations, home maintenance recommendations, and lifestyle practice recommendations were developed. 


\section{Acknowledgements}

This study could not have been done without the support of many people. I am deeply grateful for their help. I would like to acknowledge and thank the following individuals and organizations.

Dr. Kathleen Parrott, my major advisor, for her advice, encouragement, understanding, and support throughout my doctoral study. Her expertise and kindness are deeply appreciated. study.

Dr. Julia Beamish for her thoughtful suggestions and support throughout my graduate

Dr. Karen Roberto, Dr. Lawrence Cross, and Dr. Nadia Boschi, for their guidance and suggestions. All of my committee members show me good models of teachers and researchers.

Dr. Susan Hutchinson, my former committee member, for making statistics easily understandable.

Each respondent of my questionnaires for the generosity to allow me to visit her home.

Dr. Panuvich Pumhirun, Lt. Col. Savinee Chantasartkosol, and staff at the allergy clinic, Pramongkutkloa Hospital, for allowing me to interview their patients.

Mrs. Monica Moran, Dr. and Mrs. James D. Moran, and the College of Human Resources and Education as well as the Graduate Student Assembly, Virginia Tech for funding this study.

Faculty members in the Department of Interior Architecture, King Mongkut's Institute of Technology Ladkrabang for giving me an opportunity to pursue graduate degrees.

Graduate students, faculty members, and staff in the Department of Near Environments as well as those in the Center for Gerontology for their assistance throughout my graduate study.

Dr. Belhu Metaferia for his love and friendship.

Mrs. Narumol Ratchakum, my dearest friend, for her understanding, joyfulness, and life long friendship.

All of my relatives for their love and support, especially, Na Noi (Mrs. Mantanee Chandarasorn), Na Neng (Dr. Voradej Chandarasorn), and Na Taew (Mrs. Sudarut Limpabundhu) for their help throughout my research.

My brothers and my cousins for their assistance. Special thanks to Jome (Mr. Issadee Kutintara), Kob (Mr. Buncha Limpabundhu), and Pun (Miss Maneekwan Chandarasorn) for their assistance with data collection. 
My grandparents for their love and caring. I pursued gerontology studies because of them.

My parents, Dr. Utis Kutintara and Mrs. Pussadee Kutintara, they inherited me not only allergy genes that inspired me a research topic, but they also gave me the abilities to complete this research. They provided me all supports and continue to do so with their unconditional love. They are my role models. 


\section{Table of Contents}

Abstract.......................................................................... ii

Acknowledgment............................................................. ii

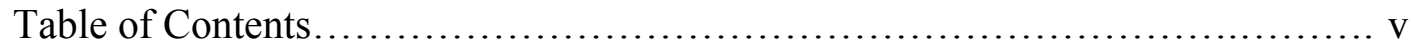

List of Tables................................................................. vii

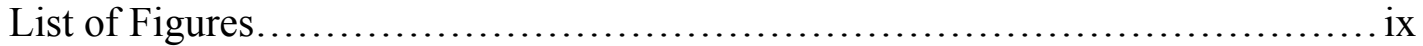

Chapter 1: Introduction........................................................ 1

Statement of the Problem..................................................

The Purpose of the Study ................................................

The Objectives of the Study.......................................... 3

Theoretical Perspective..................................................... 3

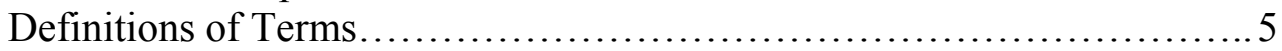

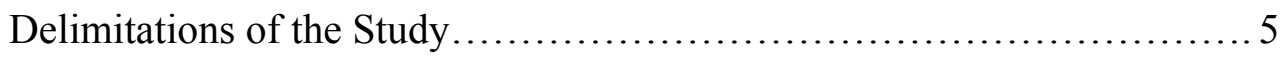

Limitations of the Study ............................................ 5

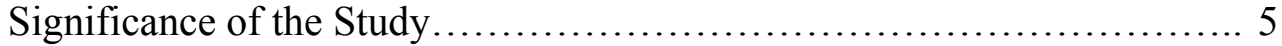

Chapter 2: Literature Review.............................................. 7

Healthy House....................................................... 7

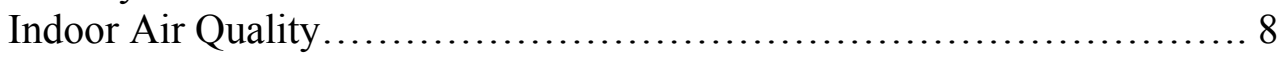

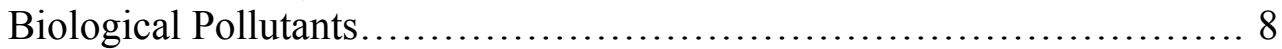

Allergic Diseases................................................. 8

Allergic Rhinitis................................................. 9

Seasonal and Perennial Allergic Rhinitis................................... 9

Allergic Symptoms.............................................. 10

Prevalence of Allergic Rhinitis..................................... 11

Allergy Triggers................................................. 12

Impacts of Allergic Rhinitis..................................... 12

Treatment............................................................. 13

Allergen Avoidance and Environmental Control......................... 14

Dust Mite................................................................. 14

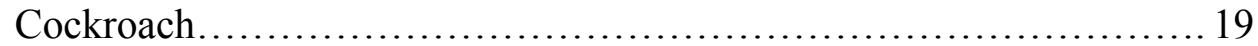

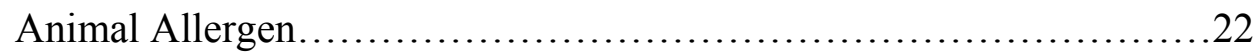

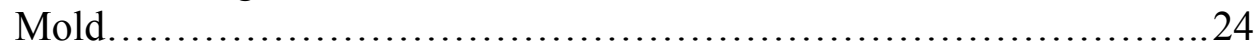

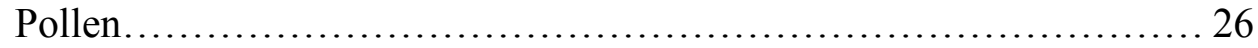

Implementation of Allergen Avoidance................................... 29

Outdoor Air Pollution..................................................... 30

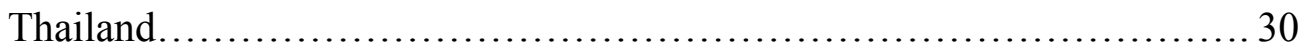

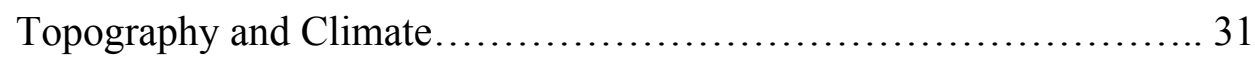

Humidity and Moisture ............................................ 31

Thai People........................................................ 31

Characteristics of Dwellings in Thailand.............................. 32

Housing Satisfaction.................................................... 32

Theoretical Framework............................................... 33

Chapter 3: Methodology ...................................................... 36

Hypotheses of the Study ......................................... 36

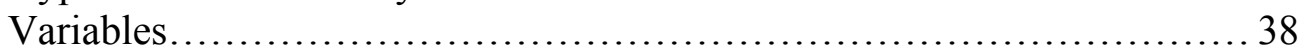

Home Conditions..................................................... 38 


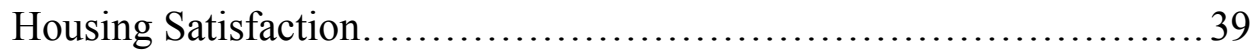

Allergen Avoidance Practices..........................................39

Age................................................................. 40

Research Design................................................ 40

Population and Sample................................................. 41

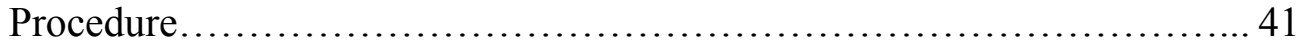

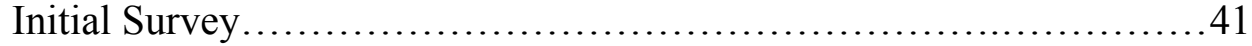

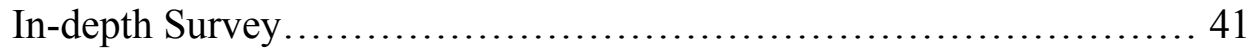

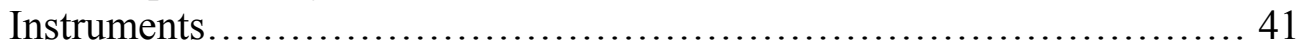

Screening Questionnaire............................................. 42

In-depth Survey Questionnaire................................... 42

Pilot Test................................................................. 42

Data Analysis......................................................... 42

Chapter 4: Findings and Discussion......................................... 43

Demographic Characteristics, Housing, and Health Situations...............43

Description of the Sample........................................ 43

Allergy Information............................................... 44

Respondents' Housing Situation....................................... 44

Indoor Humidity and Temperature................................... 46

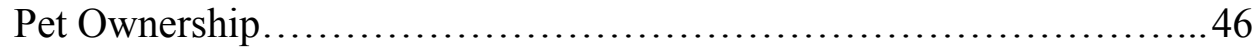

Home Conditions....................................................... 48

Allergy Related Items........................................... 48

Allergy Related Conditions........................................50

Housing Satisfaction................................................ 51

Allergen Avoidance Practices............................................53

Household Changes................................................ 53

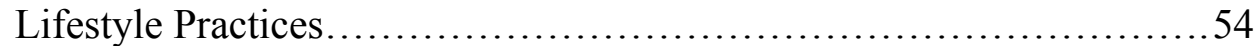

Hypothesis Testing Results.......................................56

Relationships Among Composite Variables...........................5 56

Differences in Age Groups.......................................... 57

Results from Open-ended Questions................................... 58

Intended Changes.................................................59

Suggestions about Improving Home Indoor Air Quality..................59

Obstacles to the Improvement of the Homes.............................59

Help in Controlling Allergens in Homes.................................59

Additional Statistical Analysis Results....................................59

Relationship between Each Home Condition and Housing Satisfaction.. 60

Relationship between Housing Satisfaction and Avoidance Practices.... 60

Relationship between Home Conditions and Each Avoidance Practice...60

Relationship between Age and Each Home Condition......................61

Relationship between Age and Each Housing Satisfaction.................61 61

Respondents' Housing Situations.................................... 61

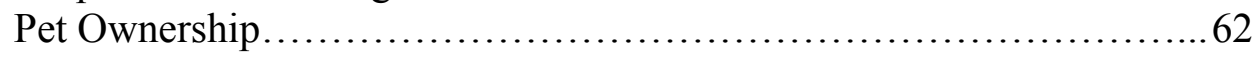

Home Conditions.................................................... 62

Allergen Avoidance Practices: Household Changes.................... 63

Allergen Avoidance Practices: Lifestyle Practices.......................63 63 


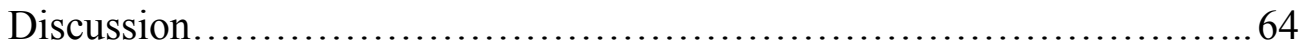

Demographic Characteristics, Housing, and Health Situations............ 64

Home Conditions....................................................... 65

Housing Satisfaction............................................ 65

Allergen Avoidance Practices.........................................65

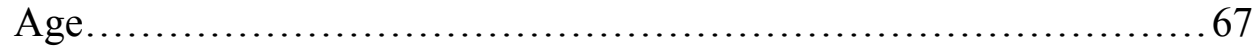

Discussion of the Theoretical Model...................................6 67

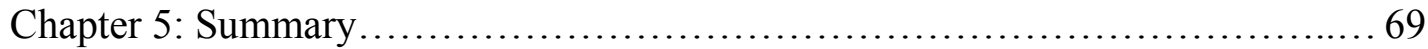

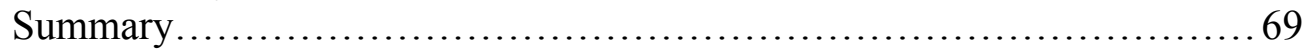

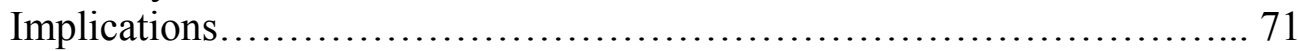

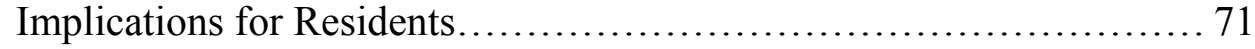

Implications for Designers and Builders.............................. 71

Implications for Researchers................................... 71

Implications for Educators....................................... 72

Implications for Policy Makers.................................. 72

Recommendations ................................................ 73

Design Recommendations......................................... 73

Home Maintenance Recommendations................................ 73

Lifestyle Practice Recommendations..............................74

Recommendations for Further Research............................. 74

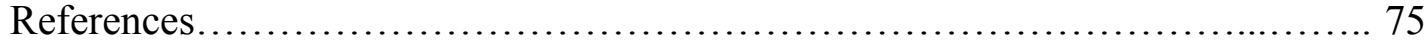

Appendices

A. Screening Questions: English Version............................ 86

B. Screening Questions: Thai Version................................. 88

C. Questionnaire: English Version..................................... 90

D. Questionnaire: Thai Version.................................... 95

E. Things That the Respondents Planned to Change in Their Homes....... 101

F. Suggestions from the Respondents............................... 102

G. Obstacles to the Improvement of the Homes......................... 103

H. Sources of Professional Help in Controlling Allergens in Homes......... 104

I. Types of Help in Controlling Allergens in Homes........................ 104

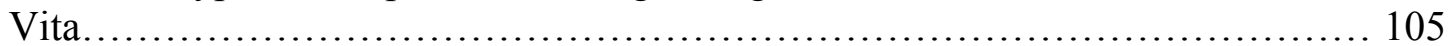




\section{List of Tables}

Table

1 Age of Respondents.

2 Marital Status of Respondents....................................... 44

3 Duration of Allergic Rhinitis and Treatment............................... 44

4 Allergens to Which Respondents were Allergic.............................. 44

5 Housing Type...................................................... 45

6 Homeownership................................................. 46

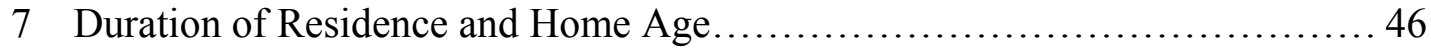

8 Pet Ownership.......................................................... 46

9 Location of Pets........................................................ 47

10 Washing Pets...................................................... 47

11 Presence of Allergy Related Items in the Respondents' Bedrooms............ 48

12 Presence of Allergy Related Conditions in Dwellings...................... 50

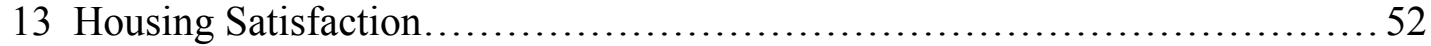

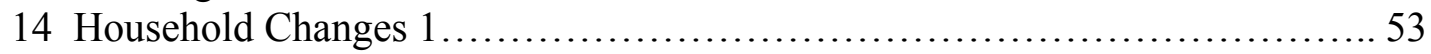

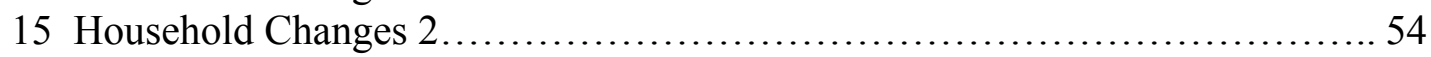

16 Lifestyle Practices.................................................... 55

17 Means and Standard Deviations of Composite Variables.....................57

18 No Significant Difference between the Age Groups......................... 58

19 Relationship between Presence of Molds in Kitchens and Housing Satisfaction60

20 Significant Relationship Between Age and Each Allergen Avoidance Practice 61

21 Distribution of Respondents by Housing Type and Pet Ownership............ 62

22 Distribution of Respondents by Suggestions from Doctors and the Usage of Kapok Pillows.....................................................6 62

23 Relationship between Household Changes and Other Variables................63

24 Relationship between Lifestyle Practices and Other Variables.................64 


\section{List of Figures}

Figure Page

1 Visual Model of Housing Adjustment Theory .............................. 34

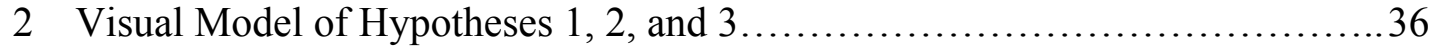

3 Visual Model of Hypotheses 4, 5, and 6................................. 37

4 Visual Model of Hypotheses 7, 8, and 9................................... 38

5 House.......................................................... 45

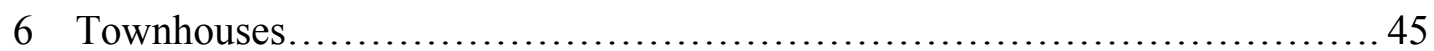

7 Shophouses........................................................ 45

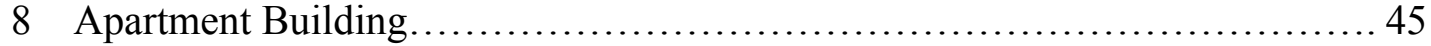

9 Nuns' Apartment......................................................... 45

10 A Parrot................................................................... 47

11 A Hill Myna........................................................... 47

12 A Pet Not Allowed Indoors............................................ 47

13 Pets Allowed Indoors.................................................. 47

14 Open Shelves............................................................. 48

15 Open Bookcases....................................................... 48

16 Drapes............................................................ 49

17 Upholstered Furniture................................................. 49

18 Carpet Flooring ...................................................... 49

19 Wooden Flooring ...................................................... 49

20 No Open Shelve and No Drape.......................................... 49

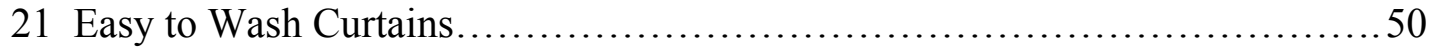

22 Molds in Bedroom........................................................ 50

23 Molds in Kitchen....................................................... 50

24 Relationships Among Composite Variables................................ 57

25 Housing Adjustment Theory........................................... 67

26 A Final Model......................................................... 68 


\section{Chapter 1}

\section{Introduction}

Allergies are chronic diseases which affect approximately $20 \%$ of people worldwide. Strong scientific evidence indicates that the prevalence of allergic disorders has increased in the last decade (Peat, 1994). Allergic rhinitis is the most common of all allergic disorders. Allergic rhinitis is the condition when allergies cause the inflammation of the lining of the nose. It may produce sneezing, congestion, runny nose, and itchiness in the nose, throat, eyes, and ears. Allergic rhinitis adversely affects the health and quality of life of sufferers. Allergic rhinitis causes pain and suffering as well as affects how people perform at work, school, and home (Bousquet et al., 1994). Allergic rhinitis contributes to substantial economic loss due to medication cost and reduced productivity. Allergic rhinitis is associated with fatal diseases such as asthma. The prevalence of allergic rhinitis around the world ranges from $4 \%$ to more than $40 \%$ (Schoenwetter, 2000). It is estimated that the prevalence of allergic rhinitis in Thailand is $20 \%$ of population (Pumhirun, Towiwat, \& Mahakit, 1997). The increasing prevalence of allergic rhinitis in many countries, including Thailand, demands more research studies on treatment and prevention of the disease (Vichyanond, Jirpongsananuruk, Visitsuntorn, \& Tuchinda, 1998).

Allergic rhinitis is caused by exposure to allergens such as dust mite droppings, cockroach droppings, animal dander, mold spores, and pollen. There is not yet a cure for allergic rhinitis; however, there are many treatments available to lessen symptoms (Storms, Meltzer, Nathan, \& Selner, 1997a). Allergen avoidance is an effective means of reducing allergy symptoms (Corren, 2000). A large percentage of hospital visits can be prevented by educating allergy sufferers about allergen avoidance practices (Pope, Patterson, \& Burge, 1993). Allergen avoidance practices also help increase the effectiveness of medical treatments (Berger, 2000). Allergen avoidance practices are discussed widely in the medical field, but the implementation of allergen avoidance by patients is still limited (Platts-Mills, Vaughan, Melody, Carter, \& Woodfolk, 2000; de Blay, et al., 2001; Callahan, et al., 2001). Many allergy sufferers are not aware of the association between allergen exposure and their allergic symptoms.

Brown and Hawkins (1999) pointed out that surveys of allergic diseases are often based on children and practices of parents. Previous research on allergies and allergen avoidance was aimed at children because allergies (as well as asthma and eczema) are the most frequently reported chronic condition in children. However, in allergic rhinitis, the prevalence was highest among those aged 18 to 49 years (Nathan, Meltzer, Selner, \& Storms, 1997). Adult-onset allergies are becoming more common (Corren, 2000). A longitudinal study showed that the frequency of allergic rhinitis increased with age (Settipane, Hagy, \& Settipane, 1994). The prevalence of allergic rhinitis is likely to increase with the aging of the population (Meltzer, 1997). However, there are limited research studies on allergies in the older population.

The percentage of older population in Thailand will grow from 9\% in the year 2000 to $15 \%$ in the year 2020 (Titapunkul \& Bunnag, 1997). The Royal Thai government policy on the care of older persons encourages researchers to study issues related to the prevention of diseases 
(Titapunkul \& Bunnag, 1997). Thus, allergies and allergen avoidance are important topics of study.

The studies on allergen avoidance are interdisciplinary. Several medical experts indicated the need of collaboration from researchers in many areas, including interior design, to solve this complex problem (Pope et al., 1993; Tovey \& Marks, 1999). Health becomes a priority for designing home environments when the occupants have special health needs such as allergies. Air quality becomes the major emphasis in these cases (Rousseau \& Wasley, 1997). Interior designers work directly with homeowners to specify floor coverings, furniture, window treatments, and accessories for new construction and remodeling projects. The understanding of the potential adverse health effects associated with indoor environments can help designers create healthier home environments. Studies on home environments of people with allergic rhinitis should be conducted to provide information for allergy sufferers and interior designers.

\section{Statement of the Problem}

The prevalence of allergic rhinitis is increasing rapidly in Thailand (Vichyanond, Pothikamjorn, \& Raxrungtham, 2000). This increase leads to the need for urgent treatment. Medical experts recommended that the primary treatment is to prevent allergic rhinitis by allergen avoidance. Control of allergens in homes can reduce allergy symptoms. Home environments and lifestyle practices play significant roles in allergen avoidance. However, the implementation of allergen avoidance by allergy sufferers is still limited (Platts-Mills et al., 2000; de Blay, et al., 2001; Callahan, et al., 2001).

There are only a few studies on allergen avoidance practices in hot and humid climates although people who live in these areas have a high risk of allergen exposure. Hot and humid climates support the growth of the dust mites, cockroaches, and molds that are major sources of allergens. Moreover, pollen exist in the hot and humid climates all year round. Most of the previous studies on allergic rhinitis were conducted in countries with cold or temperate climates. Allergy information from hot and humid climates is needed.

It is predicted that the prevalence of allergic rhinitis is likely to increase with the aging of the population (Meltzer, 1997). However, research studies on older people with allergic rhinitis are rare worldwide. Even though the aging population is increasing in Thailand (Petchurai \& Wiriyawachkul, 1995), no study on Thai older people with allergic rhinitis could be found. The Allergy and Immunology Society of Thailand indicated the need for research-based information on people with allergic rhinitis, especially adults and older adults (Vichyanond et al., 2000). There are limited reports on homes of allergy sufferers in Thailand. Moreover, information concerning allergen avoidance practices of Thai adults and older adults with allergic rhinitis has not been documented. For these reasons, it is important to examine home environments of people with allergic rhinitis in Thailand.

\section{The Purpose of the Study}

The purpose of the study was to examine home conditions, housing satisfactions and allergen avoidance practices of people with allergic rhinitis in a hot, humid climate. 
The objectives of the study were:

\section{Objectives of the Study}

1. To describe home conditions, housing satisfaction, and allergen avoidance practices of people with allergic rhinitis.

2. To investigate the interrelationship among home conditions, housing satisfaction, and allergen avoidance practices of people with allergic rhinitis.

3. To investigate the relationship between chronological age and home conditions, housing satisfaction, and allergen avoidance practices of people with allergic rhinitis.

\section{Theoretical Perspective}

The theory of housing adjustment (Morris \& Winter, 1978) provides a theoretical base for this study. This theory stresses that cultural, community, and family norms provide the basis for housing satisfaction. When the household's dwelling does not meet the household's needs, a housing deficit occurs, leading to housing dissatisfaction. The household makes an adjustment in order to increase housing satisfaction. This theoretical perspective will be discussed further in the next chapter. The theory is widely used in housing studies. However, this theory has not been broadly explored in a healthy house context. This study explored the role of housing adjustment and housing satisfaction in promoting a healthy house.

\section{Definitions of Terms}

The following definitions are based on information from the American Academy of Allergy, Asthma, and Immunology (2001a).

Allergen - A foreign substance that leads to allergies by starting an immune response. Allergens include airborne pollens and molds, animal dander (dead skin flakes), house dust mite and cockroach droppings, and indoor molds.

Allergic Rhinitis - Inflammation of the mucous membrane that lines the nose due to an allergic response to pollen, dust, or other airborne substances. The inflammation causes sneezing, runny nose, postnasal drip, and congestion. Seasonal allergic rhinitis is known as hay fever.

Allergy - Inappropriate or exaggerated reactions of the immune system to substances that in the majority of people cause no symptoms.

Antibody - An antibody is a protein (also called an immunoglobulin) that is manufactured by lymphocytes (a type of white blood cell) to neutralize an antigen or foreign protein. When the body forms a type of antibody called $\operatorname{IgE}$ (immunoglobulin $\mathrm{E}$ ), an allergic response may result when the patient is again exposed to the substance which caused IgE antibody formation (allergen). 
Antigen - An antigen is a substance that can trigger an immune response, resulting in production of an antibody as part of the body's defense against infection and disease. Many antigens are foreign proteins (those not found naturally in the body).

Asthma - Asthma is a chronic, inflammatory lung disease characterized by recurrent breathing problems. Episodes of asthma are triggered by allergens, infection, exercise, cold air, and other factors.

Histamine - Histamine is a chemical present in cells throughout the body that is released during an allergic reaction. Histamine is one of the substances responsible for the symptoms of inflammation and is the major cause for running of the nose, sneezing, and itching in allergic rhinitis. It also stimulates production of acid by the stomach and narrows the bronchi or airways in the lungs.

Immune System - The immune system is a collection of cells and proteins that works to protect the body from potentially harmful, infectious microorganisms such as bacteria, viruses, and fungi. The immune system plays a role in the control of diseases, but also is the culprit in allergies and hypersensitivity.

Immunoglobulin E (IgE) - A class of antibodies normally presents in very low levels in humans but found in larger quantities in people with allergies and certain infections. Evidence suggests that IgE is the primary antibody responsible for the allergic reaction.

Immunoglobulins - Immunoglobulins, also known as antibodies, are proteins found in blood and in tissue fluids. Immunoglobulins are produced by cells of the immune system called B-lymphocytes. Their function is to bind to substances in the body that are recognized as foreign antigens (often proteins on the surface of bacteria and viruses). This binding is a crucial event in the destruction of the microorganisms that bear the antigens. Immunoglobulins also play a central role in allergies when they bind to antigens that are not necessarily a threat to health and provoke an inflammatory reaction.

Immunotherapy - Immunotherapy (allergy shots) is a form of preventive and antiinflamamtory treatment of allergy to substances such as pollen, house dust mites, fungi, and stinging insect venom. Immunotherapy involves gradually increasing doses of the substance, or allergen, to which the person is allergic. The incremental increases of the allergen cause the immune system to become less sensitive to the substance, perhaps by causing production of a particular blocking antibody, which reduces the symptoms of allergy when the substance is encountered in the future.

Inflammation - Inflammation is the redness, swelling, heat, and pain in a body tissue due to chemical or physical injury or to infection. It is a characteristic of allergic reactions in the nose, lung, and skin.

Mast cell - Mast cells play an important role in the body's allergic response. Mast cells are present in most body tissues, but are particularly numerous in connective tissue, such as the dermis (innermost layer) of skin. In an allergic response, an allergen stimulates the release of 
antibodies, which attach themselves to mast cells. Following subsequent allergen exposure, the mast cells release substances such as histamine (a chemical responsible for allergic symptoms) into the tissue.

Respiratory system - The respiratory system is the group of organs responsible for carrying oxygen from the air to the bloodstream and for expelling the waste product carbon dioxide.

Sensitization - Repeated exposure to a foreign substance (antigen) that results in IgE production and makes the patient susceptible to an allergic reaction.

\section{Delimitations of the Study}

The research location was limited to the Bangkok Metropolitan Area, Thailand. Other parts of Thailand were not included. The sample included only people with allergic rhinitis. The sample did not include people with other kinds of allergies such as food allergies and eczema. Only five major allergens were studied. The five major allergens were dust mite allergen, cockroach allergen, animal allergen, mold allergen, and pollen.

\section{Limitations of the Study}

The sample of this study was a convenience sample. Therefore, the results of this study will be less generalizable than those based on a randomly selected sample.

\section{Significance of the Study}

This study of home environments of people with allergic rhinitis in a hot, humid climate is important for several reasons.

1. This study provides research-based information on Thai people with allergic rhinitis. This information is needed by the Allergy and Immunology Society of Thailand.

2. This study responds to a health policy of the Royal Thai government that emphasizes disease prevention. A primary way to prevent allergy symptoms is to avoid allergens. This study focuses on allergen avoidance practices in home environments where people spend most of their time.

3. This study provides information on home environments of allergic patients who live in a hot and humid climate.

4. This study provides information about older people with allergic rhinitis. The Allergy and Immunology Society of Thailand indicated the need for studies on adults and older adults with allergic rhinitis (Vichyanond et al., 2000). 
5. This study provides information on special needs of people with allergic rhinitis. This information is useful for designers in order to better design appropriate home environments for allergy sufferers.

6. This study provides information on the interrelationship among home conditions, housing satisfaction, and allergen avoidance practices. This information is useful for researchers and practitioners concerned about healthy houses. The study can help raise awareness of healthy environments and the significance of the interrelationships among health conditions, people' behaviors, and home environments.

7. The results of this study are useful for allergy sufferers, designers, housing professionals, gerontologists, medical experts, educators, and researchers. 


\section{Chapter 2}

\section{Literature Review}

The review of literature for this study explored related research on allergen avoidance practices. First, the concept of a healthy house and indoor air quality are discussed. Then, allergic rhinitis and allergen avoidance practices are discussed. The final section of this chapter focuses on the housing adjustment theory.

\section{Healthy House}

The concept of a healthy house was introduced by the Baubiologie movement from Germany in 1975. Baubiologie means building biology. It deals with the study of the impact of built environments upon the health and well being of people and animals (Hunter, 1989; Pearson, 1998). Health and ecology are primary concerns in the concept of a healthy house. The concept of a healthy house emphasizes how buildings should be designed with the optimum health of inhabitants in mind. The aim of the healthy house is to provide living environments that are free from pollutants, are in tune with the needs, feelings, and spiritual aspirations of the family, and in concert with nature (Baggs \& Baggs, 1996). Healthy houses can play a significant role in preventing health problems while living in unhealthy houses can lead to negative health symptoms (Rousseau \& Wasley, 1997).

\section{Indoor Air Quality}

Good air quality is an important component of a healthy house. The indoor air should be free from significant levels of odors, dust, and contaminants and should circulate to prevent stuffiness without creating drafts. The quality of the indoor air in homes has a major impact on people who live in them. Good indoor air quality enhances occupant health, well being, and productivity. In contrast, breathing polluted indoor air can lead to immediate health problems (irritation of the eyes, nose, and throat, headaches, dizziness, fatigue, allergies, asthma, hypersensitivity pneumonitis, and humidifier fever) and long-term health problems (respiratory diseases, heart disease, and cancer) (U.S. Environmental Protection Agency [EPA], 2001a).

The length of exposure, the type of exposure, age, health status, and sensitivity affect how people react to indoor pollution (Parrott, 1997). It is widely recognized that most people spend a majority of their time indoors at home. A study from Italy confirmed that people spent almost two-thirds of their daily lives at home (64\%) (Simoni et al., 1998). People spend around one-third of their time in bedrooms. Infants, elderly people, and most urban residents are most susceptible to the effects of air quality because they spent greater amounts of time indoors.

Studies showed that the quality of indoor air could be worse than that of outdoor air (Wallace, et al., 1986; U.S. EPA, 2001a). The concentrations of many pollutants indoors exceed those outdoors. In order to minimize heating and air-conditioning costs, many homes are built tightly without regard to healthy indoor air. Tighter houses can trap pollutants indoors. Indoor air pollutants come from many sources including biological pollutants, combustion products, household products and furnishings, tobacco smoke, asbestos, formaldehyde, lead, radon, and 
outdoor air pollution. Inadequate ventilation can increase indoor pollutant levels as well as high temperature and humidity levels that can increase concentration of some pollutants (U.S. EPA). This study will focus on biological pollutants only.

\section{Biological Pollutants}

Biological pollutants come from living things such as bacteria, viruses, dust mites, cockroaches, dander from animals, molds, and pollen from plants. Biological pollutants are found to some degree in every home. These biological pollutants can cause health problems. Viruses cause illnesses such as influenza. Dust mites, cockroaches, animal dander, molds, and pollen trigger allergic reactions, allergic rhinitis, and asthma (Pope et al., 1993; U.S. EPA, 2001b). The U.S. Environmental Protection Agency indicates that allergic reactions may be the most common health problem associated with indoor air quality in homes.

Biological pollutants from dust mites, cockroaches, and molds are related to indoor moisture problems. High humidity levels, inadequate ventilation, and poor home maintenance encourage the growth of these biological pollutants. The U.S. EPA (2001b) reported that $30 \%$ to $50 \%$ of all structures in the United States and Canada have moisture problems that may encourage the growth of biological pollutants. The percentage was expected to be higher in hot and humid climates.

\section{Allergic Diseases}

Allergy means altered reaction. Allergy is a genetic condition causing the body to respond to harmless substances in the environment as though they were dangerous invaders. This response produces symptoms that may be mild to life-threatening. When the allergic person comes into contact with the offending substance, the body's immune system begins to produce antibodies. These antibodies alter the way in which the body reacts and produce allergic symptoms. Any substance that can trigger an allergic response is an allergen. Types of allergens that cause allergic reactions include pollens, dust particles, mold spores, food, latex rubber, insect venom, and medicines. People who have allergies often are sensitive to more than one substance (American Lung Association Asthma Advisory Group [ALAAAG] \& Edelman, 1997; The National Institute of Allergy and Infections Diseases [NIAID], 1998; Berger, 2000).

Allergic diseases consist of diseases caused directly by an allergy and diseases that result indirectly from allergy. The most common allergic diseases are allergic rhinitis, asthma, food allergies, drug allergies, urticaria (hives), and eczema (Young, Dobozin, \& Miner, 1999). Allergic rhinitis is characterized by sniffling, sneezing, and watery eyes. Asthma is characterized by shortness of breath and wheezing due to a narrowing of the bronchial tubes. Allergies to certain foods, such as fish, eggs, milk, nuts, and wheat, induce intestinal disturbances. Hives or urticaria is characterized by swelling, redness, and itching. Eczema is characterized by an itchy rash (American Academy of Allergy, Asthma, and Immunology [AAAAI], 2001a). This study focuses on allergic rhinitis and airborne allergens. 


\section{Allergic Rhinitis}

Allergic rhinitis is the most common of all allergic disorders (Sly, 1999; Scadding, Richards, \& Price, 2000). The word rhinitis means inflammation of the lining of the nose. When allergies cause this inflammation, the condition is called allergic rhinitis. Allergic rhinitis is a chronic disease caused by airborne allergens such as pollens, mold spores, animal dander, dust mites droppings, and cockroach droppings. Allergic rhinitis happens when an allergic person inhales the airborne allergen. The immune system identifies normally harmless particles as dangerous and begins to produce IgE antibodies to fight off the invader. The allergen stimulates IgE antibodies, causing mast cells to explode and release chemicals that cause upper airway inflammation (Young et al., 1999; AAAAI, 2001b).

Three basic things need to happen for a person to develop allergies (Young et al., 1999; AAAAI, 2001b). First, a person must have the gene to develop allergies. If only one parent has an allergic disease, the chance of the child developing allergies is $48 \%$. If both parents have allergies, the chance of the child developing allergies is $70 \%$.

Second, a person has to be exposed to the allergen to which he or she is allergic before developing allergies. When allergens first enter the body of a person, allergen-specific IgE antibodies are produced. Each type of $\mathrm{IgE}$ is specific for one type of allergen only. Allergy sufferers have 10 times as much IgE in their blood as people unaffected by allergies. Then, these antibodies travel in the bloodstream to mast cells. The mast cells are plentiful in the nose, eyes, lungs, and gastrointestinal tract. The IgE antibodies attach themselves to the surface of the mast cells and wait for their particular allergen.

Third, a person needs to be exposed to the particular allergen in a great enough amount to trigger an allergic reaction. The IgE antibodies capture the allergens. This initiates the release of chemical mediators such as histamine and other chemicals (arachidonic acid, prostaglandins, and leukotrienes) from the mast cells. These mediators produce the symptoms of an allergic reaction, such as swelling of tissues, sneezing, and other reactions.

\section{Seasonal and Perennial Allergic Rhinitis}

Allergic rhinitis falls into two categories: seasonal and perennial (ALAAAG \& Edelman, 1997; AAAAI, 2001c).

Seasonal Allergic Rhinitis. Seasonal allergic rhinitis is caused by a sensitivity to outdoor allergens including the pollen of trees, grasses, and weeds as well as molds. People with seasonal allergic rhinitis have a seasonal pattern to their symptoms. This pattern is related to the times when pollens or mold spores are carried on the wind. Seasonal allergic rhinitis is commonly known as hay fever. However, sufferers are not allergic to hay, nor do they have a fever. According to a study in Thailand, only $28 \%$ of allergy cases comprise seasonal allergic rhinitis (Pumhirun et al., 1997).

Perennial Allergic Rhinitis. Perennial allergic rhinitis is not connected to the time of year because it is triggered by nonseasonal allergens. It is a year-round problem. The symptoms can be triggered by indoor allergens such as dust mite allergen, indoor molds, animal dander, and 
cockroach droppings. According to a study in Thailand, more than $72 \%$ of cases comprise perennial allergic rhinitis (Pumhirun et al., 1997).

\section{Allergy Symptoms}

Allergy symptoms are the result of an abnormal sensitivity of the immune system to particular allergens, substances that are otherwise harmless. The most common symptoms in allergic rhinitis include violent, prolonged sneezing; watery, clear nasal discharge; nasal congestion, nose itching or rubbing, reduction in the sense of smell, breathing through the mouth, constant clearing of the throat; and itching, tearing eyes (ALAAAG \& Edelman, 1997; NIAID, 1998). The findings from a United Kingdom survey (Scadding et al., 2000) show that sneezing and runny nose were the most common symptoms in patients both with seasonal rhinitis and in patients with perennial rhinitis. Other common symptoms in patients with seasonal rhinitis were itchy eyes, watery eyes, and itchy nose. Other common symptoms in patients with perennial rhinitis were a blocked nose and a headache.

Allergies and colds share many symptoms. However, allergies cause itching in the eyes, nose, and throat, but colds rarely cause itching. Fever, aches, and pain that occur with a cold rarely occur with an allergy. Allergy symptoms begin immediately after exposure to allergens while cold symptoms take a few days to develop and cold symptoms should end within several days to a week (ALAAAG \& Edelman, 1997).

There are physical signs that indicate allergy. People with allergic rhinitis have dark circles under the eyes called allergic shiners. Many people show signs of the allergic salute. The allergic salute produces a horizontal crease across the nose from wiping a runny nose upwards with the palm of the hand (NIAID, 1998).

Symptoms of Dust Mite Sensitivity. Signs of dust mite allergy include persistently stuffy nose or ears, repeated sneezing on awakening, and itchy, watery eyes. The symptoms occur when the bed is being made, when sitting on upholstered furniture, in a library, in the bedroom, when a person arises in the morning, and when a person has been in bed for 30 to 60 minutes. The symptoms improve outside the house (Krohn, Taylor, \& Larson, 1996).

Symptoms of Pollen Sensitivity. Symptoms of pollen sensitivity are itching of eyes or nose with thin, watery nasal discharge. Many patients develop symptoms when pollen counts are 20-100 grains per cubic meter. The symptoms are worse at peaks of specific pollen seasons. The symptoms are worse outdoors from 8:00A.M. to noon, especially on clear and windy days. The symptoms are improved on rainy days and indoors with the house closed and air conditioning and filtration operating (Krohn et al., 1996).

Symptoms of Animal Dander Sensitivity. Reaction to animal dander or saliva can include sneezing, an itchy or runny nose, itchy or watering eyes, itchy throat, hives, difficulty breathing, and headaches. The degree of animal sensitivity varies from person to person. These symptoms occur when people are exposed to animals, such as cats or dogs. For most people symptoms occur quickly, within minutes after exposure to the animal. For some people, symptoms may 
build and become most severe eight to 12 hours after they have had contact with the animal (Krohn et al., 1996).

\section{Prevalence of Allergic Rhinitis}

The prevalence of allergic rhinitis is increasing worldwide including the Asia Pacific region (Leung \& Lai, 1997; Nathan et al., 1997; Sly, 1999). Strong evidence from a study in Denmark and a study in Japan showed that the prevalence of allergic rhinitis had increased significantly (Linneberg et al., 1999: Shida et al., 2000). The prevalence estimates of allergic rhinitis around the world ranged from $4 \%$ to more than $40 \%$ (Schoenwetter, 2000). Allergic rhinitis was estimated to affect at least $14 \%$ of Americans (Nathan et al., 1997). Nearly one in seven adults in London, England had allergic rhinitis (European Academy of Allergology and Clinical Immunology [EAACI], 1998).

Allergic conditions are very common among children residing in Bangkok, Thailand. According to the results of a research study in Bangkok (Vichyanond et al., 1998), in 1990, 18\% of children had allergic rhinitis, and in 1995, $44 \%$ of children had allergic rhinitis. Allergy experts estimate that the number of Thai adults with allergies is increasing also (Vichyanond et al.), but few research studies in the adult population have been conducted in Thailand.

One study was conducted in Narn, a northern province, and in Khonkaen, a northeastern province of Thailand (Bunnag, Jorencharsri, Voraprayoon, \& Prasansuk, 1995). According to this study, $23 \%$ of Thai adults had allergic rhinitis. Another research study showed that around $24 \%$ of Thai medical students in Bangkok had allergic rhinitis (Tuchinda, 1978); however, the average age of Thai medical students is younger than in the United States. Most of the Thai medical students go to medical school right after they graduate from high school. Thus, the results of this study represented only people in early adulthood (undergraduate college students). Pumhirun et al. (1997) estimated that the prevalence of allergic rhinitis in Thailand was $20 \%$ of the total population in Thailand.

Adults with Allergic Rhinitis. Allergic rhinitis is the most common allergic disease affecting the general population. Typically, allergic rhinitis symptoms begin in childhood and adolescence and continue into adulthood (Schoenwetter, 2000). Nathan et al. (1997) found that the prevalence of allergic rhinitis was highest among age 18 to 49 years. However, there is growing concern for older people with allergic rhinitis due to the increase of older people around the world. A few current studies on allergic rhinitis and some studies on asthma started presenting information on allergic diseases in older people. Bellanti, Azem, MacDowellCarneiro, Tutunchuoglu, and Wallerstedt (2000) points out that allergic rhinitis continues to be an important health issue for elderly people.

Adult-onset allergies are becoming more common (Corren, 2000). For those who do not have allergies, it does not mean that they never will because they can have an allergy at any age. People are never too old to develop an allergy. Many people never have an allergy until they pass 50. Older patients still have a tendency to have allergic symptoms, although they may become less noticeable with maturity (Corren, 2000). 
Settipane et al. (1994) conducted a 23-year follow up study of college students. Around $24 \%$ of the students had allergic rhinitis as college freshmen. During the 23 years, $18 \%$ of former students developed new allergic rhinitis. The result from this longitudinal study showed that the frequency of allergic rhinitis increased with age. Greisner, Settipane, and Settipane (1998) found that the majority of allergy sufferers (86\%) did not outgrow allergic rhinitis. Around 9\% of sufferers reported worsened symptoms, 45\% reported no change, and 32\% reported being better but not symptom free. Meltzer (1997) pointed out that the prevalence of allergic rhinitis is likely to increase with the aging of the population.

\section{Allergic Triggers}

Pollen, dust mite, and animal dander were reported as the most common allergic triggers in the United Kingdom (Brown \& Hawkins, 1999). However, the most common allergic triggers in tropical countries differ from those in temperate or cold countries. Pumhirun et al. (1997) conducted a study to determine the aeroallergen sensitivity of Thai patients with allergic rhinitis. The findings showed that dust mites and cockroaches were the most important sources of allergic triggers in Thailand. Sensitivity to indoor allergens is more prevalent than to outdoor allergens.

The most common allergic triggers among Thai patients were dust mite $D$. farinae $(79 \%)$, and D. pteronyssinus (76\%), American cockroach (60\%), German cockroach (41\%), feathers (37\%), kapok (30\%), cat (29\%), and dog (28\%) (Pumhirun et al., 1997). These results were quite similar to results of a study from Indonesia, another Southeast Asia country with a tropical climate. The most common allergic trigger among Indonesian patients was dust mite $D$. pteronyssinus (78\%) (Baratawidjaja et al., 1999).

The most common allergic triggers from trees in Thailand were acacia (19\%), mango (16\%), and coconut (12\%) (Pumhirun et al., 1997). The most common allergic triggers from grasses were Johnson (21\%), orchard (18\%), and bermuda (17\%). The most common allergic triggers from mold spores were Fusarium (26\%), Curvalaria (26\%), Rhodotorula (20\%), and Penicillium (16\%) (Pumhirun et al.).

\section{Impacts of Allergic Rhinitis}

Having allergies can be a critical issue for well-being and quality of life. Around $30 \%$ of British patients reported that allergic rhinitis had impacts on their work, home, and social life (Scadding et al., 2000). A study from France (Bousquet et al., 1994) and a study from the United States (Meltzer, Nathan, Selner, \& Storms, 1997) confirmed that allergic rhinitis adversely affected the physical and mental health status of sufferers.

Allergic rhinitis causes pain and suffering. When people have allergy symptoms, they need to blow their nose repeatedly and they often have a disrupted sleep pattern. They may have problems concentrating, have mood swings, and feel more tired. They may feel sick, depressed, and irritable (Juniper, 1997). Allergy sufferers may not be fully aware of the problem because they have been living with their condition for their entire life and have become accustomed to their health status (Meltzer et al., 1997). 
According to a study from Hungary (Stauder, Szedmak, \& Kopp, 2001), allergic people reported more psychological problems than the rest of the population. People with allergies had higher hostility scores and reported more conflicts with their family compared to people without allergies. Allergic rhinitis was also associated with higher rates of depression and anxiety disorder (Cuffel, Wamboldt, Borish, Kennedy, \& Crystal-Peters, 1999).

Allergy symptoms have contributed to millions of work and school absences. Allergies are responsible for 3.5 million lost U.S. workdays and 2 million lost school-days each year. A significant large number of Thai children indicated that their allergy symptoms were severe enough to limit their activities. Vichyanond et al. (1998) stated that allergic diseases are the most common childhood diseases in Thailand and could lead to a substantial economic loss for the country.

Eighty-two percent of allergic rhinitis sufferers in the United States reported that they always or usually have symptoms at work or school (Storms et al., 1997a). A recent study on the cost of absenteeism and reduced productivity associated with allergic rhinitis reported that atwork productivity losses were estimated to range from $\$ 2.4$ billion to $\$ 4.6$ billion (CrystalPeters, Crown, Goetzel, \& Schutt, 2000). The most significant productivity losses resulted from reduced at-work productivity associated with the use of sedating, over-the-counter allergy medications. An estimated medication cost associated with allergic rhinitis in the United States is $\$ 2.4$ billion and an estimated physician billing cost is $\$ 1.1$ billion yearly (Storms et al., 1997a). Allergy sufferers account for more than 8.4 million physician visits each year.

When allergic rhinitis is not treated, it can lead to sinus infections, ear infections, and asthma. Seventy-eight percent of people with asthma also have allergic rhinitis. Forty-three percent of allergic rhinitis sufferers experienced sinusitis and 23\% experienced asthma at some time in the past (Storms et al., 1997a).

\section{Treatment}

The treatment of allergic rhinitis is aimed to control the symptoms with minimal or no side effects in order to allow patients to live a normal, productive life (Storms et al., 1997a). Although there is not yet a cure for allergic rhinitis, there are many treatments available to lessen symptoms. The treatment of allergic rhinitis includes (1) avoidance, (2) medication, and (3) immunotherapy. This study focuses on avoidance. Allergen avoidance methods will be discussed in detail after brief discussions of medication and immunotherapy.

Medication. Allergic rhinitis sufferers usually require medication to relieve allergy symptoms. The most common medications for allergic rhinitis are antihistamines, decongestants, and antihistamines-decongestant combinations (Corren, 2000). Antihistamines block the effects of histamine, a chemical released during an allergic reaction. Antihistamines reduce symptoms of itching, sneezing, and runny nose. Side effects are sedation, fatigue, dizziness, impairment of cognition and performance, dry mouth and eyes, and constipation. However, newer antihistamines rarely cause drowsiness (AAAAI, 2001a). Decongestants relieve nasal congestion and other symptoms associated with allergies. Decongestants can cause nervousness, sleeplessness, or elevation in blood pressure (Corren, 2000). 
There are many medical treatments for allergic rhinitis, but all of them have side effects (Stadtner, 2000). Storms, Meltzer, Nathan, and Selner (1997b) reported that 31\% of patients experienced side effects from the medications and $65 \%$ of patients would not take some drugs because of the side effects. Forty-eight percent worried about side effects from the medications.

Immunotherapy. Allergen immunotherapy treatment is also called allergy vaccinations or allergy shots. Allergen immunotherapy is a vaccination treatment program for allergic patients with moderate to severe symptoms. Immunotherapy treatment is considered in patients who do not respond to medications, experience substantial side effects with medications, and have symptom throughout most of the year (Corren, 2000). The immunotherapy decreases a patient's sensitivity to allergens, lessens symptoms, and reduces the need for future medications. This treatment involves receiving injections periodically over a period of three to five years (AAAAI, 2001d). Although the immunotherapy can reduce allergy symptoms, patients should still continue practicing allergen avoidance. Practicing allergen avoidance while receiving immunotherapy can significantly enhance the effectiveness of the treatment (Berger, 2000).

\section{Allergen Avoidance and Environmental Control}

Avoidance is the primary method of treatment for allergic rhinitis (Corren, 2000; PlattsMills et al., 2000). People with allergies can reduce many allergy symptoms by reducing exposure to allergens. Allergen avoidance can minimize the amount of medication needed to control allergic symptoms. Many allergic rhinitis patients do not prefer taking antihistamines and steroids due to side effects (Storms et al., 1997b). Allergen avoidance can be readily employed by anybody with allergic rhinitis because it has no side effects on people. A research study showed that education of patients on the benefits of allergen avoidance could improve the level of satisfaction with therapy (Scadding et al., 2000). The benefit of allergen avoidance is not only controlling symptoms of people with allergies, but also promoting healthy environments for everyone. Allergen avoidance practices will produce an indoor environment that is less allergenic, easier to clean, and healthier for the whole family.

Allergen avoidance practices should be allergen specific because allergen avoidance practices differ for dust mites, cockroaches, pets, mold, and pollen. It is also important to understand the biology and the ecology of each allergen because it helps in conducting avoidance practices. Avoidance should start by recognizing which allergen causes allergic rhinitis symptoms (ALAAAG \& Edelman, 1997; Corren, 2000; Platts-Mills et al., 2000). The allergen can be identified through a detailed history and skin testing by an allergist (Storms et al., 1997b). The results of the testing will help guide allergen avoidance practices. Each allergen and its avoidance practices will be discussed in the following section. The discussion will include the most common allergens in Thailand: dust mite allergen, cockroach allergen, animal allergen, mold, and pollen.

\section{Dust Mite}

The role of dust mites as a source of house dust allergens has been realized for many years. Mites are harmful only to people who are allergic to them. The feces of dust mites and pieces of dead mites are inhaled into the lungs when a person breathes in tiny dust particles. 
When the feces land on mucus membranes, the antigen is released within 30 seconds (ALAAAG \& Edelman, 1997). Live mites are not inhaled, as they have sticky feet that cling to surfaces. The average dust mite produces about 20 highly allergenic fecal pellets per day. The pellets are so light that they stay in the air for 10 minutes after being disturbed (Krohn et al., 1996). These tiny particles float into the air whenever people fluff a pillow, pat a stuffed animal, or walk across a carpet (Zellerbach, 1995).

Dust mites live and multiply in warm, humid places. They require a relative humidity of $60 \%$ at $21 \mathrm{C}$ and above because they have a poor homeostatic mechanism for retaining water (Murray \& Zuk, 1979). They die if the relative humidity drops below 50\%. Dust mites do not live in dry climates or at high altitudes. In Thailand, dust mites are prevalent all year round. A high prevalence period occurs between August and November due to the rainy season (Malainual et al., 1992).

In damp climates, mites are found in abundance in dust (Krohn, et al., 1996). Dust mites live on a diet of human or animal skin particles found throughout houses (Beck \& Bjerring, 1987; ALAAAG \& Edelman, 1997). They cannot survive on living skin. Dust mites can live in surface dust, but their preferred home is fabric on mattresses, pillows, bedding, carpets, upholstered furniture, stuffed animals, clothing, closets, drawers, and curtains. Bed dust tends to be the most potent source for dust mite allergen. The greatest exposure to dust mite allergen occurs in the bedroom (Zellerbach, 1995; ALAAAG \& Edelman, 1997).

A study from the United States revealed that the levels of dust mite allergens in beds were 19-31 times higher in houses than those in apartments (Chew, Higgins, Gold, Muilenberg, \& Burge, 1999). Living in a house was a predictor of having high dust mite allergen levels. A study from The Netherlands revealed that an increasing number of residents was significantly associated with higher dust mite allergen concentrations (van Strien, Verhoeff, Brunekreef, \& van Wijnen, 1994). Van Strien and colleagues (1994) also found that mattress dust from bedrooms with solid brick outer walls had higher dust mite allergen levels than that from bedrooms with outer cavity walls. Most Thai houses and apartments have solid brick outer walls. Outer cavity walls are not common in Thai dwellings. Higher dust mite allergen concentrations in floor dust were associated with increasing age of the dwelling (van Strien et al., 1994; Chanyeung et al., 1995). High relative humidity and poor ventilation increase the risk of mite infestation in homes. Mite allergen levels were higher in homes with dampness problems, in homes with a smoker, and in homes without basement (van Strien et al., 1994; Munir et al, 1995; Alvarez et al., 1997).

As early as 1920, W. Storm Van Leeuwen in Holland found out that mites in grain were allergenic. Several years later, H. Dekker in Germany discovered that the mites that live on human dander cause allergy. These findings were neglected for many years. During 1960s and 1970s, a Dutch scientist, R. Voorhorst, and a Japanese researcher, T. Miyamoto, established the dust mite's worldwide role in causing allergy (Young et al., 1999).

There are more than 50,000 species of dust mites living around the world (Platts-Mills \& Chapman, 1987). Only a few species of dust mites cause allergies in humans. House dust mites Dermatophagoides Pteronyssinus and Dermatophagoides Farinae are major causes of allergic 
rhinitis and asthma in Thailand (Wongsathuaythong, Fuangtong, \& Ketavan, 1977). The term Dermatophagoides means "skin eaters." According to a study on aeroallergen sensitivity of Thai patients with allergic rhinitis, $79 \%$ of the patients were sensitized to dust mite $D$. farinae (Pumhirun et al., 1997). Around $76 \%$ of the patients were sensitized to dust mite $D$. pteronyssinus. Dust mite allergen is the most important allergen in Thailand (Pumhirun et al., 1997).

In 1994, Malainual, Chairat, Chapman, \& Vichyanond investigated the geographical distribution of the house dust mites in Thailand. Dust samples were collected by vacuuming of mattresses from central, northern, and northeastern Thailand. D. pteronyssinus was the most abundant species with count ranging from 1 to 1,460 mites per gram of dust (mean $=87.2)$. Highest density of the house dust mites was found in dust from the northern part. There was no significant difference in the mite count and mite allergen found among various types of housing. The researchers concluded that house dust mites are a significant source of allergen found in all parts of Thailand (Malainual, et al.).

Although $D$. pteronyssinus is the predominant species in subtropical dwellings, $D$. pteronyssinus is also the most prevalent species in tropical dwellings in Thailand. It is interesting that dust mites Blomia tropicalis were found more prevalent than D. pteronyssinus in many tropical countries such as Singapore and Columbia. However, B. tropicalis is infrequently present in house dust in Thailand (Malainual, Vichyanond, \& Phan-urai, 1995; Leung \& Lai, 1997).

Dust Mite Allergen Avoidance. There are three effective ways to lower the number of dust mites: (1) remove objects in which they live, such as carpets, upholstered furniture, and stuffed animals; (2) wrap mattresses and pillows in protective covers so the mites cannot get out; and (3) try to wash them out of some objects, such as bed sheets. All these three approaches should be employed by allergy sufferers in order to minimize exposure to dust mites (Tovey \& Marks, 1999).

Dust mite avoidance should begin in the bed. Several studies suggested that pillows and mattresses must be encased in allergy-proof covers (EAACI, 1998; Tovey \& Marks, 1999; Platts-Mills et al., 2000). The cover should encase the entire pillow or mattress and should zipper shut to control dust mites. These casings provide a barrier that separates patients' noses from the dust mites inside. When plastic covers were recommended in the past, many patients did not tolerate plastic mattress covers and pillowcases. Now, allergy-proof cases are made out of vapor and air permeable synthetic materials or fine-woven fabrics. These new materials and fabrics are more comfortable to sleep on than plastic or vinyl. The fine-woven fabrics can be produced with different pore sizes to allow airflow. A pore size of $6 \mu \mathrm{m}$ is recommended to prevent leakage of mite allergen (Platts-Mills et al., 2000).

However, the cost of a fine-woven fabric cover is higher than a plastic cover. PlattsMills et al. (2000) suggested patients with limited budgets use inexpensive plastic covers on the mattress and use good-quality fine-woven fabric for the pillowcases. A washable mattress pad can be put on top of the plastic cover in order to increase comfort. 
All bedding, including sheets, pillowcases, blankets, and other bedclothes, must be washed in hot water $\left(58^{\circ} \mathrm{C}\right.$ or $\left.130^{\circ} \mathrm{F}\right)$ weekly. Dust mites and their allergen will build up on top of the casings as people continue to shed skin, so regular washing is recommended. Washing at a temperature of $58^{\circ} \mathrm{C}$ or $130^{\circ} \mathrm{F}$ is important because lower temperatures will not kill dust mites (Tovey \& Marks, 1999; Platts-Mills et al., 2000). Drying outside in the sun is an alternative practice to kill mites (Platts-Mills et al., 2000); however, this practice is not recommended for patients who are allergic to both dust mites and pollens. Drying in a tumble dryer at $58^{\circ} \mathrm{C}$ or $130^{\circ} \mathrm{F}$ for at least 20 minutes is another alternative (Miller \& Miller, 1996).

Allergy sufferers must use only washable materials on the bed. Comforters or pillows made of natural materials such as kapok or feather must be avoided. Thirty-seven percent of allergic rhinitis patients in Bangkok were allergic to feather and 30\% were allergic to kapok (Pumhirun et al., 1997). Comforters and pillows made of natural materials should be replaced with items made from synthetic fibers (EAACI, 1998). Polyester fiberfill pillows are recommended for allergy sufferers (Ulean, 1999).

Dust-Free Bedroom. A bedroom is where people spend around 8 hours or more daily. Therefore, people who are allergic to dust mites can significantly reduce some of their symptoms by creating a dust-free bedroom. There should be smooth, uncluttered surfaces in the bedroom with few small objects. Stuffed animals, knickknacks, books, tapes, and compact discs should be placed in drawers and closed cabinets or they should be removed from the bedroom. Clothing should be stored in closed closets with the doors shut at all times. Unused clothing should be stored away from the bedroom. Dust-catchers, such as pennants, pictures, trophies, books, models, and dried or silk flower arrangements should be limited in bedrooms. The bedroom should not be used as a library or a study room (Cutler, 1998).

Routine cleaning is necessary to maintain a dust-free bedroom. The bedroom must be cleaned thoroughly and completely once a week. It should be vacuumed regularly and cleaned with a damp cloth or wet mop (EAACI, 1998; Tovey \& Marks, 1999; Platts-Mills et al., 2000). Intense vacuum-cleaning significantly reduces the dust mite allergen level (Wickman, Paues, \& Emenius, 1997). The downside to vacuuming is that most vacuums blow particles throughout the air and can actually kick up allergens that linger for 1 to 2 hours after vacuuming. Using allergen-controlling bags or a vacuum cleaner with a HEPA (High Efficiency Particulate Air) filter can minimize this problem (Platts-Mills et al., 2000). The allergen-controlling bags have much smaller openings than traditional vacuum bags. The vacuum cleaner with a special HEPA filter can trap particles before they are blown back into the air. The patient should wear a mask during cleaning or ask someone else to do vacuum cleaning (EAACI, 1998).

Carpets are reservoirs for dust mites. The dust mite allergen concentrations were found six to 14 times higher than dust from smooth floors (van Strien et al., 1994). Carpeting makes dust control impossible because all carpets trap dust. Removal of carpeting can significantly improve symptoms caused by dust mites. The best way to reduce dust mite allergen in homes is to replace carpet flooring with hard surface flooring such as wood, vinyl, linoleum, or tile (EAACI, 1998). Any area carpets should be removed from bedrooms except for those that can be washed easily. Loose carpets should be washed to remove allergen and placed in the sun to kill all mites (Tovey \& Marks, 1999; Platts-Mills et al., 2000). Removing wall-to-wall carpeting 
is an expensive procedure. Therefore, it should be done only after a family member has been found to be allergic to dust mites.

If allergy sufferers prefer carpets in their homes, wool carpets would be a better choice rather than nylon carpets (Andes, 2000). Andes found that there was no difference in numbers of mite growth on wool carpets and on hard floors. Nylon carpets had the highest number of mite growth. Therefore, nylon carpets should be avoided (Andes). However, having carpets in homes of allergy sufferers requires very frequent cleaning and humidity controls. Carpets should be vacuumed weekly. In homes with wall-to-wall carpet located in hot, humid climates, thorough vacuuming and a central cooling and heating system with dehumidification to below $60 \%$ relative humidity can maintain dust mite allergens below clinically significant levels (Chandra, Codina, Beal, \& Lockey, 2000).

Drapes and horizontal blinds should be replaced with washable curtains or wipable shades or vertical blinds. Air conditioners and dehumidifiers are recommended in order to keep relative humidity below 50\%. Upholstered sofa and chairs should be removed from bedrooms. Furniture should be wood, leather, plastic, or metal. Living in basements or in rooms with cement slab floor should be avoided (EAACI, 1998; Platts-Mills et al., 2000).

The following brief recommendations for dust mite allergen avoidance are arranged from most important to least important.

\section{Priorities.}

1. Encase pillows and mattresses in allergy-proof covers.

2. Wash all bedding including sheets, pillowcases, blankets, and other bedclothes in hot water $\left(58^{\circ} \mathrm{C}\right.$ or $\left.130^{\circ} \mathrm{F}\right)$ weekly.

3. Use only washable materials on the bed. Do not use bedding or pillows that cannot be washed, such as kapok or feather pillows.

4. Use closed cabinets rather than open shelves. Keep all knickknacks and books in closed cabinets or remove them from the bedroom. Keep all clothes in the closet with the doors shut at all times.

5. Clean the room thoroughly with a damp cloth or wet mop once a week.

6. Vacuum regularly. Use allergen-controlling bags and a vacuum cleaner with a HEPA (High Efficiency Particulate Air) filter. Wear a particle mask when an allergy sufferer does vacuuming.

\section{Long-Term Improvements.}

1. Remove carpets from bedrooms. 
2. If needed, use wool carpets instead of nylon carpets and vacuum frequently.

3. Replace drapes and blinds with washable curtains.

4. If necessary, use air conditioners and dehumidifiers to keep relative humidity in the house below $50 \%$. Clean air conditioning filters monthly.

5. Remove upholstered sofa and chairs. Furniture should be wood, leather, plastic, or metal.

\section{Cockroach}

The cockroach has been identified as an important source of indoor allergens throughout the world (Platts-Mills et al., 2000). Cockroaches are tropical in origin and can live outside in warm areas. Cockroaches are active at night and prefer to hide in cracks and crevices in the daytime. Cockroaches prefer warm, dark, humid habitats where they can breed year-round. Cockroaches feed on many kinds of plants, and animal products, including human food, sewage, garbage, bindings of books, and wallpaper paste. Roaches can foul food, damage wallpaper and books, eat glue from furniture, and produce an unpleasant odor (Kulczycki, 1992).

Cockroach allergen includes secretions and feces from the cockroach. Cockroach allergens are widely distributed in house dust and are highest in kitchen (Eggleston et al., 1999). Sarpong, Hamilton, Eggleston, and Adkinson (1996) found that cockroach allergen is detectable throughout the house, including the bedroom environment and the rate of cockroach sensitization was directly related to the level of bedroom exposure. Living in an apartment was a predictor of having high cockroach allergen levels (Chew et al., 1999). Cockroach allergen levels in apartments were 5 times higher than those of houses. The higher cockroach allergen level in apartments result from the difficulty of pest management in a whole building because cockroaches can spread from one apartment to another.

Low socioeconomic status is a significant risk factor for cockroach allergen sensitization in children with asthma. Research studies have established that cockroach allergens are important sensitizing agents in the induction of rhinitis and asthma in urban areas. A study from Madrid, Spain revealed that $47 \%$ of patients with rhinitis and asthma had visual evidence of cockroach infestation in their home and $26 \%$ had a positive prick test to cockroach (Sastre, Ibanez, Lombardero, Laso, \& Lehrer, 1996). Pumhirun et al. (1997) reported that $60 \%$ of allergic patients in Bangkok, Thailand demonstrated skin sensitivity to American cockroach allergen. Around $41 \%$ of allergic patients demonstrated skin sensitivity to German cockroach allergen.

According to a study on cockroaches in Thailand (Tawatsin et al., 2001), cockroaches were found in $65 \%$ of the surveyed houses. Cockroaches are common pests found throughout Thailand. Cockroach density per house was 5.3 on the average and the majority of the cockroaches (48\%) were caught in the kitchen. American cockroach (64\%) was the most common cockroach species in Thailand. 
However, the results from Bangkok differed from those in other provinces. German cockroach (51\%) and American cockroach (49\%) were the most common cockroach species in Bangkok. A cockroach density per house was 8.3 on the average. In Bangkok, $21.4 \%$ of cockroaches were caught in the kitchen, $0.4 \%$ and $78.2 \%$ were caught in the bedroom and outside dwellings, respectively. The majority of the cockroaches in Bangkok were caught outside dwellings. Tawatsin et al. assumed that drainages throughout Bangkok provided suitable habitats for cockroaches due to plentiful foods, warmth, and moisture. They pointed out that the cockroaches in Bangkok could easily get inside the houses through drainages connecting to inside. Since German cockroaches and American cockroaches are the most common in Bangkok, this study will focus on the control of these two species.

German cockroaches (Blattella germanica) are generally found in kitchens, bathrooms, and other food areas. This species usually hides in areas close to moisture and food such as behind baseboard molding, in cracks around cabinets, closets or pantries, under stoves, and refrigerators. However, they can develop into large populations and live throughout the house. They prefer to rest on wood rather than on metal or other smooth surfaces. The German cockroaches prefer fermented foods and beverage residues. The German cockroach is an active species, moving around within structures. They can pass through very small openings. They are regularly carried from place to place in beverage cartons, grocery bags, other food packages, handbags, and the folds of clothing. Adult German cockroaches can live up to one year, but most will die before that time (Kulczycki, 1992; Virginia Cooperative Extension, 2001a).

American cockroaches (Periplaneta Americana) generally live in moist, shady areas. They prefer warm temperatures around $84^{\circ} \mathrm{F}$ and do not tolerate cold temperatures. American cockroaches are commonly found in the landscape. They are abundant in yards, hollow trees, and palm trees. These cockroaches are also common in basements, sewers, crawl spaces, cracks and crevices of porches, foundations, and walkways adjacent to buildings. They feed on a wide variety of plant and animal materials. They prefer decaying organic matter, syrup, and other sweets. American cockroaches may enter houses via sewer connections, under doors, around utility pipes, air ducts, or other openings in the foundation. Movement indoors often increases during periods of cold, extreme hot and dry weather, or excessive rainfall (Virginia Cooperative Extension, 2001b).

Cockroach Allergen Avoidance. Because of a growing concern on the use of insecticides, cockroach control measures emphasize the biology and the ecology of the cockroaches as well as non-toxic methods (Platts-Mills et al., 2000). Cockroaches in the home should be controlled in the most nontoxic way possible because allergy sufferers can be dangerously harmed by toxic insecticide.

Cockroach control measures begin with cockroach inspection. The inspection must be conducted in order to determine cockroach species, cockroach locations, and numbers of cockroaches (Miller, 2001). It is also important to note safety considerations such as the location of pets and presence of small children. Then, appropriate treatments and other management activities can be selected based on this information. Check places such as cracks and crevices, under tops of tables, behind and under sinks, in cabinets, the motor compartments of refrigerators, underneath the bases of kitchen equipment, and almost anywhere else conditions 
are favorable. The presence of cockroaches is often detected by their smell or by their droppings.

Cockroach inspection also involves the use of sticky traps (American Thoracic Society [ATS], 1997). The trap includes a sticky floor area and a pheromone to attract cockroaches. Traps are designed to fit into a corner in order to cover the normal pathways of roaches (PlattsMills et al., 2000). Traps should be placed in strategic locations within the house or in the landscape. Cockroaches prefer to have the side or top of their body touching another object. Thus, they prefer to walk along walls and close to furniture, and to hide in cracks and crevices. Traps should be placed either against a wall, in a corner of the floor, or a shelf or a drawer (Miller, 2001).

Baits and insect growth regulators are recommended in order to eliminate cockroaches (Platts-Mills et al., 2000; Miller, 2001). Bait-containing chemicals can be applied as a bait station or as a paste. Bait stations should be placed around the corners of the room and where cockroaches reside. Gel bait should be applied only places where cockroaches are found. The gel bait should be applied in the area around the refrigerator, trash, and stove in the kitchen as well as under furniture, in cracks, behind painting, etc. (Platts-Mills et al., 2000).

Insect growth regulators (IGRs) are chemicals which mimic the cockroach's natural juvenile hormone. IGRs prevent immature cockroaches from becoming reproductively capable as adults (Miller, 2001). IGRs are useful in multi-family housing units or other situations with chronic cockroach problems. High reproductive potential is a key aspect of the persistence of cockroach populations. IGRs restrict the high reproductive potential of the cockroach population. However, IGRs are not effective when used alone because the adult cockroaches present at the time of IGR application will not be sterilized. Insecticide spray is not recommended as the method of control because it can be extremely irritating to the respiratory tract of allergy sufferers. Moreover, cockroaches can develop resistance to insecticides (ATS, 1997; Platts-Mills et al., 2000).

Exclusion techniques such as caulking or sealing various cockroach entry points are effective at reducing the cockroach problem indoors (Kulczycki, 1992; ATS, 1997). Research studies confirmed that control of sources of food and water plus routine cleaning could help reduce the populations of cockroaches (Sarpong, Wood, \& Eggleston, 1996; Eggleston et al., 1999). All food must be encased. It is important to repair leaky faucets and pipes, since cockroaches need moisture to survive. Food spills and debris should be thoroughly removed to limit the cockroach's food supply and help prevent further establishment (Pedigo, 1999). All washable surfaces should be routinely cleaned using a household cleaner containing $0.5 \%$ sodium hypochlorite. It should be applied and allowed to dry for 10 minutes before being wiped off with a wet sponge (Eggleston, Wood, Rand, \& Lukk, 2000).

The recommendations for controlling cockroaches and reducing cockroach allergens are summarized as follows. 
1. Inspect the home. Look for cockroach evidence. Check cracks between walls and floors, behind sinks, and under appliances. Use sticky traps in kitchens, bathrooms, and near source of water. Leave the traps over night to monitor cockroaches.

2. Use bait stations, gel bait, or insect growth regulators to eliminate cockroaches.

3. Seal entry points to prevent roaches from entering the home. Repair cracks and holes in walls, floors, and window and door screens. Apply caulking around pipes that might provide a way in for roaches. Place fine mesh screening over crawl space vents and basement floor drains. Seal exterior doors with weather stripping.

4. Repair dripping faucet and leaky pipes.

5. Keep food in tight-lidded containers to keep cockroaches from returning.

6. Vacuum and sweep the floor after meals. Wash dishes immediately after use in hot, soapy water. Wipe off the stovetop and clean other kitchen surfaces and cupboards regularly. Clean under stoves, refrigerators, or toasters where loose crumbs can accumulate.

7. Use lidded garbage containers in the kitchen. Take out garbage and recyclables frequently. Do not store grocery bags, cardboard boxes, newspapers, and empty bottles in a home because cockroaches prefer these items.

8. Do not over water indoor plants because cockroaches prefer soggy soil.

\section{Animal Allergen}

Animal allergen can cause allergic symptoms such as sneezing, runny nose, and watery eyes. The most important animal allergen is derived from mammals, mainly cats, dogs, rats, mice, horses, and cows. The most common animal allergens are saliva, urine, skin, and dandruff. When people are allergic to animals such as cats or dogs, they are not allergic to the hair. They are allergic to the saliva, urine, or dander of the animal. When the saliva and urine are dry, the particles become airborne and cause problems. The allergy symptoms occur soon after people have contact with animals or something animals have touched (NIAID, 1998).

Sixty percent of American households have pets and one in four persons scratch-tested for allergy will react positively to dog and cat dander. It was estimated that between $5 \%$ and $10 \%$ of people in the United States were allergic to one or more animals (ALAAAG \& Edelman, 1997). Around 29\% of allergy patients in Bangkok were allergic to cat and 28\% were allergic to dog (Pumhirun et al., 1997). The highest levels of cat and dog allergen were found in homes with furred pets compared to homes of former pet-owners and homes without pets (Alvarez et al., 1997; Egmar, Emenius, Almqvist, \& Wickman, 1998; Chew et al., 1999).

Cat allergens commonly cause allergies in the home (NIAID, 1998). Most domestic cats carry a large quantity of allergen. The highest concentration of allergens is on their neck. Male 
cats shed more allergen than female cats. The cat dander is very lightweight and difficult to remove from an area (Zellerbach, 1995; Purohit \& de Blay, 1999).

Dogs are the second most common source of animal allergies. All species of dog, shortor long-haired, can cause sensitivities. The belief that short-haired dogs are less allergenic than long-haired dogs is a myth. All dogs share common allergens, as well as having special, breedspecific antigens. Some people may tolerate one breed better than another. Some dog breeds shed very little, and if these are kept clean and trimmed, they cause less problem. Some people may be sensitized to a single type of dog but able to tolerate other breeds. Puppies and kittens have no old skin to shed; therefore, they have less dander (Krohn et al., 1996).

Horses and farm animals provide strong allergens. Animal allergies carry over to all related products: fur, horsehair upholstery, down comforter, wool, and mohair sweater (Zellerbach, 1995). For the very sensitive person, animal hair or dander on the clothing of another person can trigger symptoms (Krohn et al., 1996).

Animal Allergen Avoidance. The best way to minimize animal allergen in homes is to permanently remove pets from homes (Tovey \& Mark, 1999). However, this recommendation is often not taken due to pets' social role. People have emotional attachment to their pets. If allergy sufferers want to keep their pets, the pets should not be allowed indoors. The pets should be kept outside or in a garage. A study confirmed that the allergen levels dropped by $70 \%$ after cats were removed from rooms (Custovic et al., 1998). However, homes with pets in the yard still have higher concentrations of animal allergens than those without pets.

If the pets are allowed to stay inside the houses, the pets should be kept out of bedrooms and other rooms in which allergy sufferers spend most of their time (Tovey \& Mark, 1999). Pets should not be allowed into rooms with carpets. The pet owners should keep them in rooms with hard surfaces so that allergen can be washed. However, limiting pets to one part of the house is not really an effective practice because animal allergen can be transferred around the house (Platts-Mills et al., 2000).

Regular bathing of cats and dogs helps decrease their allergen (Platts-Mills et al., 2000). Platts-Mills et al. reviewed some articles on washing cats and dogs. Then, they concluded that the most effective way to reduce allergen was washing cats or dogs twice a week because the allergen decrease lasted only a few days. Washing a pet should start when the pet is young. Wiping a pet with a wet towel is an alternative practice; however, this does not remove as much allergen as washing does. Allergy sufferers should wear an allergen-filtering mask when brushing pets and cleaning pets living quarters. Pets' beddings should be washed every week (EAACI, 1998).

Since carpets and soft furnishings provide a reservoir for animal allergen, removing carpeting and upholstered furniture is recommended, especially in the bedroom (Purohit \& de Blay, 1999). The rate of allergen accumulation is at least 100 times higher in a carpet than on plastic sheeting. A combination of noncarpeted floors, plastic or leather furniture, HEPA air cleaners, frequent vacuuming with HEPA vacuum cleaners, and frequent washing of the pet can reduce levels of allergen (de Blay, Chapman, \& Platts-Mills, 1991). Encasing mattresses, 
pillows, and box springs with allergen-proof cases as well as washing all bedding weekly in hot water $\left(58^{\circ} \mathrm{C}\right)$ could help reducing animal allergen in bedrooms (EAACI, 1998; Platts-Mills et al., 2000).

In order to reduce the level of animal allergen in homes, these recommendations should be followed.

1. Keep pets outdoors.

2. When indoors, keep pets in the kitchen or other uncarpeted areas with hardwood floor, tile, vinyl, or linoleum.

3. Keep pets out of the bedroom and keep bedroom doors closed.

4. Wash pets and their beddings every week. Groom pets outside the house.

5. Use allergen-proof casings on all mattresses and pillows.

6. Wash all bedding in hot water weekly.

7. Remove carpeting and upholstered furniture, especially in the bedroom.

8. Vacuum frequently using a HEPA filter vacuum cleaner.

9. Use an HEPA air cleaner.

Mold

Molds or fungi are primitive plants that lack chlorophyll. Molds are tiny parasites that live on decaying plants or animal matters. Molds decompose other organic materials in order to produce food for them. Molds grow almost everywhere: on soil, wood, fabrics, and foods.

Molds reproduce by forming spores (asexual reproductive cell) and sending them into the air all year round.

Molds require an abundance of moisture for growth and spore dispersion. They are thriving at $70 \mathrm{~F}$ to $90 \mathrm{~F}$. Mold spores can be spread by winds, insects, and humans. The spores do best in a wet climate and can be carried by the wind for 15 to 20 miles. Molds thrive in warm moist darkness. Dryness is their enemy (Krohn et al., 1996).

Fungi species of Alternaria, Aspergillus, and Cladosporium can give rise to human IgE antibody responses and inhalation of their spores can cause allergic rhinitis and asthma (Jelks \& Solomon, 1985). In South-east Asia, 20-50\% of asthmatic children in Taiwan and Thailand had positive skin tests to one or more species of Penicillum, Cladosporium, Alternaria, and Aspergillus (Leung \& Lai, 1997). Pumhirun et al. (1997) found that 9-26\% of Thai allergy patients were allergic to molds. People who get allergic reactions during humid or rainy weather are most likely sensitive to molds. 
Molds can grow both indoors and outdoors. A musty smell signals the presence of mold. Indoor mold levels are proportional to the relative humidity. Molds are often found in bathrooms and kitchens. These areas of the home often have high humidity levels. Molds are found on bathroom tiles, in refrigerators, garbage containers, carpets, upholstery, and on stalks and leaves of indoor plants. Molds can also grow in rugs, mattresses, feather and foam rubber pillows, stuffed furniture, and air conditioners. In the bathroom, molds grow on the caulking between the tub and the tile, on the shower curtain, and on the floor behind the toilet. In the kitchen, molds frequently develop at the sink-wall junction and around the bottom of the coldwater pipe. The surplus water tray on self-defrosting refrigerators is a mold source. Areas of the house that contain houseplants are major sources of mold from the soil (Zellerbach, 1995; Krohn et al., 1996; ALAAAG \& Edelman, 1997).

Mold Allergen Avoidance. If moisture is allowed to stand on the interior surfaces, mold will begin to grow. Visible mold growth on the surfaces inside homes can indicate high relative humidity (Kuwahara et al., 2001). A study confirmed that home dampness was associated with increased sensitization to molds and allergic rhinitis symptoms (Verhoeff, van Strien, van Wijnen, \& Brunekreef, 1995). Avoidance is the best strategy for those who are sensitive to molds. Molds can be controlled by locating and eliminating their breeding grounds. Mold should be removed by scrubbing thoroughly with water and detergent, then drying completely. Large areas of mold may require professional assistant (U.S. EPA, 2002). If moldy items such as shower curtains cannot be cleaned thoroughly, they should be discarded. These may also include old newspaper, books, or magazines; old furniture; bedding; carpet; clothing; and pillows (PlattsMills et al., 2000).

Allergy sufferers should use humidity gauges to monitor humidity levels in home. When the humidity is high, they should use air conditioners or dehumidifiers. All rooms, especially bathrooms and kitchens, require ventilation and consistent cleaning to prevent mold growth. Allergy sufferers should use an exhaust fan in a bathroom while they shower to reduce the mold buildup. Using an exhaust fan over the stove when cooking helps remove excess humidity in a kitchen. All leaks and moisture damage should be fixed (EAACI, 1998; Platts-Mills et al., 2000).

Mold allergy sufferers should carefully select household items. Allergy sufferers should not use foam rubber pillows because sweat makes them moldy. Hypoallergenic pillows are recommended for mold allergy sufferers. Keeping a nightlight on in dark closets can reduce the growth of mold. Allergy sufferers should limit the number of indoor plants because wet soil encourages mold growth. Indoor plants should be excluded from bedroom. Any carpeting in the bathroom or on cement slab flooring should be removed. Allergy sufferers should use washable bath mats in bathrooms. When painting indoor walls, allergy sufferers should use paints with additives that block mold formation (Brody, 1997; Goldfarb, 2000).

Brief recommendations for mold allergen avoidance are presented as follows.

1. Identify areas of mold growth. The most common areas where molds will grow are shower curtains, and bathroom walls and fixtures. 
2. Clean areas of mold growth with a cleaning solution containing detergent.

3. Discard moldy items.

4. Clean the drip pan of self-defrosting refrigerators regularly and check for mildew on refrigerator seals. Clean garbage cans regularly.

5. Clean bathrooms and kitchen regularly.

6. Use an exhaust fan in bathroom when showering.

7. Use an exhaust fan over the stove when cooking.

8. Use an air conditioner or a dehumidifier to reduce humidity.

9. Do not use foam rubber pillows or kapok pillows. Use hypoallergenic pillows and wash pillows regularly.

10. Remove any carpeting in the bathroom and on cement slab flooring. Use washable floor mats.

11. Keep lights on in closets to reduce dampness.

12. Do not grow too many, or over water, houseplants.

13. Use mold-inhibiting paints.

Pollen

Pollen are microscopic particles that allow plants to reproduce. All seed-bearing plants produce pollen as part of their reproductive cycle. The male reproductive parts of a plant make pollen to fertilize the female reproductive parts. Pollen can be carried by insects, water, wind, and gravity.

Pollen can cause the symptoms of allergic rhinitis. Many people with allergies can develop pollen-related symptoms when pollen counts are between 20 and 100 grains per cubic meter of air (ALAAAG \& Edelman, 1997). When inhaled, these small grains enter the nose and pass into the small ducts of the bronchi, causing mild to severe problems. Eighty-five percent of the pollen ends up in the stomach. Some pollen contains as many as 15 allergenic compounds, while others contain only one or two (Krohn, et al., 1996). Pollen can get into houses through open windows and on people's clothing.

There are about 100 plant species that produce pollen that can be significant in human sensitivities. Only the plants that transfer pollen via wind cause troubles for people with allergies. Plants that cause pollen problems in humans must: (1) be abundant and widely distributed, (2) produce pollen in large quantities, (3) produce pollen that is airborne (15 and 50 
microns in diameter), (4) produce pollen light enough to be carried in some distance, and (5) produce pollen containing specific antigens for hypersensitivity (Zellerbach, 1995; Krohn, et al., 1996).

Generally, plants that display brightly colored, perfumed flowers do not affect the allergic person. These plants have heavy pollen that can be spread by insects and birds, and if the pollen falls it will stay on the ground because of its weight and will not become airborne. Trees, grasses, and weeds are the prime sources of pollen allergen because these plants have small, unattractive flowers that lack odor or nectar and they produce pollen grains that are dry, containing no fats, pigments, or waxes. They also have a mechanism to arrest pollen release so that it occurs only as a result of the shaking motion of the wind. The pollen in these trees, grasses, and weeds is light and very small. Most of the pollen can travel only a few feet from the parent plant. However, some pollen from trees and weeds can travel many miles, even to the heart of a major urbanized city.

There are several factors affecting the amount of pollen in the air. Most pollen is released between 6:00 A.M. and 9:00 A.M. Heavy rains prevent distribution and help destroy the pollen more quickly. High humidity weighs down the pollen and slows its movement. Dew tends to weigh down pollens, but in the heat of the sun, the pollen dries and begins to rise, usually at about 9:00A.M. On dry, sunny days the slightest breeze can send pollen far and wide (Krohn et al., 1996; Young et al., 1999).

Pumhirun et al. (1997) conducted a study to determine the aeroallergen sensitivity of Thai patients with allergic rhinitis. They found that the most common allergic triggers from trees were acacia (19\%), mango (16\%), and coconut (12\%). The most common allergic triggers from grasses were Johnson (21\%), orchard (18\%) and Bermuda (17\%). Bunnag, Dhorranintra, \& Limsuvan (1985) found the following plants were the most important sources of allergenic pollens in Bangkok: (1) sedge, (2) Johnson grass, (3) fern, (4) Bermuda grass and Para grass, (5) Careless weed (Amaranthaceae), (6) Myrtaceae, (7) Fabaceae, (8) Urticaceae, (9) Palm, (10) Lythraceae, (11) Casuarinaceae, (12) Acacia, (13) Pine, and (14) Compositae. The pollen season in Thailand is essentially all year round (Bunnag et al.).

Pollen Avoidance. In order to control pollen, the first step is to identify types of pollen allergens that trigger allergic reactions (Ulean, 1999). Allergy sufferers should pay attention to the type of plants they are surrounded by when they have an attack. The second step is to avoid those plants (Ulean). Simple lifestyle changes and allergy-free gardening can help decrease allergic symptoms. Windows and doors in homes should be closed to block pollen. People with pollen allergy should limit their outdoor activities when pollen levels are high. Wet clothes should not be hung outside to dry overnight, early in the morning, or in windy days because they will be covered with pollen. A clothes dryer is recommended for people who are allergic to pollen (ALAAAG \& Edelman, 1997; Ulean).

Ferns should not be used as houseplants because they produce airborne spores on the undersides of the leaves (Ogren, 2000). These spores can cause allergy. Hanging ferns and large tree ferns may drop spores on tables, chairs, and people below them. 
Most lawn grasses release pollen from 3 A.M. to 8 A.M. (Ogren, 2000); therefore, lawns should not be mowed early in the morning. Windows should be closed for a few hours when lawns are mowed. Vacant lots are often filled with allergenic weeds. It is very important to keep vacant lots mowed down and localities should enforce rules about this (Ogren).

There are two groups of plant that rarely cause pollen problems (Ogren, 2000). The first group is a group of plants with large, showy, lightly scented flowers. The male flower parts of these plants are few in number or deeply recessed within the blossom. The second group is a group of female plants. These plants are separate-sexed species. Individual plants are either males or females. The males produce pollen that causes allergy problems. The males should not be used in gardens. The females have no pollen at all. The females are the best choices for allergy-free gardens.

High-allergy grasses may be replaced in the lawn with low-allergy ground covers (Ogren, 2000). High-allergy plants that already exist in the garden may be removed and replaced with low-allergy plants. Removing high-allergy trees can be a difficult decision for some allergy sufferers. For example, Thai people prefer having fruit trees in their gardens. Tettoni and Warren (1988) comment that fruit trees such as mango trees and coconut palms are very common in Thai gardens. However, these trees are high-allergy plants (Pumhirun et al., 1997; Ogren, 2000). Thai allergy sufferers may not be willing to replace these trees.

Ogren (2000) pointed out that the closer a person is to the pollen source, the greater the chance of exposure. Therefore, high-allergy plants should not be planted near windows, doors, decks, or patios, and especially bedroom windows. Night blooming plants should not be placed near bedroom windows because they are most fragrant at night (Ogren). The most common night blooming plant in Thailand is jasmine.

The recommendations for pollen avoidance are summarized as follows.

1. Keep windows closed at night to prevent pollen. If needed, keep all windows and doors shut and run an air conditioner.

2. Ventilate homes when pollen levels are low or after 10 A.M.

3. Limit outdoor activities in the morning and on windy days.

4. Do not hang clothes outside overnight, early in the morning, or on windy day. Use a clothes dryer.

5. Do not mow lawns early in the morning. Wear a particle mask when working in the yard and garden.

6. Replace high-allergy plants with low-allergy plants.

7. Choose female plants that have no pollen. Avoid male plants that produce pollen. 
8. Choose plants that produce large, showy, lightly scented flowers.

9. Do not plant high-allergy plants near windows, doors, decks, or patios.

10. Limit ferns as houseplants.

11. Limit cut and dried flowers in homes.

12. Keep vacant lots mowed often.

\section{Implementation of Allergen Avoidance}

Allergen avoidance is recommended as the primary method of treatment for allergic rhinitis. However, research studies showed that practice of allergen avoidance recommendations was inconsistent and limited. Only small numbers of patients followed allergen avoidance recommendations.

According to a study on knowledge and implementation of dust mite control behavior, $26 \%$ of families who saw an allergist reported no knowledge of any environmental control recommendations for dust mite (Callahan, et al., 2001). Only 36\% of families who saw an allergist were using allergen-proof mattress covers on their child's bed. Only 29\% of families were using allergen-proof pillowcases. Only $19 \%$ of families removed carpet and only $10 \%$ of families removed stuffed toys from children's bedrooms. However, the parents of dust mite sensitive children who saw allergist were more aware of dust mite allergen control recommendations than those who had not. A study from France showed that around $27 \%$ of patients covered the mattress (de Blay, et al., 2001). Platts-Mills et al. (2000) reported that compliance of weekly vacuum cleaning of mattresses was uncommon.

A study on removal of cockroach allergen from inner-city homes (Eggleston et al., 1999) showed that participants in their study had socioeconomic barriers to cleaning. Even though the participants followed some routine cleaning techniques, most of the participants did not have a vacuum cleaner. Another study (Swartz, et al., 2001) revealed that cost was a barrier for $36 \%$ of families making allergen avoidance changes in homes.

Swartz, et al. (2001) pointed out that awareness was a main barrier for making allergen avoidance changes in homes for $61 \%$ of families. Awareness barriers included: never advised, not sure what to do, and no statement about pet advice for pet allergy. Attitude was a barrier for $46 \%$ of families. Attitude barriers included: too much energy or time, not sure changes will help, procrastination, and complacency. Emotion was a barrier for $29 \%$ of families with a pet in the home.

Allergy experts suggest allergy education is a key of allergen avoidance as well as allergy prevention (Storms et al., 1997b; Lewis, Kunkel, Wright, \& Olson, 2000). Allergy education is important for allergy sufferers to identify early symptoms and seek appropriate treatment. A research study confirmed that education for the family regarding routine cleaning and techniques 
to prevent reinfestion resulted in a decrease of cockroach allergen throughout most homes (Eggleston et al., 1999).

British patients with allergic rhinitis reported that the main sources of information about the disease and treatment were physicians, magazine and newspaper articles, pharmacists, and family members (Scadding et al., 2000).

\section{Outdoor Air Pollution}

The relationship between outdoor air pollution and the prevalence of allergic rhinitis is still controversial. Several studies showed that the prevalence of allergic diseases were significantly lower in the polluted cities of East Germany compared with West German cities (von Mutius, 2000). However, other studies showed that air pollution was correlated with allergic diseases. Samir, Magdy, and el Fetoh (1997), from Cairo, Egypt, investigated the relationship between allergic rhinitis and the exposure to air pollution. The cadmium level was used as a proximity of exposure to air pollution. They found that blood cadmium levels were significantly high in the allergic rhinitis group compared with the nonallergic rhinitis and control groups. A study from Brazil (Sih, 1999) confirmed that chronic exposure to urban levels of air pollution was associated with allergic diseases. When compared to children who lived in a pollution-free rural area, children who lived in a city had high prevalence of respiratory diseases such as rhinitis. Another study from Germany (Kramer, Koch, Ranft, Ring, \& Behrendt, 2000) confirmed that traffic-related air pollution in urban areas were associated with prevalence of allergic rhinitis symptoms and sensitization against pollen, dust mites, and cats.

Major sources of outdoor air pollution are industry and road traffic. Heavy industry is concentrating on the outer fringes of Bangkok, with industrial parks along major highways leading out into the country (Office of the Prime Minister [OPM], 1991). Traffic emissions are a major source of air pollution in Bangkok (Wangwongwattana, 1995). According to his study on the overall quality of air in 1993, along 16 major roads in Bangkok, dust and suspended particles were above the recommended level set, with other gases within the limits. With dust and suspended particles, the smaller their size, the greater the danger. Those under 10 microns can enter the lungs and cause allergies, irritation of the respiratory system, and increased susceptibility to illness (Wangwongwattana). Results of the Chulalongkorn indoor air quality study (Wongsekiarttirat, 1991) indicated a high correlation between outdoor and indoor air pollution for all pollutants measured in Bangkok. The outdoor pollutants strongly influence the indoor environment, though there are also indoor sources (Wongsekiarttirat). Leslie and Lunau (1992) pointed out that in the urban areas of developing countries with warm climates only a small number of people could afford air conditioning. Ventilation was largely natural via open windows and assisted by fans. In these situations, the quality of internal air was largely dependent on the quality of the external environment.

\section{Thailand}

Thailand is situated in the heart of the Southeast Asian mainland. The country sits like a reverse comma between the Indian Ocean and the South China Sea. Thailand is divided into four natural regions: the north mountain region, the central plain, the northeast plateau, and the 
south peninsula. Thailand has 76 provinces and Bangkok is the capital of Thailand. This study focuses on the Bangkok metropolitan area.

\section{Topography and Climate}

Bangkok is located in the central plain of Thailand. The Bangkok metropolitan area covers both sides of the Chao Phraya River. Bangkok has been built over a swamp for some 200 years. Bangkok has weathered annual floods every monsoon season. Bangkok has a hot and humid climate with significant rainfall. Its climate is influenced by tropical monsoon winds. Bangkok's climate has three seasons: hot, rainy, and very dry. Temperature is highest from mid-March to mid-May, coolest in December. Average daytime temperatures in Bangkok range from $30^{\circ} \mathrm{C}\left(87^{\circ} \mathrm{F}\right)$ in the dry season to $36^{\circ} \mathrm{C}\left(97^{\circ} \mathrm{F}\right)$ or more in the hot season. Rainy season in Bangkok lasts from May to October (OPM, 1991). Average monthly rainfall in Bangkok ranges from about $9 \mathrm{~mm}$ in January to as much as $344 \mathrm{~mm}$ in September.

\section{Humidity and Moisture}

An average outdoor relative humidity in Bangkok is $77 \%$ and it rarely dips below $65 \%$. Excess moisture is a big problem in Bangkok because the climate is tropical with high humidity. For Thai houses, excess moisture comes from various sources both external and internal including: ground water, rain penetration, roof leaks, plumbing leaks, and condensation. In poorly constructed houses, damp can rise up from the ground, water can diffuse from a wet area to a dry area, or rainwater can enter the interior. In addition, moisture is produced by the occupants of a house including the people, pets, and plants living in the house. Excess moisture inside homes can lead to allergy rhinitis because moisture encourages the growth of dust mites, molds, and cockroaches.

\section{Thai People}

In 2000, Thailand had a population of 60.6 millions with the annual population growth rate of 1\% (National Statistical Office, 2000). There were 29.8 million males and 30.8 million females. Around $24 \%$ of the population was children (0-14) and $67 \%$ was adults age 15 to 59 . Around $9 \%$ of the population was older people age 60 and over and almost $1 \%$ of Thai population was older people age 80 and over. In 1996, life expectancy at birth in Thailand was 69.8 for males and 74.9 for females (Ministry of Public Health [MPH], 1999). The average 60 year-old man could expect to live another 20 years, the average woman, nearly 24 years. By 2020, Thai's people's life expectancy at birth will rise to 72.2 years for males and 76.5 years for females (MPH).

Bangkok had the largest population in Thailand. There were 6.3 million people in Bangkok or $10 \%$ of the total population. There were 3.0 million males and 3.3 million females in Bangkok. Bangkok also had the highest population density in Thailand. In 2000, the population density of Bangkok was 4,029 people per $\mathrm{km}^{2}$ while the average population density of Thailand was 118 people per $\mathrm{km}^{2}$. There were around 1.8 million households in Bangkok with the average household size of 3.8 (National Housing Authority [NHA], 1999; National Statistical Office, 2000). 


\section{Characteristics of Dwellings in Thailand}

There are several types of dwellings in Bangkok, Thailand. These include houses, townhouses, high-rise apartments, and shophouses. Around $84 \%$ of dwellings in Thailand were single-unit houses (NHA, 1999). Around 60\% of households in Bangkok owned their dwellings (NHA).

The most common dwelling for middle-income people in Bangkok is a two-story house (Kutintara, 1997). A living room, a dining room, a kitchen, a bathroom, terraces, and a garage are located on the first floor of the house. Some houses also have a housekeeper's bedroom and a bathroom in the back of the house. The second floor of the house consists of bedrooms and bathrooms. Basements and attics are uncommon in houses in Bangkok.

A shophouse is a typical dwelling for people who own small businesses or retail shops. Shophouses usually have two to four stories. The ground floor is used for commercial purposes and the upper floors are residential. Shophouses are usually found bordering main and secondary roads in Bangkok (NHA, 1984).

Most Thai dwellings use wood parquet floor or ceramic tile floor rather than wall-to-wall carpeting floor. Dwellings in Bangkok do not have heating systems and fireplaces due to the hot climate. Central air conditioning units are uncommon in houses in Bangkok. Some dwellings are cooled with an individual air conditioner in each room. High temperatures, high humidity, opened windows, and lack of central air conditioning units in many Thai homes may lead to increased exposure and sensitization to allergens.

\section{Housing Satisfaction}

Housing satisfaction is a state of the level of contentment with current housing conditions (Morris \& Winter, 1978). Housing satisfaction refers to the entire continuum of satisfaction from very dissatisfied to very satisfied. The level of satisfaction is inferred in addition to the idea of a state of being satisfied (Morris \& Winter). Housing satisfaction can be studied in terms of overall satisfaction and in terms of satisfaction with specific aspects of housing (Parrott, 1985). This study will focus on specific aspects of housing: housing satisfaction in terms of health issues.

Many studies found that housing satisfaction is the highest among elderly people (Morris $\&$ Winter, 1978). There were two interpretations. Their housing needs have been met, thus they were highly satisfied or they might have little hope of improving their housing conditions and so have rationalized and accepted poorer conditions (Morris \& Winter). A study on psychosocial characteristic of people reporting allergic symptoms in Hungary showed that allergy sufferers appeared to be more unsatisfied with their living conditions and to report more problems with their environment compared to the rest of the population (Stauder et al., 2001). According to results from a study on moisture problems in houses, satisfaction with house performance increased with the age of the head of household (Cheple \& Yust, 1999). It is interesting to study housing satisfaction further in a healthy house context. 
Many housing characteristics have been associated with housing satisfaction. Size of the dwelling and amount of space available has been positively related to housing satisfaction (Morris, Crull, \& Winter, 1976). Housing features such as adequate closet and storage space and good kitchen layout have been related to housing satisfaction (Johnson \& Abernathy, 1983). Good lighting and comfortable temperature has been related to housing satisfaction among older people (Windley \& Scheidt, 1983). There are limited research studies on the relationship between indoor pollutants and housing satisfaction.

Al-Najadah (1996) studied the housing satisfaction of Kuwaiti households before and after their homes were contaminated by oil-related pollution. Unexpected results revealed that overall satisfaction with housing conditions remained high even after home contamination with oil-related pollution. However, oil-related pollution reduced the housing satisfaction of half of the participants. The contamination of residential interiors reduced the housing satisfaction of $31 \%$ of the participants. Al-Najadah also found that around $26 \%$ of the participants developed allergic symptoms after their exposure to oil-related pollution. Allergy was a major health problem reported. Around 5\% of the participants experienced an increase in allergic symptoms. Allergy was a major existing health problem aggravated by oil-related pollution. Around 10\% of the children of the participants developed allergic symptoms after their exposure to oil-related pollution and around $8 \%$ of the children experienced an increase in allergic symptoms.

Cheple and Yust (1999) studied a relationship between moisture problems in houses and housing satisfaction. They reported a negative relationship between some moisture problems in houses (condensation, mold, water stains) and the satisfaction with the performance of the house. They asked homeowners to rank their satisfaction level regarding the performance of their house on a scale of -10 to +10 . The majority of households $(82 \%)$ were satisfied with the performance of their house. Cheple and Yust asked homeowners to rank the performance of their house in comparison to what they perceive as the performance of other houses. Half of them ranked their house as average, $36 \%$ ranked their house above average, and 17\% ranked their house below average. Results of this study indicated that around half of the homeowners reported three or more serious moisture problems in their house; however, they were not aware of health effects and structural effects of these moisture problems.

\section{Theoretical Framework}

The theory of housing adjustment provides a theoretical framework for this study. The theory was developed by Morris and Winter (1978). This theory suggests that cultural and/or family norms provide the basis for housing satisfaction. Housing dissatisfaction results from a normative housing deficit. A perceived, salient gap between actual housing conditions and those required by the norms (an idealize version of the dwelling) produces a normative housing deficit for a family. The normative housing deficit represents the concept of unmet needs. Deficits may also arise because actual housing does not meet the special needs of individuals: for example, older people or people with disabilities. If the dwellings were to have more negative than positive features, the level of satisfaction would be low. The goal of the family is to maintain the overall normative housing deficit at near zero (Morris \& Winter). 
The housing dissatisfaction produced by normative deficits motivates four types of responses: (1) residential mobility, (2) residential alterations, (3) normative family adaptation, and (4) structural family adaptation. The first two represent housing adjustment behavior; the second two represent adaptive responses. The family chooses residential mobility or residential alteration to remove the deficit. If behavioral responses cannot be accomplished, the family adapts either their family structure or their family housing norms. After housing adjustment has occurred, satisfaction can be expected to rise (Morris \& Winter, 1978). Figure 1 represents a visual model of housing adjustment theory.

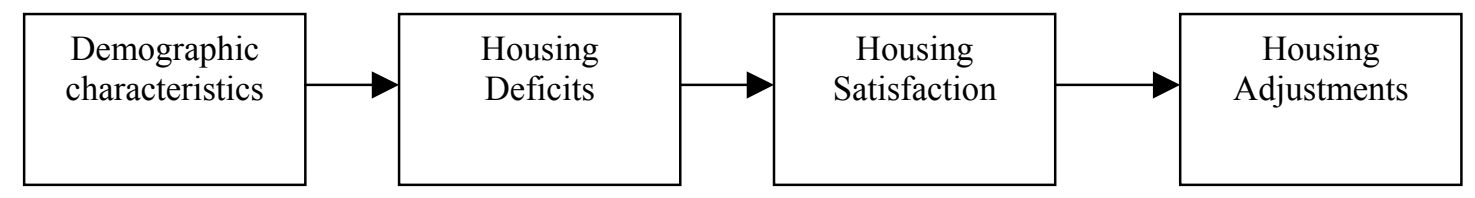

Figure 1: a visual model of housing adjustment theory

The theory of housing adjustment is a guide to research and presents the implications of various housing actions. This theory has been applied to a broad range of housing research; for example, home remodeling process (Parrott, 1993), housing satisfaction (Lee, Brandt, \& McFadden, 1994; Ukoha, 1995), impact of pollution on housing satisfaction (Al-Najadah, 1996), home modifications (Murphy, Finsten, Morris, Pettit, \& Winter, 1997), and sustainable consumption (Parrott, 2000). Research on residential alterations and additions has been conducted to examine remodeling and maintenance behavior. However, some types of housing adjustments, such as allergen avoidance practices, have not been studied. In addition, the housing adjustment theory has not been broadly explored in a healthy house context.

Cheple and Yust (1999) conducted a study on moisture problems in houses in Minnesota. They used the theory of housing adjustment as the basis for the study design. They investigated relationships among the presence of moisture problems, the satisfaction with the performance of the house, and residential mobility. If homeowners perceive symptoms of moisture damage as a deficit, they will be dissatisfied with the performance of their house. If the dissatisfaction is great enough and if the moisture problems cannot be overcome by residential alterations, the homeowner will choose to move to another house. Cheple and Yust found some negative relationships between moisture problems reported and satisfaction with the performance of the house. They also found that even with moisture problems, people would not consider a move.

This dissertation focuses on home conditions (potential housing deficits) of people with allergic rhinitis, their housing satisfaction in terms of health issues, and their adjustment behaviors in terms of allergen avoidance practices. People with allergic rhinitis have special needs. They have additional needs that arise from their health problems. Breathing poor indoor air can result in a vast range of allergic symptoms. However, they can reduce their allergic symptoms by minimizing exposure to airborne allergens. Allergy sufferers need good indoor air that is free from biological pollutants or has low allergen levels. High allergen levels in homes result from the presence of allergen sources in home environments; for example, presence of cockroaches, molds, furry pets, and high allergy plants. Thus, the presence of allergen sources in home environments can create housing deficits for allergy sufferers. 
Housing deficits arise if current housing does not meet the special needs of allergy sufferers. In addition, a perceived, salient gap between actual housing conditions and those recommended by allergy experts produces a normative housing deficit for an allergy sufferer. Their special needs could reduce housing satisfaction in terms of health issues. The housing dissatisfaction produced by housing deficits motivates housing adjustment behaviors. It is expected that allergy sufferers would be likely to conduct allergen avoidance practices to overcome the deficits. They may choose to modify their homes and/or change their lifestyles to reduce allergen levels in their homes. 


\section{Chapter 3}

\section{Methodology}

The purpose of this study was to examine home conditions, housing satisfactions, and allergen avoidance practices of people with allergic rhinitis in a hot, humid climate. This chapter describes the design and methodology of this study. This chapter starts with hypotheses. Then, variables, the research design, the population, and the instrument are discussed. Finally, data analysis is described.

\section{Hypotheses of the Study}

Nine hypotheses were tested in this study. Each hypothesis of this study is presented in the form of a research hypothesis, a null hypothesis, and a visual model. Objective one of the study was to describe home conditions, housing satisfaction, and allergen avoidance practices of people with allergic rhinitis. Objective two of this study was to investigate the interrelationship among home conditions, housing satisfaction, and allergen avoidance practices of people with allergic rhinitis. The following hypotheses were used to investigate relationships between each pair of variables.

Research Hypothesis 1. There is a negative relationship between home conditions and housing satisfaction.

Null Hypothesis 1. There is no relationship between home conditions and housing satisfaction.

Research Hypothesis 2. There is a positive relationship between housing satisfaction and allergen avoidance practices.

Null Hypothesis 2. There is no relationship between housing satisfaction and allergen avoidance practices.

Research Hypothesis 3. There is a negative relationship between home conditions and allergen avoidance practices.

Null Hypothesis 3. There is no relationship between home conditions and allergen avoidance practices.

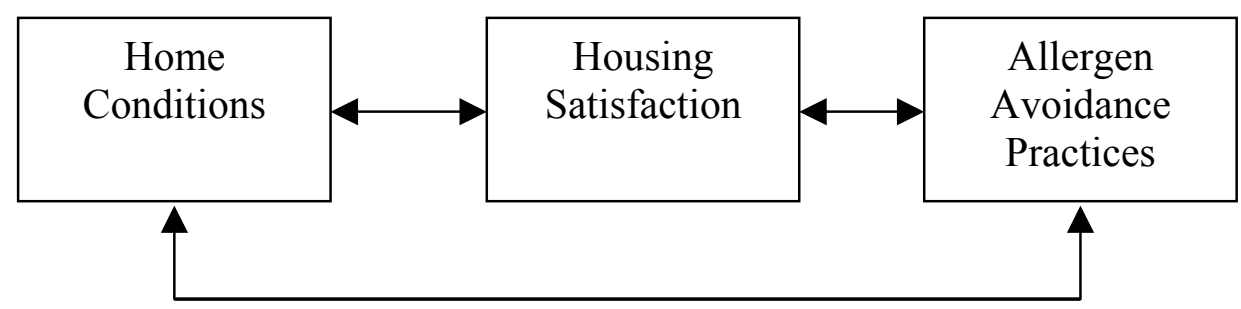

Figure 2. Visual Model of Hypotheses 1, 2, and 3

Objective three of this study was to investigate the relationship between chronological age and home conditions, housing satisfactions, and allergen avoidance practices of people with 
allergic rhinitis. The following hypotheses will be used to investigate relationships between age and each variable.

Research Hypothesis 4. There is a positive relationship between age and home conditions.

Null Hypothesis 4. There is no relationship between age and home conditions.

Research Hypothesis 5. There is a positive relationship between age and housing satisfaction.

Null Hypothesis 5. There is no relationship between age and housing satisfaction.

Research Hypothesis 6 . There is a negative relationship between age and allergen avoidance practices.

Null Hypothesis 6. There is no relationship between age and allergen avoidance practices.

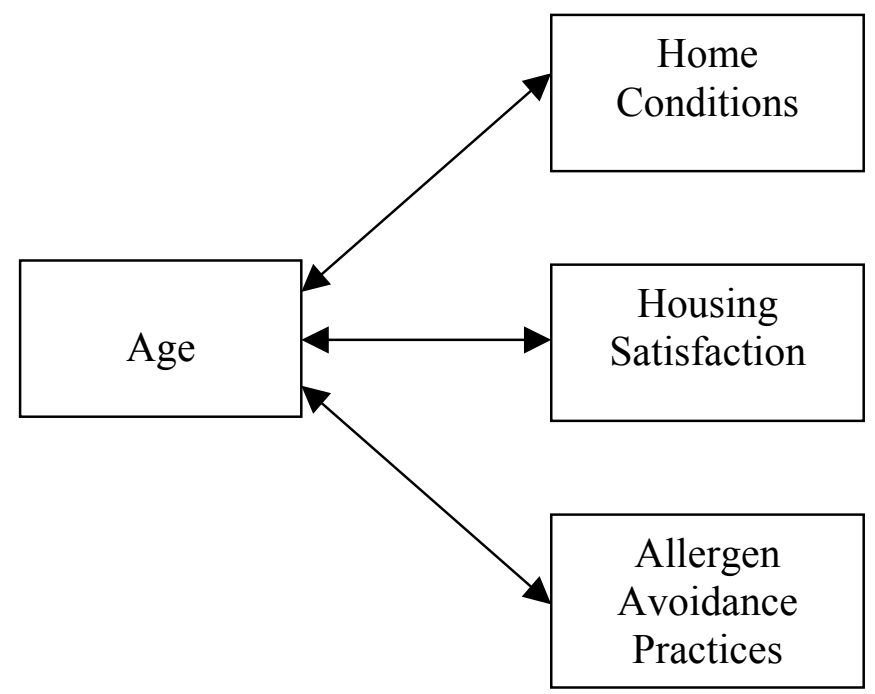

Figure 3. Visual Model of Hypotheses 4, 5, and 6

Research Hypothesis 7. The older group has more problematic home conditions than the younger group.

Null Hypothesis 7. The younger group and the older group do not differ in their home conditions.

Research Hypothesis 8. The older group express greater housing satisfaction than the younger group.

Null Hypothesis 8 . The younger group and the older group do not differ in their housing satisfaction. 
Research Hypothesis 9. The older group does less allergen avoidance practices than the younger group.

Null Hypothesis 9. The younger group and the older group do not differ in their allergen avoidance practices.

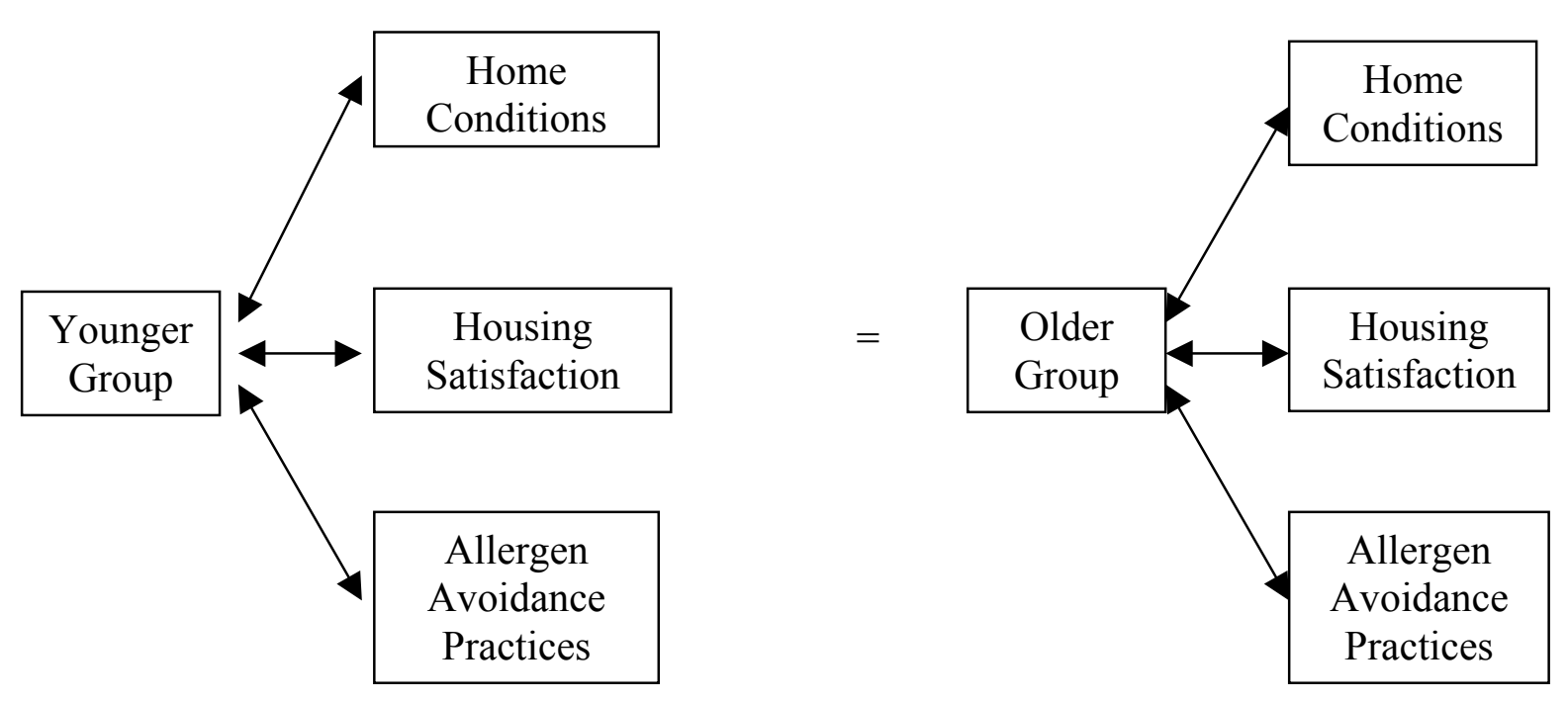

Figure 4. Visual Model of Hypotheses 7, 8, and 9

\section{Variables}

There are four major groups of variables in this study. Each group contains specific variables. The four groups of variables are: (1) home conditions, (2) housing satisfaction in terms of health issues, (3) allergen avoidance practices, and (4) age.

\section{Home Conditions}

The home conditions variable consists of 16 descriptions of problematic home conditions that lead to high allergen levels in homes or allergic symptoms. The presence of each problematic home condition received a score of 1 . An absence of each problematic home condition received a score of 0 . A total score of all home conditions was tabulated and used as a composite score. The composite scores of home conditions ranged from 0 to 16 . The problematic home conditions are:

1. Carpet flooring in a bedroom.

2. Open shelves or bookcases in a bedroom.

3. Drapes or horizontal blinds in a bedroom.

4. Upholstered furniture in a bedroom.

5. Use of kapok pillows in a bedroom.

6. Use of feather pillows in a bedroom.

7. Use of foam rubber pillows in a bedroom.

8. Presence of molds in a bedroom. 
9. Presence of molds in bathrooms.

10. Presence of molds in a kitchen.

11. Leaks and moisture damage.

12. Presence of cockroaches.

13. Presence of indoor plants in a bedroom.

14. Presence of a furry pet outdoor.

15. Presence of a furry pet in the house.

16. Presence of a furry pet in a bedroom.

\section{Housing Satisfaction}

The housing satisfaction variable consists of 4 questions concerning housing satisfaction in terms of health issues. Housing satisfaction was rated on a four-point Likert scale from "very dissatisfied" $=1$ to "very satisfied" $=4$. A composite score of all housing satisfaction items was calculated by summing the responses to the four items. The composite scores of housing satisfaction ranged from 4 to 16.

\section{Allergen Avoidance Practices}

The allergen avoidance practice variable is a composite variable based on practices that are recommended by experts in order to reduce allergen levels in homes. Allergen avoidance practices consist of two groups of subvariables: (1) household changes and (2) lifestyle practices.

Household Changes. The household change variable consists of 10 items that should be changed in houses of allergy sufferers. The composite score of household changes ranged from 0 to 20 . The following practices were scored 0,1 , or 2 . The rating scale contained: $0=I$ don't plan to do this, $1=$ I plan to do this in the future, and $2=$ I did this or not applicable.

1. Remove carpet from a bedroom.

2. Replace drapes and horizontal blinds with other options.

3. Remove upholstered furniture from a bedroom.

4. Remove plants from a bedroom.

5. Give a pet away.

The following practices were scored 0,1 , or 2 . The rating scale contained: $0=$ I don't do this and I don't plan to do this, $1=$ I would like to do this, but I really don't do it now, and $2=\mathrm{I}$ do this now.

6. Use allergen-proof pillowcases.

7. Use allergen-proof sheets.

8. Use polyester fiber-filled pillows.

9. Use a vacuum cleaner with a high efficiency filter or allergen-controlling bags.

10. Use lidded garbage containers. 
Lifestyle Practice. The lifestyle practice variable consists of 14 practices that allergy sufferers should do regularly. The composite score of lifestyle practices range from 0 to 42 . These following practices were scored $0,1,2$, or 3 . The rating scale contained: $0=\mathrm{I}$ don't do this and I don't plan to do this, 1 = I would like to do this, but I really don't do it now, 2 = I do this sometimes, and $3=\mathrm{I}$ do this regularly.

1. Wash pillowcases and sheets weekly.

2. Wash pillowcases and sheets in hot water.

3. Clean a bedroom with a damp cloth weekly.

4. Wet mop or vacuum a bedroom floor weekly.

5. Vacuum your bedroom weekly.

6. Wear a particle mask when vacuuming.

7. Use cockroach traps.

8. Use an exhaust fan in a kitchen.

9. Use an exhaust fan in bathrooms.

10. Use an air conditioner in a bedroom.

11. Clean an air filter monthly.

12. Use a dehumidifier.

13. Use an air cleaner.

14. Use a clothes dryer.

Age

Chronological age was used in this study. First, age was treated as a continuous variable to investigate relationships between age and each variable (home conditions, housing satisfactions, and allergen avoidance practices).

Second, age was separated into two groups: a younger group (20 to 59) and an older group (60 to 77). The age group was treated as a categorical variable to investigate the differences between a younger group and an older group of people with allergic rhinitis on home conditions, housing satisfactions, and allergen avoidance practices.

\section{Research Design}

The survey method was used for this study because of lower costs, less time-consuming, and the ability to identify attributes of a population from a small group of people. The survey was cross-sectional. Cavanaugh (1997) suggested that cross-sectional studies could provide a snapshot view of age differences as long as their limits are recognized. This study compared people of different ages at a single point in time. A major problem with cross-sectional studies is the confounding of age and cohort (Cavanaugh). An age effect is a difference due to chronological age whereas a cohort effect is a difference due to the experiences or characteristics of the particular birth cohort (Quadagno, 1999).

This study is a quantitative study. However, this study also applies a dominant-less dominant design model (Creswell, 1994) in order to triangulate findings and to demonstrate convergence in results. A quantitative approach (a survey questionnaire) dominates the study 
and a qualitative approach (a residential observation) was used in the data collection phase. The study is theoretically driven by the quantitative method (a survey questionnaire), incorporating a complementary qualitative data collection procedure (a residential observation). Data were collected by both questionnaires and observations.

\section{Population and Sample}

The population of this study was adults and older adults with allergic rhinitis who live in Bangkok, Thailand. The adult group was defined as those aged 20 to 59 years and the older adult group was defined as those aged 60 years and over.

The sample of this study was a convenience sample. A sampling frame was not available because there is no list of Thai people with allergies. A Pramongkutklao hospital report (1996) had around 75 allergic patients per day and 60 patients per day who got an allergy test and an allergy shot. The sample for this study was recruited from female outpatients who visited the allergy clinic in Pramongkutklao Hospital, Bangkok, Thailand during June and July 2001. Sixtyseven female patients filled out the screening questionnaire and were then asked for permission to visit and take photographs of their homes. Forty-one patients (67\%) gave their permission.

\section{Procedure}

The procedure of this study includes two phases.

\section{Initial Survey}

During June and July 2001, the researcher visited an allergy clinic and asked patients in a waiting room to participate in the study. Before allergy outpatients received a questionnaire, they were asked whether they had allergic rhinitis or not. The researcher asked patients who had allergic rhinitis to fill out the brief screening questionnaire. A letter of introduction and a consent form were given to each patient along with the questionnaire. The researcher asked each patient for permission to observe and take photos of her home.

\section{In-Depth Survey}

During the home visit, the researcher asked each participate to fill out an in-depth survey questionnaire. The researcher recorded indoor relative humidity as well as temperature. The researcher observed features and conditions in the home and took photos. The photos served as visual records to support the participants' responses.

\section{Instruments}

The instruments of this study included a screening questionnaire and an in-depth survey questionnaire. 


\section{Screening Questionnaire}

The one-page questionnaire consists of questions on age, housing type, allergens to which a patient is allergic, and allergen avoidance practices (See Appendix A and B). In the last part of the questionnaire, the researcher asked permission to visit and take photos of participants' dwellings. The questionnaire was designed in a format as recommended by Dillman (2000).

\section{In-depth Survey Questionnaire}

The questionnaire is four-pages. The questionnaire contains questions on home conditions, housing satisfactions, allergen avoidance practices, and demographic information (See Appendix C and D).

\section{Pilot Test}

The questionnaires were written in English and tested with a selected group of 5 people. The questionnaires were then translated into Thai. The questionnaires in a Thai version were reviewed by translators. The original questionnaires in Thai were tested with a selected group of 5 Thai people with allergic rhinitis in order to improve the questions and the format. The questionnaires were sent to this group during April 2001 with the help of research assistants in Thailand. The questionnaires were revised according to results of the pilot test.

\section{Data Analysis}

A descriptive analysis of all variables in the study was conducted using a SPSS release 9.0.0 statistical package. The frequency scores were reported. The means, standard deviations, and range of scores for these variables were reported. Pearson's product-moment correlation was used to test interrelationships among home conditions, housing satisfaction, and allergen avoidance practice as well as relationships between age and these three variables. T-tests were used to test differences on home condition, housing satisfaction, and allergen avoidance practice between the two age groups. A level of significance was set at $\underline{p}<.05$. Data from open-ended questions were counted, categorized, prioritized and reported. Photos were presented according to responses from the questionnaires. 


\section{Chapter 4}

\section{Findings and Discussion}

The purpose of this study was to examine home conditions, housing satisfactions, and allergen avoidance practices of people with allergic rhinitis in a hot, humid climate. This chapter includes the following sections: (1) demographic characteristics, housing, and health situations, (2) home conditions, (3) housing satisfaction, (4) allergen avoidance practices, (5) hypothesis testing results, (6) results from open-ended questions, (7) additional statistical analysis results, and (8) discussion.

\section{Demographic Characteristics, Housing, and Health Situations}

\section{Description of the Sample}

The sample for this study included 41 female patients. The average age of the respondents was 54 years $(\underline{\mathrm{SD}}=13.6)$ and ranged from 20 to 77 years (see Table 1$)$. In Thailand, people who are 60 years old and over are considered as the older population (National Statistical Office, 2000). Thai people normally retire at the age of 60 . Therefore, 60 years old was selected as the age classification break point for this study. Forty-one percent of the respondents (17 people) were seniors aged 60 and over. Fifty-nine percent of the respondents ( 24 people) were 20 to 59 years old. The average age of the older group (60 to 77 years) was 66 years old $(\underline{\mathrm{SD}}=5.3)$. The average age of the younger group (20 to 59 years $)$ was 45 years old $(\underline{\mathrm{SD}}=10.4)$. Approximately half $(56 \%)$ of the respondents were married (see Table 2$)$.

Table 1

Age of Respondents

\begin{tabular}{lrr}
\hline Age & Percent & $\underline{\mathrm{n}}$ \\
\hline Younger group (20-59) & & \\
20-29 years & $5 \%$ & 2 \\
30-39 years & $15 \%$ & 6 \\
40-49 years & $17 \%$ & 7 \\
50-59 years & $22 \%$ & 9 \\
\hline Younger group total & $59 \%$ & 24 \\
\hline Older Group (60 and over) & & \\
60-69 years & $34 \%$ & 14 \\
70 years and over & $7 \%$ & 3 \\
\hline Older group total & $41 \%$ & 17 \\
\hline Total & $100 \%$ & 41 \\
\hline
\end{tabular}


Table 2

Marital Status of Respondents

\begin{tabular}{lrrrrrr}
\hline Marital status & $\begin{array}{c}\text { Younger group } \\
(20-59)\end{array}$ & \multicolumn{2}{c}{$\begin{array}{c}\text { Older group } \\
\text { (60 and over) }\end{array}$} & \multicolumn{2}{c}{ Total } \\
& Percent & $\underline{\mathrm{n}}$ & Percent & $\underline{\mathrm{n}}$ & Percent & $\underline{\mathrm{n}}$ \\
\hline Single & $17 \%$ & 7 & $5 \%$ & 2 & $22 \%$ & 9 \\
Married & $39 \%$ & 16 & $17 \%$ & 7 & $56 \%$ & 23 \\
Widow & $3 \%$ & 1 & $20 \%$ & 8 & $23 \%$ & 9 \\
\hline Total & $59 \%$ & 24 & $42 \%$ & 17 & $100 \%$ & 41 \\
\hline
\end{tabular}

Note. Percentages may not total $100 \%$ due to rounding.

\section{Allergy Information}

The respondents had suffered from allergic rhinitis for long time periods. The average duration of allergic rhinitis was 19 years and the average duration of treatment was 13 years (see Table 3). Almost all of the respondents (95\%) reported that they were allergic to dust mite allergen (see Table 4). Other common allergens were pollen (66\%) and dog allergen (61\%). Approximately two-thirds of the respondents $(68 \%, 28$ people) received suggestions from doctors on how to improve their home to avoid allergens. All of the respondents were nonsmokers; however, $34 \%$ (14 people) had family members who were smokers.

Table 3

Duration of Allergic Rhinitis and Treatment

\begin{tabular}{lclccr}
\hline & $\underline{\mathrm{N}}$ & Minimum & Maximum & $\underline{\mathrm{M}}$ & $\underline{\mathrm{SD}}$ \\
\hline Duration of allergic rhinitis & 41 & 5 years & 69 years & 19 years & 15.3 \\
Duration of treatment & 41 & 1 year & 46 years & 13 years & 9.5 \\
\hline
\end{tabular}

Table 4

\begin{tabular}{|c|c|c|}
\hline Allergen & Percent & $\underline{\mathrm{n}}$ \\
\hline Dust mite allergen & $95 \%$ & 39 \\
\hline Pollen & $66 \%$ & 27 \\
\hline Dog allergen & $61 \%$ & 25 \\
\hline Mold allergen & $49 \%$ & 20 \\
\hline Cat allergen & $44 \%$ & 18 \\
\hline Cockroach allergen & $27 \%$ & 11 \\
\hline
\end{tabular}

Note. $\underline{\mathrm{N}}=41$, multiple responses possible

\section{Respondents Housing Situation}

The majority of the respondents (64\%) resided in single-family detached houses (see Table 5 and Figure 5 to Figure 9). Most respondents lived in homes they owned (73\%) or homes that were owned by family members (22\%, see Table 6). Average length of residency was 17 years and average age of homes was 19 years (see Table 7). Only 12\% of the respondents' homes were designed or decorated by architects or interior designers. 
Table 5

Housing Type

\begin{tabular}{lrr}
\hline Housing type & Percent & $\underline{\underline{\mathrm{n}}}$ \\
\hline House & $64 \%$ & 26 \\
Townhouse & $15 \%$ & 6 \\
Apartment & $12 \%$ & 5 \\
Shophouse & $7 \%$ & 3 \\
Nuns' apartment in the temple & $2 \%$ & 1 \\
\hline
\end{tabular}

Note. $\underline{\mathrm{N}}=41$

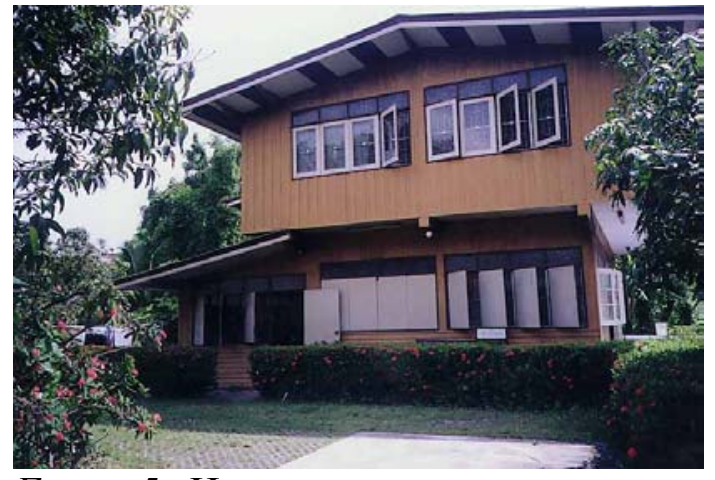

Figure 5. House

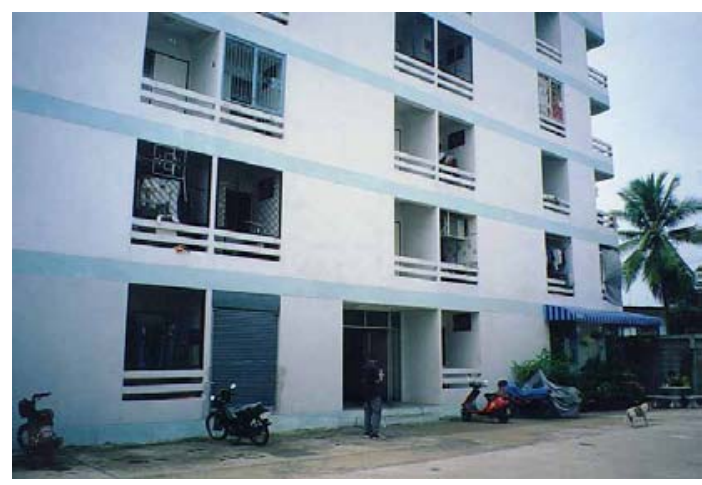

Figure 7. Apartment building

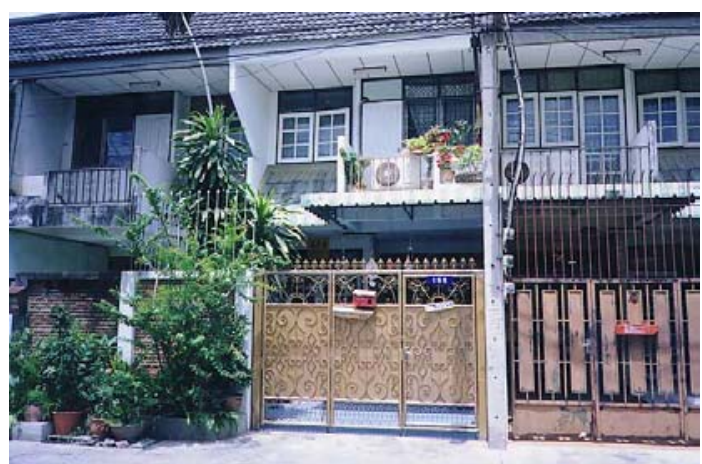

Figure 6. Townhouses

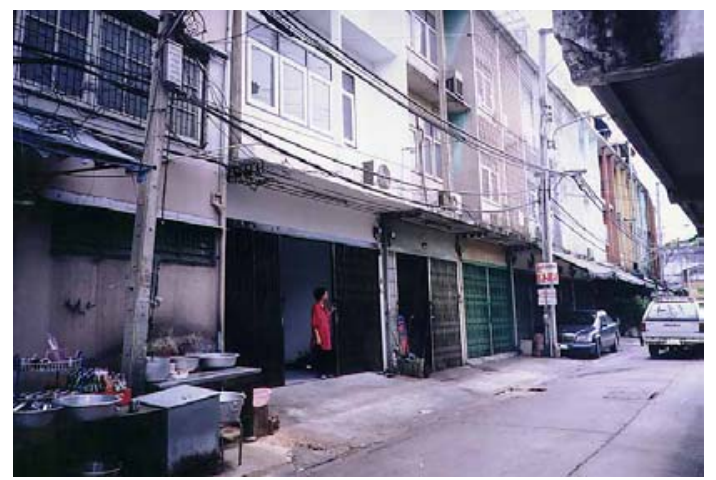

Figure 8. Shophouses

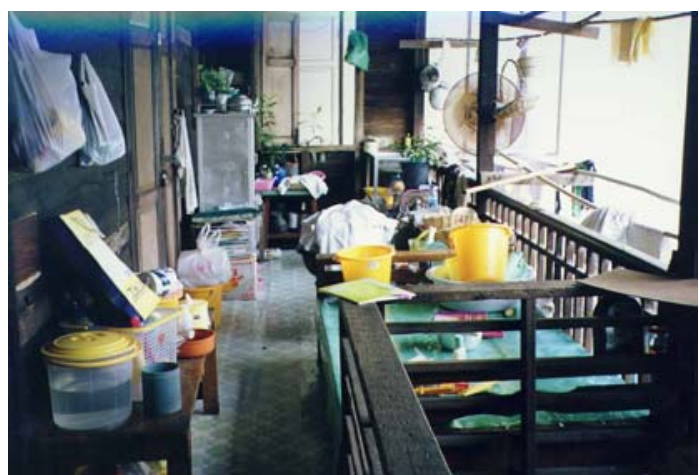

Figure 9. Nuns' apartment 
Table 6

Homeownership

\begin{tabular}{lrrrrrr}
\hline Homeownership & $\begin{array}{c}\text { Younger group } \\
(20-59)\end{array}$ & \multicolumn{2}{c}{$\begin{array}{c}\text { Older group } \\
(60 \text { and over })\end{array}$} & \multicolumn{2}{c}{ Total } \\
\cline { 2 - 7 } & Percent & $\underline{\mathrm{n}}$ & Percent & $\underline{\mathrm{n}}$ & Percent & $\underline{\underline{n}}$ \\
\hline Owned & $42 \%$ & 17 & $32 \%$ & 13 & $74 \%$ & 30 \\
Owned by the family member & $15 \%$ & 6 & $7 \%$ & 3 & $22 \%$ & 9 \\
Rent & $2 \%$ & 1 & $2 \%$ & 1 & $4 \%$ & 2 \\
\hline Total & $59 \%$ & 24 & $41 \%$ & 17 & $100 \%$ & 41 \\
\hline
\end{tabular}

Note. $\underline{\mathrm{N}}=41$

Table 7

Duration of Residence and Home Age

\begin{tabular}{lccccc}
\hline & $\underline{\mathrm{N}}$ & Minimum & Maximum & $\underline{\mathrm{M}}$ & $\underline{\mathrm{SD}}$ \\
\hline Duration of residence & 41 & 2 months & 44 years & 17 years & 11.92 \\
Home age & 41 & 6 months & 44 years & 19 years & 11.54 \\
\hline
\end{tabular}

\section{Indoor Humidity and Temperature}

Indoor humidity and temperature in homes of the respondents were recorded when the researcher and research assistants visited and took pictures of their homes. Home visits were done during the daytime in a rainy season (June, July, and August). The average indoor humidity was $66 \%$ and ranged from $56 \%$ to $85 \%$. The average indoor temperature was $89^{\circ} \mathrm{F}$ and ranged from $82^{\circ} \mathrm{F}$ to $94^{\circ} \mathrm{F}$.

\section{Pet Ownership}

Forty- one percent of the respondents had dogs and 12\% had cats (see Table 8, Figure 10, and Figure 11). Half of the respondents who had pets did not allow their pets to stay in their home's interior (see Table 9 and Figure 12). One-fourth of the respondents allowed their pets to stay in their living rooms, but they did not allow their pets to stay in their bedrooms (see Figure 13). Of the 22 pet owners, $64 \%$ washed their pets every week and $27 \%$ washed their pets every month (see Table 10).

Table 8

Pet Ownership

\begin{tabular}{|c|c|c|}
\hline & Percent & $\underline{\mathrm{n}}$ \\
\hline No pets & $37 \%$ & 15 \\
\hline Dog & $41 \%$ & 17 \\
\hline Cat & $12 \%$ & 5 \\
\hline $\begin{array}{l}\text { Other pets } \\
\text { (rabbit, fish, or bird) }\end{array}$ & $17 \%$ & 7 \\
\hline
\end{tabular}

Note. Some respondents had multiple pets. 


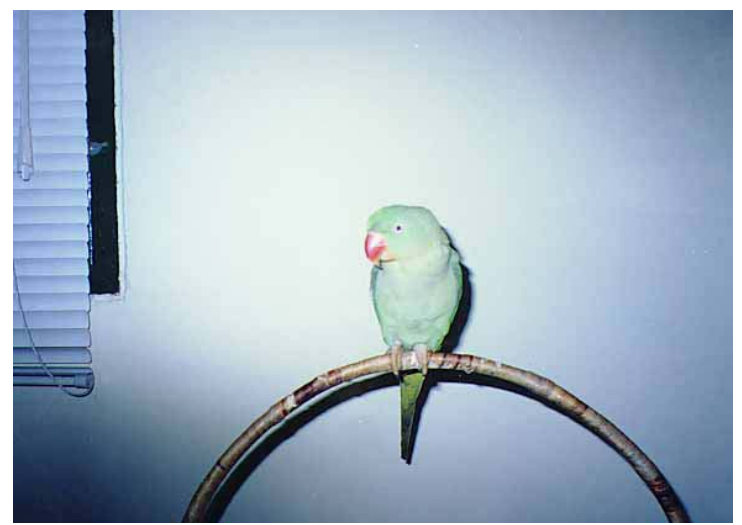

Figure 10. A parrot

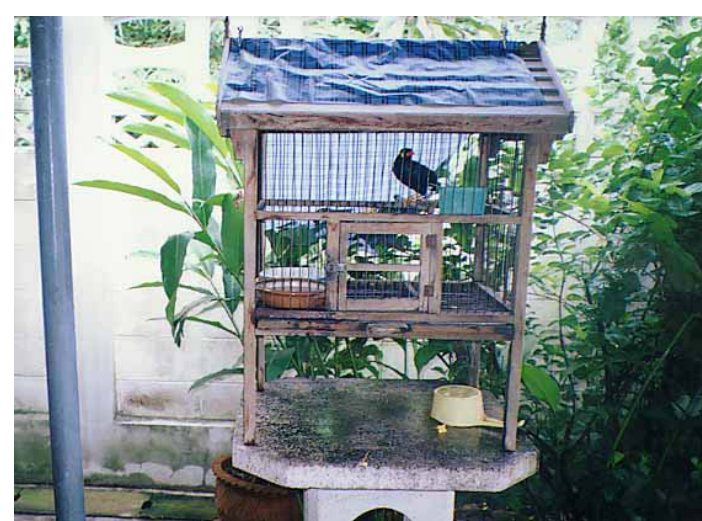

Figure 11. A hill myna

Table 9

Location of Pets

\begin{tabular}{lcr}
\hline & Percent & $\underline{\mathrm{n}}$ \\
\hline The pets stayed outdoors & $61 \%$ & 25 \\
Allowed the pets to stay in the living room & $29 \%$ & 12 \\
Allowed the pets to stay in the bedroom & $17 \%$ & 7 \\
\hline
\end{tabular}

Note. $\underline{\mathrm{n}}=$ multiple responses.

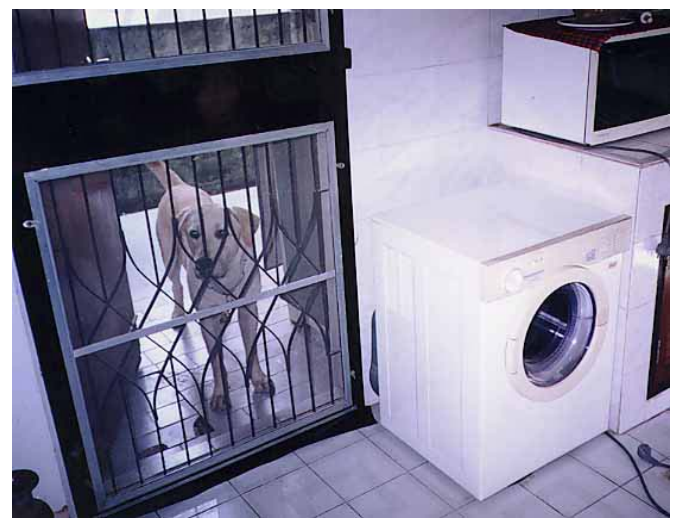

Figure 12. A pet not allowed indoors

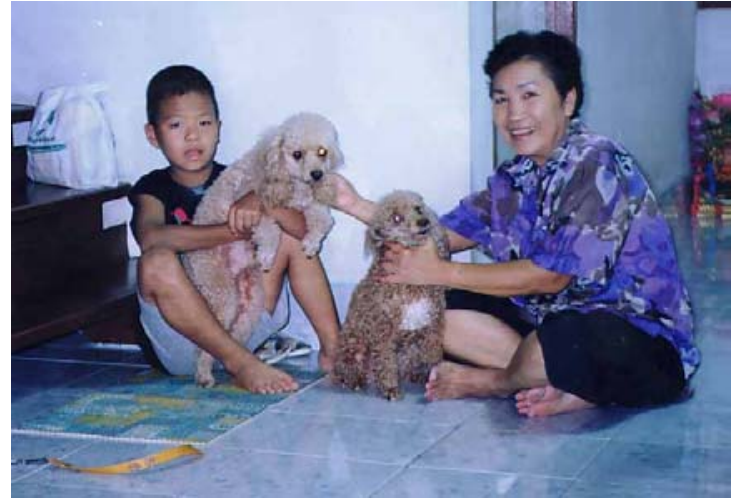

Figure 13. Pets allowed indoors

Table 10

Washing Pets

\begin{tabular}{lrr}
\hline & Percent & $\underline{\underline{\mathrm{n}}}$ \\
\hline Every week & $64 \%$ & 14 \\
Every month & $27 \%$ & 6 \\
Less than once a month & $9 \%$ & 2 \\
Total & $100 \%$ & 22 \\
\hline
\end{tabular}

In summary, the sample of this study included 41 female allergy patients aged 20 to 77 years. Dust mite allergens were reported as the most common allergy triggers among the respondents. The majority of the respondents lived in their own single-family detached houses. Around two-third of the respondents had pets. Almost two-third of the respondents who had pets washed their pets every week and did not allow their pets to stay indoors. 


\section{Home Conditions}

The home condition variable is a composite score of 16 selected problematic home conditions that can lead to high allergen levels in homes. The first eight problematic home conditions are allergy related items in the respondents' bedrooms and the last eight negative home conditions are allergy related conditions in the whole dwellings.

\section{Allergy Related Items}

The respondents reported interior features that were allergy related items in their bedrooms as shown in Table 11. Figure 14 to Figure 18 show examples of allergy related items in the respondents' bedrooms. Figure 19 to Figure 21 show bedrooms without allergy related items. Open shelves or bookcases were the most allergy related items found in the respondents' bedrooms when compared to other items. Almost half of the respondents (46\%) had drapes or horizontal blinds in their bedrooms. Around one-third of the respondents used kapok pillows $(32 \%)$ or foam rubber pillows $(37 \%)$. The majority of the respondents $(83 \%)$ did not have upholstered furniture in their bedrooms. Almost all of the respondents had wooded flooring in their bedrooms. None of the respondents had plants in their bedrooms.

Table 11

Presence of Allergy Related Items in the Respondents' Bedrooms

\begin{tabular}{lrr}
\hline & \multicolumn{2}{c}{ Frequency } \\
\cline { 2 - 3 } & Percent & $\underline{\underline{n}}$ \\
\hline Open shelves or bookcases & $51 \%$ & 21 \\
Drapes or horizontal blinds & $46 \%$ & 19 \\
Foam rubber pillows & $37 \%$ & 15 \\
Kapok pillows & $32 \%$ & 13 \\
Upholstered furniture & $17 \%$ & 7 \\
Feather pillows & $5 \%$ & 2 \\
Carpet flooring & $2 \%$ & 1 \\
Indoor plants & $0 \%$ & 0 \\
\hline
\end{tabular}

Note. $\underline{\mathrm{N}}=41$

\section{Bedrooms with Allergy Related Items.}

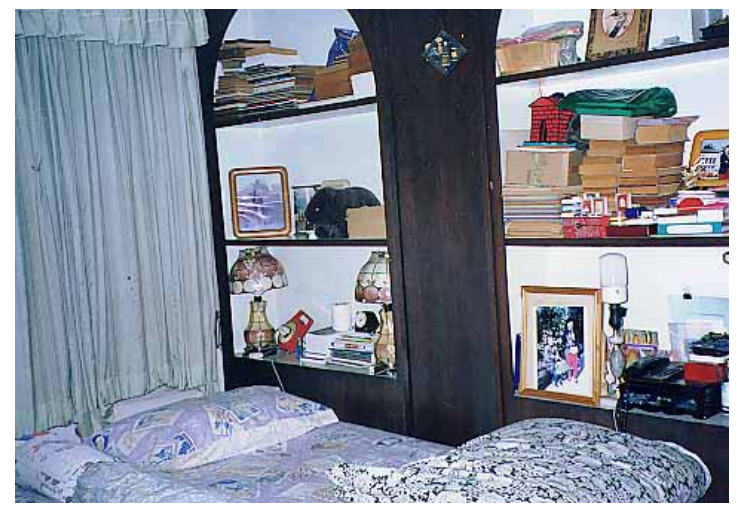

Figure 14. Open shelves

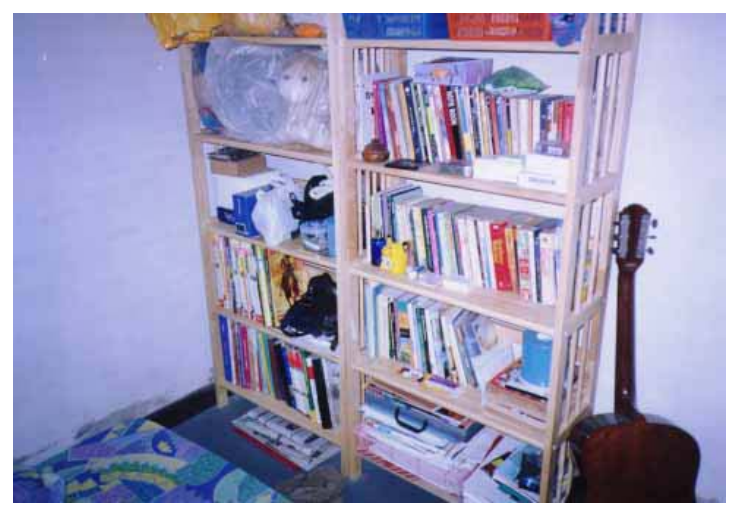

Figure 15. Open bookcases 


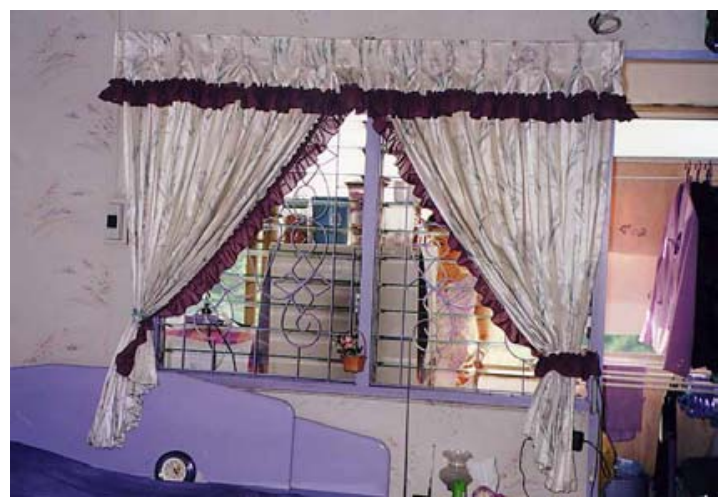

Figure 16. Drapes

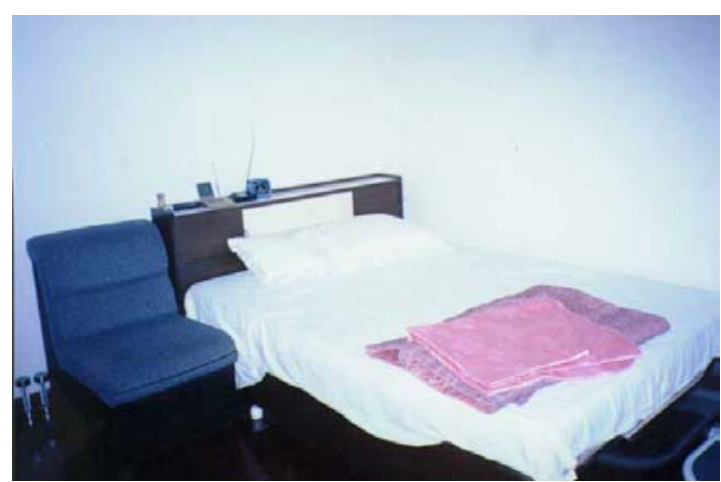

Figure 17. Upholstered furniture

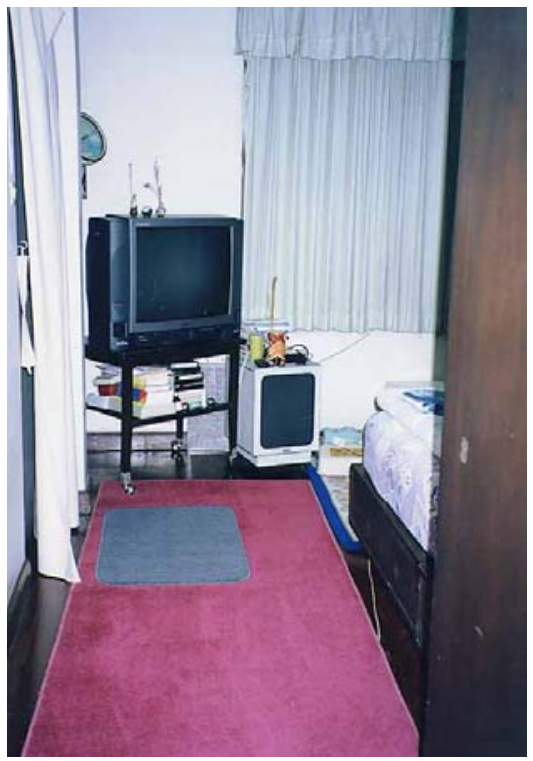

Figure 18. Carpet Flooring

Bedrooms without Allergy Related Items

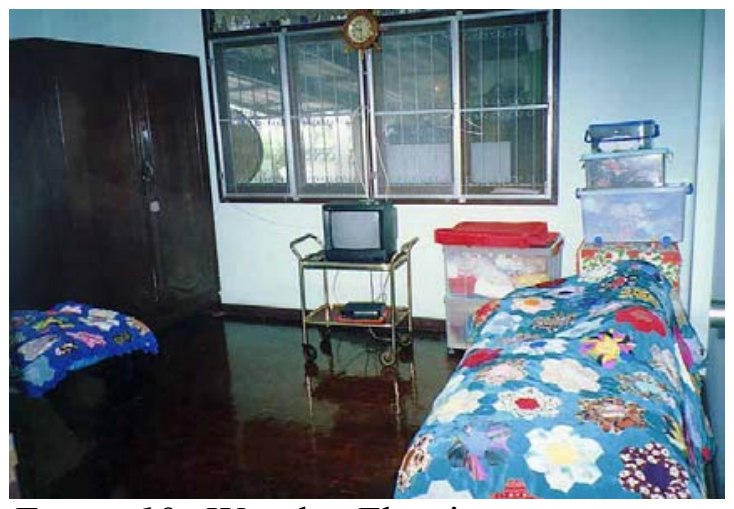

Figure 19. Wooden Flooring

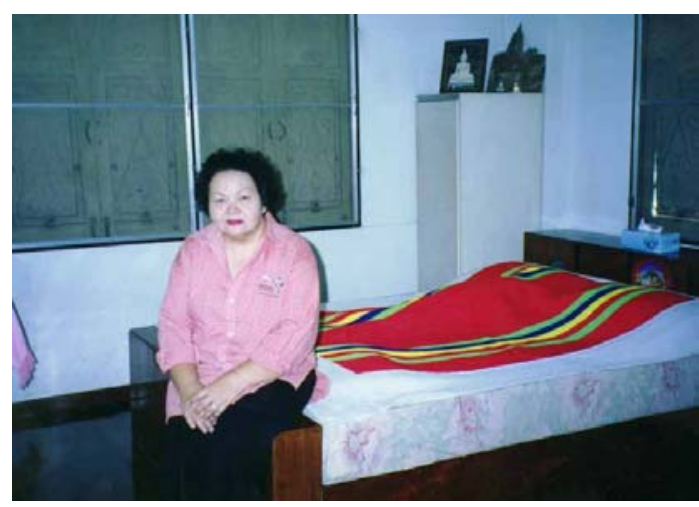

Figure 20. No open shelve and no drape 


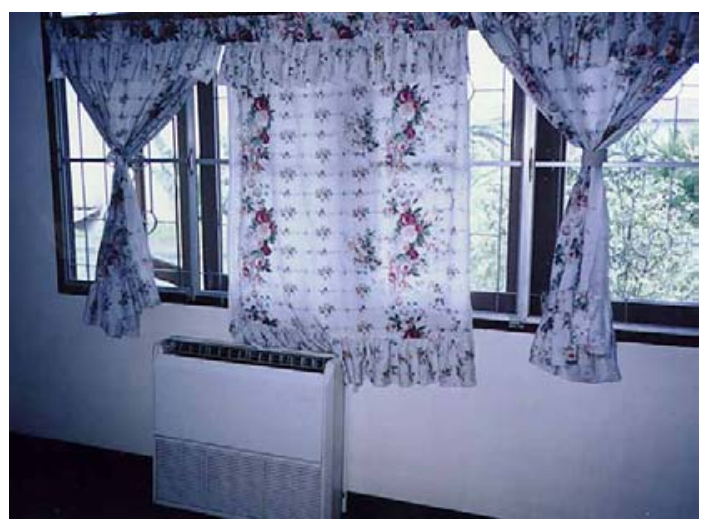

Figure 21. Easy to wash curtains

\section{Allergy Related Conditions}

A number of allergy related conditions in the whole house were noted (see Table 12). The majority of the respondents (76\%) found cockroaches in their homes. Around one-third of the respondents (32\%) found leaks and moisture damage in their homes. Only $10 \%$ of the respondents reported that they found molds in their bedrooms (see Figure 22), but 37\% found molds in their kitchens (see Figure 23), and 39\% found molds in their bathrooms.

Table 12

Presence of Allergy Related Conditions in Dwellings

\begin{tabular}{lrr} 
& \multicolumn{2}{c}{ Frequency } \\
\cline { 2 - 3 } & Percent & $\underline{\mathrm{n}}$ \\
\hline Cockroaches & $76 \%$ & 31 \\
Presence of a furry pet outdoors & $66 \%$ & 27 \\
Molds in bathrooms & $39 \%$ & 16 \\
Molds in kitchen & $37 \%$ & 15 \\
Leaks and moisture damage & $32 \%$ & 13 \\
Presence of a furry pet indoors & $29 \%$ & 12 \\
Presence of a furry pet in a bedroom & $17 \%$ & 7 \\
Molds in a bedroom & $10 \%$ & 4 \\
\hline
\end{tabular}

Note. $\underline{\mathrm{N}}=41$, multiple responses possible

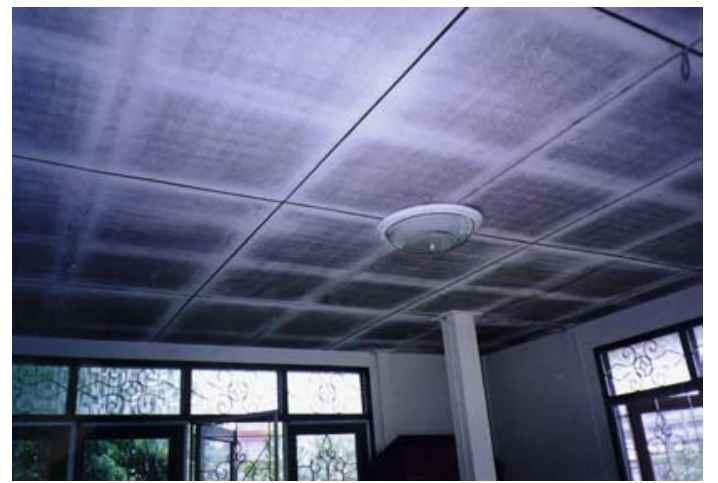

Figure 22. Molds in Bedroom

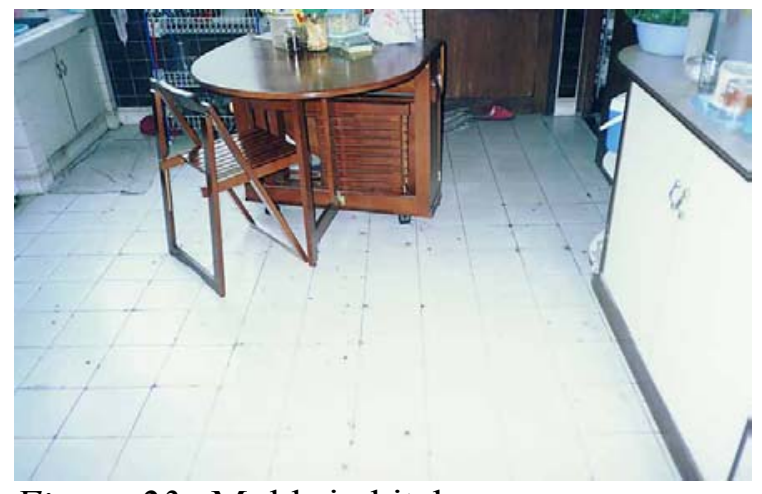

Figure 23. Molds in kitchen 
The composite score of the home condition variable included eight allergy related items and eight allergy related conditions and was used for hypotheses testing. A presence of each problematic home condition received a score of 1 . An absence of each problematic home condition received a score of 0 . A total score of all home conditions was tabulated and used as a composite score. The composite scores of home conditions ranged from 0 to 10 . The mean score of the total home conditions was $5.0(\underline{\mathrm{SD}}=1.9)$.

\section{Housing Satisfaction}

The housing satisfaction variable is a composite score that consists of responses to four questions concerning housing satisfaction in terms of health issues. The respondents expressed their satisfactions in terms of health issues as shown in Table 13. The majority of the respondents $(70 \%)$ were satisfied (very satisfied or somewhat satisfied) that their homes were healthy places to live. Sixty-one percent of the respondents were satisfied that their homes were allergy-free places to live. Two-thirds of the respondents $(66 \%)$ indicated satisfaction that their homes did not contribute to allergy problems. Two-thirds of the respondents $(66 \%)$ were satisfied that they had controlled allergens in their homes.

Housing satisfaction was rated on a four-point Likert scale from "very dissatisfied" to "very satisfied." Responses of "very dissatisfied" received scores of 1 . Responses of "very satisfied" received scores of 4. The composite score of housing satisfaction derived from adding up all four housing satisfaction scores. Reliability was estimated by computing alpha coefficient for the total housing satisfaction. The alpha coefficient for housing satisfaction was .84 . The composite scores of housing satisfaction ranged from 4 to 16 . The mean score of the total housing satisfaction was $11(\underline{\mathrm{SD}}=3.0)$. The total housing satisfaction variable was used for hypotheses testing. 
Table 13

Housing Satisfaction

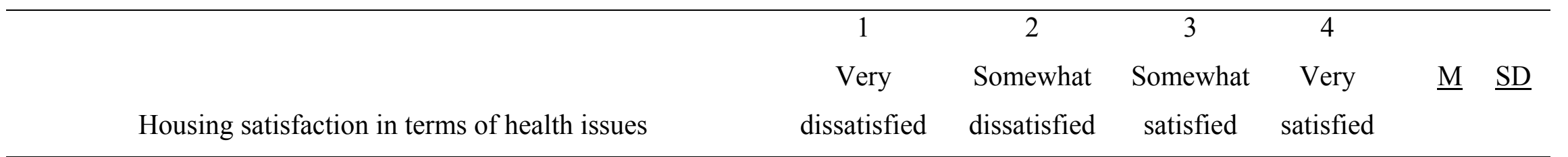

Satisfaction that the home is a healthy place to live

4

$(10 \%)$

Satisfaction that the home is an allergy-free place to live

Satisfaction that you have controlled allergens in the home
4

(10\%)

4

$(10 \%)$

$(12 \%)$
4

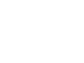

$(20 \%)$

8

$\begin{array}{rrrr}17 & 12 & 2.9 & 0.94 \\ (41 \%) & (29 \%) & & \end{array}$

$(29 \%)$

12

19

(46\%)

$\begin{array}{lll}6 & 2.7 & 0.85\end{array}$ (15\%)

10

$(24 \%)$

$(46 \%)$

(46\%)




\section{Allergen Avoidance Practices}

The allergen avoidance practice variable is a composite variable of 24 practices that are recommended by experts in order to reduce allergen levels in homes. Allergen avoidance practices consist of two groups of subvariables: (1) household changes and (2) lifestyle practices.

\section{Household Changes}

The household change subvariable consists of 10 changes that allergy patient should do in their homes. The respondents were asked about household changes that they did or planned to do. Ninety-three percent of the respondents never had carpets in their bedrooms (see Table 14). Regarding pets, $58 \%$ of the respondents who had pets did not plan to give pets away, but $15 \%$ planned to give pets away in the future.

Table 14

Household Changes 1

\begin{tabular}{|c|c|c|c|c|c|c|c|c|}
\hline \multirow[b]{2}{*}{ Household change } & \multicolumn{2}{|c|}{$\begin{array}{c}\text { N/A } \\
\text { I never have } \\
\text { this. }\end{array}$} & \multicolumn{2}{|c|}{ I did this. } & \multicolumn{2}{|c|}{$\begin{array}{l}\text { I plan to do } \\
\text { this in the } \\
\text { future. }\end{array}$} & \multicolumn{2}{|c|}{$\begin{array}{l}\text { I don't plan } \\
\text { to do this. }\end{array}$} \\
\hline & $\%$ & $\mathrm{n}$ & $\%$ & $\underline{\mathrm{n}}$ & $\%$ & $\underline{\mathrm{n}}$ & $\%$ & $\underline{\mathrm{n}}$ \\
\hline Remove plants from bedroom. & $100 \%$ & 41 & $0 \%$ & 0 & $0 \%$ & 0 & $0 \%$ & 0 \\
\hline Remove carpet from bedroom. & $93 \%$ & 38 & $7 \%$ & 3 & $0 \%$ & 0 & $0 \%$ & 0 \\
\hline Remove upholstered furniture & & & & & & & & \\
\hline from bedroom. & $46 \%$ & 19 & $12 \%$ & 5 & $25 \%$ & 10 & $17 \%$ & 7 \\
\hline Give pets away. & $37 \%$ & 15 & $17 \%$ & 7 & $10 \%$ & 4 & $37 \%$ & 15 \\
\hline Remove drap & & & & & & & & \\
\hline blinds in bedroom. & $32 \%$ & 13 & $29 \%$ & 12 & $22 \%$ & 9 & $17 \%$ & 7 \\
\hline
\end{tabular}

The majority of the respondents (78\%) used polyester-fiber-filled pillows and $17 \%$ used allergen-proof sheets (see Table 15). Over one-third of the respondents (37\%) used allergenproof pillowcases and $29 \%$ planned to use the pillowcases. Two-thirds of the respondents used lidded garbage containers. One-fourth of the respondents used vacuum cleaners with a high efficiency filter or allergen-controlling bags. Almost half of the respondents (46\%) planned to use the vacuum cleaners in the future. 
Table 15

Household Changes 2

\begin{tabular}{|c|c|c|c|c|c|c|}
\hline \multirow[b]{2}{*}{ Household change } & \multicolumn{2}{|c|}{ I do this now. } & \multicolumn{2}{|c|}{$\begin{array}{l}\text { I would like to do } \\
\text { this, but I really } \\
\text { don't do it now. }\end{array}$} & \multicolumn{2}{|c|}{$\begin{array}{l}\text { I don't do this } \\
\text { and I don't } \\
\text { plan to do this. }\end{array}$} \\
\hline & $\%$ & $\underline{\mathrm{n}}$ & $\%$ & $\underline{\mathrm{n}}$ & $\%$ & $\underline{\mathrm{n}}$ \\
\hline Use polyester-fiber-filled pillows & $78 \%$ & 32 & $15 \%$ & 6 & $7 \%$ & 3 \\
\hline Use lidded garbage containers. & $66 \%$ & 27 & $15 \%$ & 6 & $19 \%$ & 8 \\
\hline Use allergen-proof pillowcases. & $37 \%$ & 15 & $29 \%$ & 12 & $34 \%$ & 14 \\
\hline $\begin{array}{l}\text { Use a vacuum cleaner with } \\
\text { a high efficiency filter or } \\
\text { allergen-controlling bags. }\end{array}$ & $25 \%$ & 10 & $46 \%$ & 19 & $29 \%$ & 12 \\
\hline Use allergen-proof sheets. & $17 \%$ & 7 & $39 \%$ & 16 & $44 \%$ & 18 \\
\hline
\end{tabular}

Note. $\underline{\mathrm{N}}=41$

\section{Lifestyle Practices}

The lifestyle practice subvariable consists of 14 practices that allergy patients should do regularly regarding laundering, bedroom cleaning, ventilation, and pest management (see Table 16).

Two-thirds of the respondents (64\%) washed their pillowcases and sheets weekly; however, the majority of the respondents $(76 \%)$ did not wash their pillowcases and sheets in hot water. The majority of the respondents $(88 \%)$ wet mopped or vacuumed their bedroom floors weekly. Most of the respondents cleaned their bedrooms with a damp cloth weekly. Around half of the respondents vacuumed their bedrooms (15\% vacuumed weekly and 39\% vacuumed sometimes), but only $29 \%$ wore a particle mask when they were vacuuming.

A small number of the respondents regularly used an exhaust fan in their kitchen $(22 \%)$ and in their bathroom (5\%). More than half of the respondents did not plan to use an exhaust fan either in their kitchen $(56 \%)$ or in their bathroom (64\%). Forty-four percent of the respondents used an air conditioner in their bedroom; however, only $32 \%$ cleaned a filter in the air conditioner monthly. Most of the respondents (76\%) did not plan to use a dehumidifier. An air cleaner was used by only $12 \%$ of the respondents. More than half of the respondents $(56 \%)$ did not plan to use an air cleaner.

A small number of the respondents used cockroach traps (17\%), but most of the respondents $(71 \%)$ did not plan to use cockroach traps. The respondents were asked whether they used insecticide spray or not. Most of the respondents (71\%) used insecticide spray in their homes.

In summary, although some respondents followed recommended practices and household changes for allergy patients, more than half of the respondents did not follow the recommendations to reduce allergen levels in their homes. For example, some respondents still kept their pets. Some respondents did not plan to use allergen-proof pillowcases and sheets. Some of them did not plan to use a vacuum cleaner with a high efficiency filter or allergen- 
controlling bags. They did not plan to wash bedding in hot water, to use a clothes dryer, to wear a particle mask when vacuuming, to use an exhaust fan, to use an air cleaner, or to use cockroach traps.

Table 16

Lifestyle Practices

\begin{tabular}{|c|c|c|c|c|c|c|c|c|}
\hline \multirow[b]{2}{*}{ Lifestyle practices } & \multicolumn{2}{|c|}{$\begin{array}{l}\text { I do this } \\
\text { regularly }\end{array}$} & \multicolumn{2}{|c|}{$\begin{array}{l}\text { I do this } \\
\text { sometimes }\end{array}$} & \multicolumn{2}{|c|}{$\begin{array}{c}\text { I would like } \\
\text { to do this, } \\
\text { but I really } \\
\text { don't do it } \\
\text { now. }\end{array}$} & \multicolumn{2}{|c|}{$\begin{array}{l}\text { I don't do } \\
\text { this and I } \\
\text { don't plan } \\
\text { to do it. }\end{array}$} \\
\hline & $\%$ & & $\%$ & $\mathrm{n}$ & $\%$ & $\mathrm{n}$ & $\%$ & $\mathrm{n}$ \\
\hline & \multicolumn{4}{|c|}{ Laundering } & & & & \\
\hline 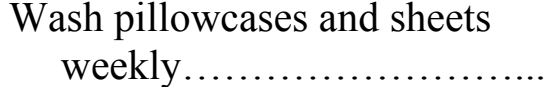 & $64 \%$ & 26 & $34 \%$ & 14 & $2 \%$ & 1 & $0 \%$ & 0 \\
\hline $\begin{array}{l}\text { Wash pillowcases and sheets } \\
\text { in hot water................. }\end{array}$ & 20 & 1 & $0 \%$ & 0 & $20 \%$ & 9 & $54^{\circ}$ & 22 \\
\hline Use clothes dryer................ & $22 \%$ & 9 & $7 \%$ & 3 & $15 \%$ & 6 & $56 \%$ & 23 \\
\hline
\end{tabular}

Wet mop or vacuum $\begin{array}{lllllllll}\text { bedroom floor weekly......... } & 88 \% & 36 & 10 \% & 4 & 0 \% & 0 & 2 \% & 1\end{array}$

Clean a bedroom with $\begin{array}{lllllllll}\text { a damp cloth weekly.......... } & 83 \% & 35 & 15 \% & 6 & 2 \% & 1 & 0 \% & 0\end{array}$

$\begin{array}{lllllllll}\text { Vacuum bedroom weekly......... } & 15 \% & 6 & 39 \% & 16 & 22 \% & 9 & 24 \% & 10\end{array}$

Wear a particle mask when \begin{tabular}{lllllllll} 
vacuuming.................. & $10 \%$ & 4 & $19 \%$ & 8 & $17 \%$ & 7 & $54 \%$ & 22 \\
\hline
\end{tabular}

Use an air conditioner in

Ventilation

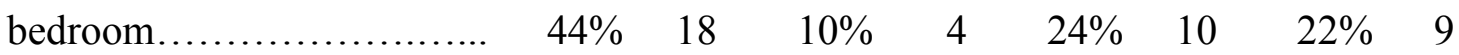

Clean filter in air conditioner

monthly..................... $32 \% \quad 13 \quad 27 \% \quad 11 \quad 17 \% \quad 7 \quad 24 \% \quad 10$

$\begin{array}{lllllllll}\text { Use an exhaust fan in kitchen... } & 22 \% & 9 & 2 \% & 1 & 20 \% & 8 & 56 \% & 23\end{array}$

Use an exhaust fan in

bathrooms.................... $5 \% \quad 2 \quad 2 \% \quad 1 \quad \begin{array}{llllll}29 \% & 12 & 64 \% & 26\end{array}$

$\begin{array}{lllllllll}\text { Use an air cleaner................. } & 12 \% & 5 & 0 \% & 0 & 32 \% & 13 & 56 \% & 23\end{array}$

\begin{tabular}{lllllllll} 
Use a dehumidifier............... & $2 \%$ & 1 & $0 \%$ & 0 & $22 \%$ & 9 & $76 \%$ & 31 \\
\hline
\end{tabular}

Pest Management

\begin{tabular}{lllllllll} 
Use cockroach traps.............. & $10 \%$ & 4 & $7 \%$ & 3 & $12 \%$ & 5 & $71 \%$ & 29 \\
\hline
\end{tabular}

Note. $\underline{\mathrm{N}}=41$

The allergen avoidance practice variable is a composite score that includes scores of household changes and scores of lifestyle practices. The household change subvariable consists 
of 10 items that should be changed in houses of allergy sufferers. The lifestyle practice subvariable consists of 14 practices that allergy sufferers should do regularly. The mean score of the total allergen avoidance practices was $32.4(\underline{\mathrm{SD}}=7.3)$. The composite score of allergen avoidance practice variable ranged from 18 to 48 and was used for hypotheses testing.

\section{Hypothesis Testing Results}

Nine null hypotheses were tested in this study. The Pearson's product-moment correlation was performed to test the relationship among variables in Hypothesis 1 to 6 (see Table 17 and Figure 24). For hypotheses 7 to 9, the t-test was performed to compare the differences between the younger group and the older group of the respondents (see Table 18). The significance level of $\underline{p}<.05$ was used.

\section{Relationships Among Composite Variables}

Hypothesis 1. There is no relationship between home conditions and housing satisfaction.

This hypothesis was rejected. There was a significant negative relationship between home conditions and housing satisfaction $(\underline{r}=-.382, \underline{p}=.014)$. The higher the score of problematic home conditions, the lower the score of housing satisfaction in term of health issues.

Hypothesis 2. There is no relationship between housing satisfaction and allergen avoidance practices.

This hypothesis was not rejected. There was no significant relationship between housing satisfaction and allergen avoidance practices $(\underline{\mathrm{r}}=.099, \underline{\mathrm{p}}=.536)$.

Hypothesis 3. There is no relationship between home conditions and allergen avoidance practices.

This hypothesis was not rejected. There was no significant relationship between home conditions and allergen avoidance practices $(\underline{\mathrm{r}}=-.003, \underline{\mathrm{p}}=.983)$.

Hypothesis 4. There is no relationship between age and home conditions.

This hypothesis was not rejected. There was no significant relationship between age and home conditions $(\underline{\mathrm{r}}=.009, \underline{\mathrm{p}}=.957)$.

Hypothesis 5. There is no relationship between age and housing satisfaction.

This hypothesis was not rejected. There was no significant relationship between age and housing satisfaction $(\underline{\mathrm{r}}=-.219, \underline{\mathrm{p}}=.169)$.

Hypothesis 6. There is no relationship between age and allergen avoidance practices. 
This hypothesis was rejected. There was a significant negative relationship between age and allergen avoidance practices $(\underline{r}=-.340, \underline{p}=.030)$. The older the patients were, the less the allergen avoidance practices were done.

Figure 24 illustrates a combination of models shown in Figure $2 \& 3$. This following model shows the relationships between the composite variables in this study.
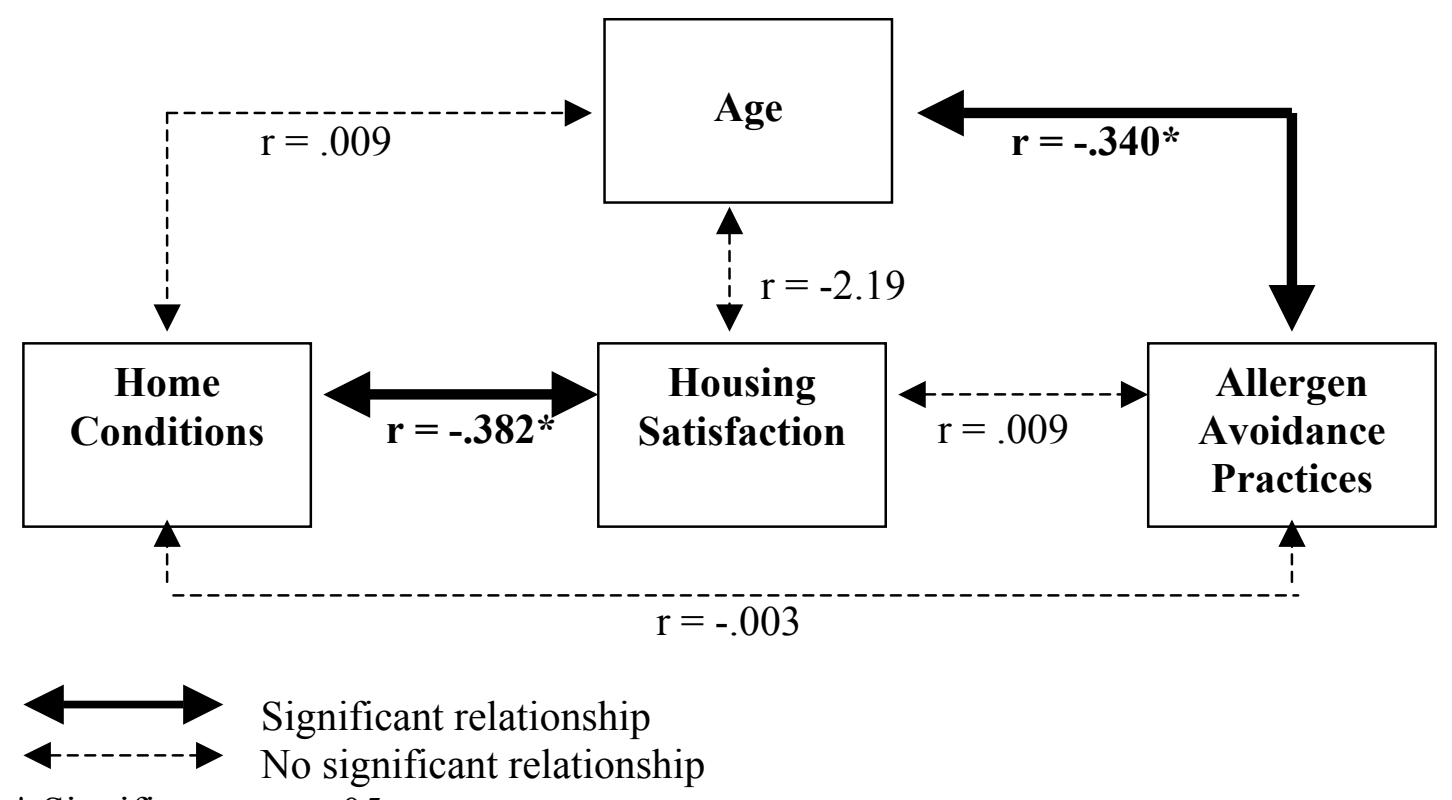

$*$ Significant at $\underline{\mathrm{p}}<.05$

Figure 24. Relationships among composite variables

Table 17

Means and Standard Deviations of Composite Variables

\begin{tabular}{lrrcc}
\hline & $\underline{\mathrm{M}}$ & $\underline{\mathrm{SD}}$ & Minimum & Maximum \\
\hline Home conditions & 5.0 & 1.9 & 0 & 10 \\
Housing satisfaction in terms of health issues & 11.0 & 3.0 & 4 & 16 \\
Allergen avoidance practices & 32.4 & 7.3 & 18 & 48 \\
Age & 53.5 & 13.6 & 20 & 77 \\
\hline
\end{tabular}

Note. $\underline{\mathrm{N}}=41$

\section{Differences in Age Groups}

The t-test was performed to compare the differences between the younger group and the older group of the respondents to test null Hypotheses 7 to 9 (see Table 18). The significant level of $\mathrm{p}<.05$ was used. conditions.

Hypothesis 7. The younger group and the older group do not differ in their home 
This hypothesis was not rejected. There was no significant difference between the younger group and the older group in their home conditions.

Hypothesis 8 . The younger group and the older group do not differ in their housing satisfaction.

This hypothesis was not rejected. There was no significant difference between the younger group and the older group in their housing satisfaction.

Hypothesis 9. The younger group and the older group do not differ in their allergen avoidance practices.

This hypothesis was not rejected. There was no significant difference between the younger group and the older group in their allergen avoidance practices.

Table 18

No Significant Difference between the Age Groups

\begin{tabular}{llcccc}
\hline & $\underline{\mathrm{n}}$ & $\underline{\mathrm{M}}$ & $\underline{\mathrm{SD}}$ & $\underline{\mathrm{t}}$ & $\underline{\mathrm{p}}$ \\
\hline Home Conditions & & & & & \\
$\quad$ Younger Group & 24 & 5.000 & 2.359 & & \\
$\quad$ Older Group & 17 & 4.882 & 1.053 & .216 & .830 \\
\hline $\begin{array}{l}\text { Housing Satisfaction } \\
\quad \text { Younger Group }\end{array}$ & 24 & 11.291 & 3.223 & & \\
$\quad$ Older Group & 17 & 10.647 & 2.548 & .714 & .479 \\
\hline Allergen Avoidance Practices & & & & & \\
$\quad$ Younger Group & 24 & 34.041 & 7.882 & & \\
$\quad$ Older Group & 17 & 30.176 & 5.908 & 1.794 & .081 \\
\hline
\end{tabular}

In summary, 9 hypotheses were tested in this study in order to examine the relationship among age, home conditions, housing satisfactions, and allergen avoidance practices of people with allergic rhinitis in Bangkok, Thailand. Significant negative relationships were found between home conditions and housing satisfaction as well as between age and allergen avoidance practices. The results show that the higher the score of problematic home conditions, the lower the score of housing satisfaction in terms of health issues. In other words, the lower the score of problematic home conditions, the higher the score of housing satisfaction in terms of health issues. The results also show that the older the allergy patients were, the less allergen avoidance practices were done. In other words, the younger the allergy patients were, the more the allergen avoidance practices were done. No significant relationship was found in the other four pairs of variables. No significant difference was found between the younger group and the older group.

\section{Results from Open-ended Questions}

In order to explore further the allergy sufferers' opinions on allergen avoidance practices, the respondents were asked to answer four open-ended questions. The questions address intended changes, suggestions about improving home indoor air quality, obstacles to the improvement, and help in controlling allergens in homes. 


\section{Intended Changes}

The respondents were asked what kind of things they planned to change in their homes to reduce their allergy symptoms. A complete list of responses is given in Appendix E. The most predominant changes were:

1. Rearrange furniture and eliminate unused furniture and belongings from the home (6 responses).

2. Clean home frequently (4 responses).

3. Install an exhaust fan (4 responses).

4. Build a new house (3 responses).

5. Install an air cleaner (3 responses).

6. Use allergen-proof bedding (2 responses).

7. Give dogs away (2 responses).

\section{Suggestions about Improving Home Indoor Air Quality}

The respondents were asked to give their suggestions to help improve air quality in homes. The respondents gave their suggestions in many categories including ventilation, home furnishing, housekeeping, landscaping, and pets (see Appendix F). The most common suggestions were plant trees and shrubs around a house to protect the house from dust from outside, have good ventilation in the home, have fewer belongings and furniture, and keep them in order.

\section{Obstacles to the Improvement of the Homes in Order to Avoid Allergens}

The respondents were asked to report what prevented them from improving their homes in order to avoid allergens. Appendix G shows the list of the responses. The responses were categorized into the following topics: economic reasons, emotional reasons, time management reasons, knowledge reasons, labor reasons, architectural reasons, outdoor pollution, and other reasons. The most common responses were in economic reasons (cost of products), emotional reasons (not wanting to give pets away,), and time management reasons (not having time to improve their homes and procrastination). Other common responses were in knowledge reasons (not sure what to do) and labor reasons (no housekeeper, it was hard to hire someone to do a home modification).

\section{Help in Controlling Allergens in Homes}

The respondents were asked what kind of help they received and who helped them control allergens in their homes. Results show that most of the respondents received suggestions about allergen avoidance practices and product selections from doctors (see Appendix $\mathrm{H}$ and I).

\section{Additional Statistical Analysis Results}

Because the variables used for hypotheses testing are composite scores of many variables, additional statistical tests were conducted to further explore relationships among 
individual variables used to create the composite variables: age, home conditions, housing satisfaction, and allergen avoidance practices.

\section{Relationship between Each Home Condition and Housing Satisfaction}

The home condition variable consists of 16 selected problematic home conditions (see Tables 11 and 12). In order to examine the relationship further, t-test analyses were conducted to find differences among each problematic home condition and housing satisfaction in terms of health issues.

A t-test analysis revealed a significant difference between housing satisfaction of the respondents who had molds in their kitchens and housing satisfaction of the respondents who had no molds in their kitchens (see Table 19). The respondents who had molds in their kitchens had less housing satisfaction than the respondents who had no molds in their kitchen. This result supports the significant negative relationship between home conditions and housing satisfaction in terms of health issues from hypothesis 1. The finding is similar to results of a study from the United States (Cheple \& Yust, 1999). They reported a negative relationship between some moisture problems in houses (condensation, mold, water stains) and the satisfaction with the performance of the house.

Table 19

Relationship between Presence of Molds in Kitchens and Housing Satisfaction

\begin{tabular}{lccccc}
\hline & $\underline{\mathrm{n}}$ & $\underline{\mathrm{M}}$ & $\underline{\mathrm{SD}}$ & $\underline{\mathrm{t}}$ & $\underline{\mathrm{p}}$ \\
\hline Respondents who had molds in kitchens & 15 & 9.3 & 3.2 & & \\
Respondents who had no molds in kitchens & 26 & 12.0 & 2.3 & 3.073 & .004 \\
\hline
\end{tabular}

\section{Relationship between Housing Satisfaction and Each Allergen Avoidance Practices}

The allergen avoidance practice variable is a composite score including 24 practices (see Tables 14, 15, and 16). Although the hypothesis testing result shows no significant relationship between housing satisfaction in terms of health issues and allergen avoidance practices, additional statistical tests were conducted to examine relationships between a composite score of housing satisfaction and each allergen avoidance practice. A correlation analysis revealed a significant relationship between housing satisfaction and the adoption of a vacuum cleaner with a high efficiency filter or allergen-controlling bag $(\underline{r}=.345, \underline{p}=.027)$. The respondents who used a vacuum cleaner with a high efficiency filter or allergen-controlling bag had higher housing satisfaction in terms of health issues than the respondents who did not use the vacuum cleaner.

\section{Relationship between Home Conditions and Each Allergen Avoidance Practices}

The hypothesis testing result shows no significant relationship between home conditions and allergen avoidance practices. Since the allergen avoidance practice variable is a composite score, additional statistical tests were conducted to examine further relationships between home conditions and each allergen avoidance practice. A correlation analysis revealed a significant negative relationship between home conditions and the removal of drapes or horizontal blinds in the bedrooms $(\underline{r}=-.498, \underline{p}=.001)$. A correlation analysis revealed a significant negative 
relationship between home conditions and the use of allergen proof sheets $(\underline{r}=-.338, \underline{p}=.031)$. The respondents who used allergen-proof sheets and removed drapes from their bedrooms had less problematic home conditions than the respondents who did not use allergen proof sheets and had drapes in their bedrooms.

\section{Relationship between Age and Each Home Conditions}

Although the hypothesis testing result shows no significant relationship between age and home conditions, additional statistical tests were conducted to examine relationships between age and each home condition. A correlation analysis revealed a significant relationship between age and the presence of cockroaches in homes $(\underline{\mathrm{r}}=.409, \underline{\mathrm{p}}=.008)$. The older respondents were more likely to have cockroaches in their homes than the younger respondents.

\section{Relationship between Age and Each Housing Satisfaction}

The hypothesis testing result shows no significant relationship between age and housing satisfaction in terms of health issues; however, additional statistical tests were conducted to examine relationships between age and each housing satisfaction. A correlation analysis revealed a significant negative relationship between age and the housing satisfaction of the respondents who have controlled allergens in their home $(\underline{r}=-.363, \underline{p}=.020)$. The older respondents had less satisfaction on allergen control in their homes than the younger respondents.

\section{Relationship between Age and Each Allergen Avoidance Practices}

The allergen avoidance practice variable is a composite score including 24 practices (see Tables 14, 15, and 16). Correlation analyses were conducted to further explore relationship between age and each practice. Correlation analyses revealed significant negative relationships between age and the adoption of allergen-proof pillowcases, allergen-proof sheets, dehumidifier, and air cleaners (see Table 20). The younger the respondents were, the more adoption of these items. These results support the significant negative relationship between age and allergen avoidance practices.

Table 20

Significant Relationship Between Age and Each Allergen Avoidance Practice

\begin{tabular}{lcc}
\hline & \multicolumn{2}{c}{ Age } \\
\cline { 2 - 3 } Allergen avoidance practice & $\underline{\mathrm{r}}$ & $\underline{\mathrm{p}}$ \\
\hline Use allergen-proof pillowcases & -.377 & .015 \\
Use allergen-proof sheets & -.347 & .026 \\
Use a dehumidifier & -.338 & .031 \\
Use an air cleaner & -.437 & .004 \\
\hline
\end{tabular}

\section{Respondents Housing Situations}

The relationships between age of the homes and other variables were tested. A correlation analysis revealed a significant relationship between age of the respondents and age of 
the homes $(\underline{r}=.40, \underline{p}=.012)$. The older the respondents were, the older the age of the homes. Elderly American homeowners are more likely to occupy older housing (U.S. Bureau of the Census, 1990). It is probably true in Thailand as well.

\section{Pet Ownership}

A chi-square test was used to determine the association between housing type and pet ownership. The significant difference was found between housing type and pet ownership (see Table 21). The large portion of the respondents who had pets lived in houses. Most respondents who had no pets lived in townhouses, shophouses, and apartments. The respondents who lived in townhouses, shophouses, and apartments did not have cats. Only respondents who lived in houses had cats. Thai people usually raise dogs and cats outdoors. The respondents who lived in townhouses, shophouses, and apartments might not choose to have pets because they did not have yards.

Table 21

Distribution of Respondents by Housing Type and Pet Ownership

\begin{tabular}{lcc}
\hline & \multicolumn{2}{c}{ Housing Type } \\
\cline { 2 - 3 } & Houses & Townhouse, Shophouses, \& Apartments \\
\hline Having pets & $21(52 \%)$ & $5(12 \%)$ \\
No pets & $5(12 \%)$ & $10(24 \%)$ \\
\hline
\end{tabular}

Note. $\chi^{2}(1, \mathrm{~N}=41)=9.226 ; \mathrm{p}=.002$

\section{Home Conditions}

Chi-square tests were used to determine the association between each home condition and suggestions received from doctor on how to avoid allergens. The respondents who received suggestions differed from the respondents who did not received suggestions in the usage of kapok pillows (see Table 22). Most of the respondents who received suggestions from doctors on how to avoid allergens did not use kapok pillows.

Table 22

Distribution of Respondents by Suggestions from Doctors and the Usage of Kapok Pillows. Usage of Kapok Pillows

\begin{tabular}{lrr} 
& Used Kapok Pillows & Not Use Kapok Pillows \\
\hline Received Suggestions & $6(15 \%)$ & $22(53 \%)$ \\
Not Receive Suggestions & $7(17 \%)$ & $6(15 \%)$ \\
\hline
\end{tabular}

Note. $\chi^{2}(1, \underline{N}=41)=4.309 ; \underline{p}=.038$

A t-test analysis $(\underline{\mathrm{t}}=-2.814, \underline{\mathrm{p}}=.008)$ revealed a significant difference between the average age of homes which had molds in bedrooms $(\underline{\mathrm{M}}=33.5, \underline{\mathrm{SD}}=4.4, \underline{\mathrm{N}}=4)$ and the average age of homes which had no molds in bedrooms $(\underline{\mathrm{M}}=17.7, \underline{\mathrm{SD}}=10.9, \underline{\mathrm{N}}=35)$. Homes which had molds in bedrooms were older than homes which had no molds in bedrooms. 


\section{Allergen Avoidance Practices: Household Changes}

The relationships between each household change variable and other variables were tested. T-test analyses revealed several significant differences (see Table 23). The respondents who were allergic to dogs tended to give pets away or did not have pets as compared to the respondents who were not allergic to dogs. No significant difference was found on pet removal between the respondent who were allergic to cats and those who were not. The respondents who did not use kapok pillows tended to use or planned to use allergen-proof pillowcases as compared to the respondents who used kapok pillows. The respondents who received suggestions from doctors tended to use or planned to use allergen-proof pillowcases as compared to those who did not receive suggestions. The respondents who received suggestions from doctors tended to remove upholstered furniture out of bedrooms or did not have it rather than those who did not receive suggestions.

\section{Allergen Avoidance Practices: Lifestyle Practices}

The relationships between each lifestyle practice variable and other variables were tested. A t-test analysis revealed significant differences on the usage of particle masks when vacuuming (see Table 24). Surprisingly, the respondents who were not allergic to cats used the particle masks more often than the respondents who were allergic to cats. The respondents who were not allergic to cockroaches used the particle masks more often than the respondents who were allergic to cockroaches.

Table 23

Relationship between Household Changes and Other Variables

\begin{tabular}{|c|c|c|c|c|c|}
\hline & $\underline{\mathrm{M}}$ & $\underline{\mathrm{SD}}$ & $\underline{\mathrm{n}}$ & $\underline{\mathrm{t}}$ & $\mathrm{p}$ \\
\hline \multicolumn{6}{|l|}{ Pets Removal } \\
\hline Respondents who were allergic to dogs & 1.4 & .9 & 25 & & \\
\hline Respondents who were not allergic to dogs & .8 & .9 & 16 & 2.277 & .028 \\
\hline \multicolumn{6}{|l|}{ Usage of Allergen-Proof Pillowcases } \\
\hline Respondents who used kapok pillows & .5 & .5 & 13 & & \\
\hline Respondents who did not use kapok pillows & 1.3 & .8 & 26 & 3.202 & .003 \\
\hline \multicolumn{6}{|l|}{ Usage of Allergen-Proof Pillowcases } \\
\hline Respondents who received suggestions from doctors & 1.2 & .9 & 28 & & \\
\hline Respondents who did not received suggestions & .6 & .7 & 13 & -2.194 & .034 \\
\hline \multicolumn{6}{|l|}{ Removal of Upholstered Furniture out of Bedrooms } \\
\hline Respondents who received suggestions from doctors & 1.2 & .9 & 28 & & \\
\hline Respondents who did not received suggestions & 1.8 & .4 & 13 & 2.081 & .034 \\
\hline
\end{tabular}


Table 24

Relationship between Lifestyle Practices and Other Variables

\begin{tabular}{lrrrrrrr}
\hline Usage of Particle Masks When Vacuuming & $\underline{\mathrm{M}}$ & $\underline{\mathrm{SD}}$ & $\underline{\mathrm{n}}$ & $\underline{\mathrm{t}}$ & $\underline{\mathrm{p}}$ \\
$\quad$ Respondents who were allergic to cats & & & & & & & \\
$\quad$ Respondents who were not allergic to cats & .4 & .9 & 18 & & & \\
\hline Usage of Particle Masks When Vacuuming & 1.2 & 1.1 & 23 & 2.296 & .027 \\
$\quad$ Respondents who were allergic to cockroaches & .2 & .4 & 11 & & \\
$\quad$ Respondents who were not allergic to cockroaches & 1.1 & 1.1 & 30 & 2.627 & .012 \\
\hline
\end{tabular}

\section{Discussion}

The following section begins with a discussion of demographic characteristics, housing, and health situations. Then, discussions of the four major variables of this study home conditions, housing satisfactions, allergen avoidance practice, and age are presented. Finally, this chapter ends with the discussion of the theoretical model.

\section{Demographic Characteristics, Housing, and Health Situations}

The respondents of this study included 41 female allergy patients aged 20 to 77 years who lived in an urban area in a hot and humid climate. Approximately half of the respondents were married. The majority of the respondents resided in single-family detached houses. This finding is similar to a report from National Housing Authority (1999) in that the majority of dwellings in Thailand were single-unit houses. Most respondents lived in homes they owned $(73 \%)$ or homes that were owned by family members $(22 \%)$. This percentage is slightly higher than that of the national result. Around $60 \%$ of households in Bangkok own their dwelling (National Housing Authority). This high percentage of ownership in the study sample might be caused by many older respondents in the sample. Only $12 \%$ of respondents' homes were designed or decorated by architects or interior designers. Therefore, guidelines for healthy house design should be distributed not only to designers, but to homeowners also.

Almost all of the respondents reported that they were allergic to dust mite allergen. This finding is similar to results of another study from Thailand (Pumhirun et al., 1997) and a study from Indonesia (Baratawidjaja et al., 1999), where the most common allergic trigger was dust mites. The home observation results showed that the average indoor humidity in the respondents' homes was $66 \%$. The average indoor temperature was $89^{\circ} \mathrm{F}$. According to the findings, humidity and temperature levels in the respondents' homes were ideal situations for dust mites, cockroaches, and molds to thrive.

The findings of this study revealed that a majority of allergy sufferers had pets, especially dogs. Since most literature on animal allergens ranked cats as the most common sources of animal allergies, allergy patients might prefer to have dogs without knowing that they might be allergic to dogs also. The finding that $63 \%$ of the respondents had pets is similar to results from the United States. Sixty percent of typical American households have pets (ALAAAG \& Edelman, 1997). The result from a study in France also notes that allergic patients own as many pets as nonallergic patients (Charpin et al., 1989). The percentage of Thai respondents who had 
cats $(12 \%)$ is less than the percentage of households in United Kingdom and the United States that contain cats (roughly 25\%) (Custovic et al., 1998; Beck \& Meyers, 1996).

\section{Home Conditions}

Open shelves, bookcases, drapes, horizontal blinds, foam rubber pillows, and kapok pillows were the most common allergy related items found in the respondents' bedrooms. Thai allergy sufferers rarely had indoor plants, carpets, and feather pillows in their bedrooms. Open shelves and bookcases collect dust. Drapes and horizontal blinds are difficult to clean. Foam rubber pillows are difficult to wash weekly to remove dust mites. Foam rubber pillows also get moldy easily. Kapok pillows, which are not washable, are reservoirs for dust mites. In order to fit the Thai lifestyle, recommendations on allergen avoidance practices for Thai people should be focused on these items.

Almost all of the respondents did not have carpet floors in their bedrooms; carpets were not major allergen sources in these Thai homes because the respondents had wood floors in their bedrooms. Moreover, most respondents wet mopped their bedroom floor and cleaned their bedrooms with damp cloths weekly. Some respondents reported that they wet mopped their bedroom floor daily. Wet mopping of the floor is a routine housekeeping practice in Thailand. Although carpet flooring in patients' bedrooms is a major concern in many countries around the world, carpet flooring in bedrooms is not a major concern for Thai allergic patients.

The majority of the respondents (76\%) found cockroaches in their homes. This percentage is slightly higher than the percentage $(65 \%)$ from a previous study on cockroach fauna in Thailand (Tawasin et al., 2001). Approximately one-third of the respondents had these following moisture problems in their homes: leaks, moisture damage, mold in bathrooms, and molds in kitchens. Presence of cockroaches and presence of mold are the leading allergy related problems in Thai homes because temperature and humidity in homes in Bangkok are suitable for cockroaches and molds to grow and breed.

\section{Housing Satisfaction}

The majority of the respondents were satisfied with their housing in terms of health issues. Approximately one-third of the respondents were dissatisfied with their housing in terms of health issues. This finding is consistent with the findings of previous studies on home indoor air quality in Kuwait and the United States (Al-Najadah, 1996; Cheple \& Yust, 1999).

\section{Allergen Avoidance Practices}

More than half of the respondents who had upholstered furniture, drapes, and horizontal blinds in their bedrooms planned to remove these items from their bedrooms. Some respondents also indicated that they wanted to have less furniture and belongings in their bedrooms. In addition, the respondents who received suggestions from doctors tended to remove upholstered furniture out of the bedrooms rather than those who did not receive suggestions. The result from an open-ended question also showed that some respondents never got advice on allergen 
avoidance practices. Lack of knowledge on allergen avoidance practices seemed to be one of the major problems for allergy sufferers.

Experts recommend that the best way to minimize animal allergens in homes is to remove pets from home (Tovey \& Mark, 1999). The results of this study showed that some of the respondents gave pets away, some of them did not have pets, some of them had fish instead of furry pets, and some of them planned to give pets away. However, approximately one-third of the respondents who had pets did not plan to give their pets away. The result from an openended question confirmed the results from a previous study (Swartz et al., 2001) that emotional attachment to their pets was one of major reasons that obstructed the respondents from reducing allergens in their homes. If allergy patients choose to have pets, experts recommend that pets should not be allowed indoors, especially in bedrooms and living rooms. However, this study revealed that some respondents allowed their pets to stay in their living rooms and even in their bedrooms. The recommendation on washing pets weekly was followed by only two-thirds of the pet owners.

According to recommendations by allergy experts, dust mite allergy sufferers should use washable polyester fiber-filled pillows. Several studies suggested that pillows and mattresses should be encased in allergy-proof covers. Bedding must be washed in hot water weekly. The findings of this study revealed that the majority of the respondents used polyester fiber-filled pillows and washed their pillowcases and sheets weekly. However, the majority of the respondents did not wash their pillowcases and sheets in hot water. Only one-third used allergen-proof pillowcases and 17\% used allergen-proof sheets. This percentage is slightly higher that that of a study in the United States (15\%, Storms et al., 1997b). Although almost all of the respondents reported that they were allergic to dust mites, their practices to avoid dust mite allergens were limited.

Although experts recommended that cockroaches should be controlled in the most nontoxic way possible, surprisingly, the majority of the respondents still used insecticide spray in their homes. The majority of them did not use cockroach traps and did not plan to use them in the future. These practices that were contrary to the recommendations from experts might result from lack of information.

Regarding home ventilation, almost half of the respondents regularly used air conditioners in their bedrooms, but they did not clean the filter monthly. The majority of the respondents did not plan to use other equipment such as an exhaust fan, an air cleaner, and a dehumidifier that help reduce allergens in their homes. An air cleaner was used by $12 \%$ of the respondents. This finding is similar to that of a study in the United States (14\%), (Storms et al., 1997b). More than half of the respondents (56\%) did not plan to use an air cleaner.

In general, allergen avoidance practices were not followed regularly. The respondents who received suggestions from doctors were more likely to follow allergen avoidance practices than those who did not receive suggestions. The cost of products and lack of information were reported as major obstacles. Availability of allergen-proof products at reasonable prices should be encouraged. Clear and complete information on allergen avoidance practices also should be provided to allergy sufferers. 
It was predicted that the prevalence of allergic rhinitis is likely to greater among the older population (Meltzer, 1997) and that adult-onset allergies are becoming more common (Corren, 2000). Although the population of older allergy sufferers has been ignored by researchers in the past, the results of this study demonstrates that they really exist. This study showed that many females were still suffering from allergic rhinitis in their later years. This group of respondents might be only the tip of an iceberg because previous studies reported that most people with allergic rhinitis did not seek healthcare (Storms et al., 1997b). According to the results of this study, older sufferers were less likely to use allergen-proof products. They also lived in older homes that were more likely to have allergy related conditions. Older allergy sufferers had high exposure to high allergen levels in their homes due to the home age and lack of allergen avoidance practices. Therefore, healthcare professionals and gerontologists should start to pay attention to the older allergy sufferers. The results of this study have laid a foundation on the importance of healthy houses for older people and links indoor air quality and gerontology areas together.

\section{Discussion of the Theoretical Model}

The theory of housing adjustment (Morris \& Winter, 1978) was used as a guide for this study (see Figure 25). When the household's dwelling does not meet the household's needs, a housing deficit occurs, leading to housing dissatisfaction. The household makes an adjustment in order to increase housing satisfaction. The theory had not been broadly explored in a healthy house context, especially considering home conditions as housing deficits and allergen avoidance practices as housing adjustments. Moreover, the theory had not been explored in the relationship between adult allergy sufferers and their home environments in a hot, humid climate. Based on the housing adjustment theory, this study was conducted to explore the relationship among age of allergy sufferers, their home conditions, their housing satisfaction in terms of health issues, and their allergen avoidance practices.

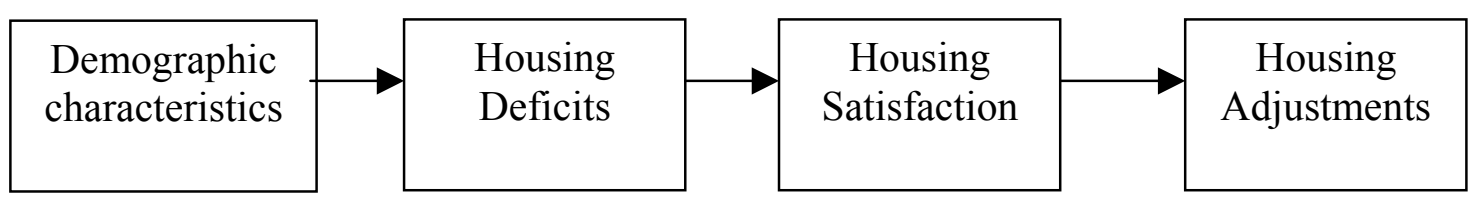

Figure 25. Housing adjustment theory

The results of this study confirm a significant negative relationship between problematic home conditions (housing deficits) and housing satisfaction in terms of health issues (housing satisfaction). The higher the negative home conditions, the lower the housing satisfaction in terms of health issues. The results also confirm a significant negative relationship between age (demographic characteristic) and allergen avoidance practices (housing adjustments). The older the allergy sufferers, the less the allergen avoidance practices were done. Figure 26 illustrates the final model that resulted from this study's findings. The bold arrows indicate the relationship between variables. The results of this study support parts of the housing adjustment theory. The 
results also support previous findings on a negative relationship between moisture problems in houses and housing satisfaction (Cheple \& Yust, 1999). Although the hypothesis testing results show no significant relationship in other pairs of variables, additional analyses show some relationships.

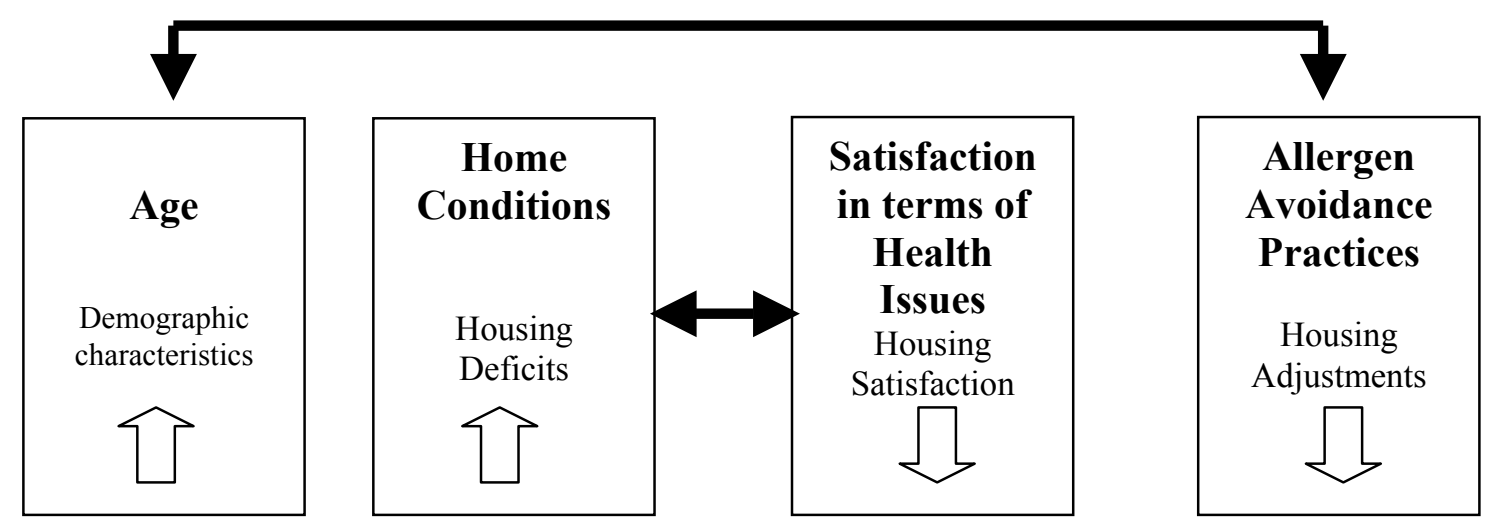

Figure 26. A final model: A significant relationship between age and allergen avoidance practices and a significant relationship between home condition and housing satisfaction in terms of health issues.

Though the data supporting the model is not strong, there is enough support to suggest that the housing adjustment theory is appropriate for guiding research on healthy houses. The results of this study establish the applicability of the housing adjustment theory in healthy house context. The information derived from this study has laid the foundation for examining the relationships among residents with health issues, home environments, housing satisfactions, and home maintenance. This study has contributed to the body of literature of housing research for special needs of residents and healthy houses in hot, humid climate. The housing adjustment theory can be used as a guide for research studies on healthy house design and home maintenance. 


\section{Chapter 5}

\section{Summary}

This chapter starts with a summary and key findings of the study. Then, implications of the study are discussed. This chapter ends with recommendations for further research.

\section{Summary}

The purpose of the study was to examine home conditions, housing satisfactions and allergen avoidance practices of people with allergic rhinitis in Bangkok, Thailand, focusing on female patients aged 20 and over who lived in an urban area in a hot and humid climate. The objectives of the study were: (1) to describe home conditions, housing satisfaction, and allergen avoidance practices of people with allergic rhinitis, (2) to investigate the interrelationship among home conditions, housing satisfaction, and allergen avoidance practices of people with allergic rhinitis, and (3) to investigate the relationship between chronological age and home conditions, housing satisfaction, and allergen avoidance practices of people with allergic rhinitis. The Morris and Winter theory of housing adjustment provides a theoretical base for this study.

The study was exploratory and survey design was used. The four major groups of variables were: (1) home conditions, (2) housing satisfaction in terms of health issues, (3) allergen avoidance practices, and (4) age. Nine hypotheses were tested in this study to investigate relationships between each pair of variables. The population of this study was female adults with allergic rhinitis who lived in Bangkok, Thailand. The age of the adult group ranged from 20 to 59 years and the age of older adult group ranged from 60 years and over. The convenience sample was drawn from outpatients who visited an allergy clinic at Pramongkutklao Hospital. A screening questionnaire and an in-depth survey questionnaire were developed, translated, pre-tested, and revised. Potential participants filled out a brief screening questionnaire that consisted of questions on age, housing type, allergens to which a patient is allergic, and allergen avoidance practices. The researcher visited participants' homes to conduct home observations and to take photos. The participants filled out an in-depth survey questionnaire that contained questions on home conditions, housing satisfactions, allergen avoidance practices, and demographic information.

Pearson's product-moment correlation was used to test interrelationships among home conditions, housing satisfaction, and allergen avoidance practice as well as relationships between age and these three variables. T-test was used to test differences on home condition, housing satisfaction, and allergen avoidance practice between the two age groups. A level of significance was set at $\underline{p}<.05$. Data from open-ended questions was counted, categorized, prioritized, and reported. Photos were presented according to responses from the questionnaires.

The sample included 41 female allergy patients aged 20 to 77 years. Dust mite allergens were reported as the most common allergy triggers. The majority of the respondents lived in their own single-family detached houses that were not designed or decorated by architects or interior designers. All of the respondents were non-smokers, but one-third lived with smokers. Approximately two-thirds of the respondents had pets, especially dogs. Almost two-thirds of the 
respondents who had pets washed their pets every week and did not allow their pets to stay indoors. Two-thirds of the respondents received suggestions from doctors on how to improve their home to avoid allergens.

Key Findings of the study are presented as follows.

1. The results show a significant negative relationship between problematic home conditions and housing satisfaction in terms of health issues. Higher problematic home conditions were related to lower housing satisfaction in terms of health issues.

2. The results show a significant negative relationship between age and allergen avoidance practices. Increasing age of the allergy sufferers was correlated with fewer allergen avoidance practices.

3. Older sufferers were less likely to use allergen-proof products. They also lived in older homes that were more likely to have allergy related conditions. Older allergy sufferers had high exposure to high allergen levels in their homes due to the home age and lack of allergen avoidance practices.

4. The results confirm the applicability of the Morris and Winter Housing Adjustment Theory in healthy houses context.

5. Presence of cockroaches, presence of furry pets outdoors, molds in bathrooms, and molds in kitchens were the most common problematic home conditions.

6. Open shelves, bookcases, drapes, horizontal blinds, and foam rubber pillows were the most common allergy related items found in respondents' bedrooms.

7. Although carpet flooring in patients' bedrooms is a major concern in many countries around the world, carpet flooring in bedrooms is not a major concern for Thai allergic patients.

8. Concerning health issues, the majority of the respondents were satisfied with their homes.

9. Allergen avoidance practices were not followed regularly, particularly, using allergen-proof pillowcases and sheets, washing bedding in hot water, wearing a particle mask when vacuuming, and using an exhaust fan, air cleaner, dehumidifier, and cockroach traps.

10. The most common allergen avoidance practices that the respondents followed included using polyester-fiber-filled pillows, using lidded garbage containers, washing bedding, wet mopping bedroom floor, and cleaning a bedroom with a damp cloth weekly. 
11. Almost all of the respondents reported that they were allergic to dust mites, but their practices to avoid dust mite allergens were limited.

12. The respondents who received suggestions from doctors were more likely to follow allergen avoidance practices than those who did not receive suggestions. Lack of knowledge on allergen avoidance practices seemed to be one of the major problems for allergy sufferers.

13. The most common obstacles that prevented respondents from improving their homes in order to avoid allergens were cost of products, emotional attachment to pets, not having time to improve homes, and procrastination.

\section{Implications}

The results of this study have implications for residents, designers, builders, researchers, educators, and policy makers.

\section{Implications for Residents}

This study provides useful information for allergy sufferers and their family members in a hot, humid climate. Design recommendations provide guidelines for allergy sufferers who are buying new homes and those who are modifying current homes. Allergy sufferers can follow home maintenance recommendations and lifestyle practice recommendations from this study in order to prevent allergy symptoms. Allergy sufferers and family members of allergy sufferers should pay attention to allergen avoidance practices, particularly pest management, home ventilation, home cleaning, and home decoration.

\section{Implications for Designers and Builders}

The design recommendations of this study provide appropriate guidelines for designing and building home environments for allergy sufferers. The results of this study provide understanding on interrelationships among health conditions of residents, age of residents, and home conditions. Designers and builders should be familiar with the effect of home environments on health issues of residents. Construction details and interior features should be provided to encourage healthy environments. For example, an exhaust fan that vents outside, sills around cabinets, and doors should become standard features in all Thai homes.

\section{Implications for Researchers}

1. The findings of this study provide research-based information on allergy patients who live in an urban area in hot, humid climate and their allergen avoidance practices.

2. This information is useful for medical researchers, housing researchers, and gerontological researchers. Researchers should study and publish more information about older population with allergies as well as inform elderly allergy sufferers through a variety of medias such as trade magazines and newspapers. Animal 
companionship programs for seniors should be conducted with cautions because animal allergens may cause allergic symptoms for older people. Current home modification recommendations for older people focus only on accessibility, safety, and usability issues. Recommendations on indoor air quality and allergen avoidance should be added.

3. The findings of the study also establish the applicability of the Theory of Housing Adjustment in healthy house context.

4. This study has contributed to the body of knowledge about the older population with allergies.

\section{Implications for Educators}

1. Educators may use the findings and recommendations of this study as information for students in interior design classes, housing classes, and gerontology classes.

2. In order to provide information on allergen free home environments, a continuing education course for designers and home builders should be developed to increase awareness on healthy houses and expand understanding on users' needs.

3. Healthcare providers may use the findings of this study to educate allergy patients.

4. An education program such as allergen free home environments should be developed for allergy sufferers and family members.

5. Information on allergen free home environments can be introduced to intergeneration programs in order to promote healthy home environments for children as well as older people.

\section{Implications for Policy Makers}

The healthcare policy of the Royal Thai Government emphasizes disease prevention. The results of this study provide research-based information for Thai healthcare policy makers on allergy prevention of Thai allergy patients. Healthcare policy makers could use the results of this study to develop a prevention program that educates the public about allergies. Policy makers should develop standards or design guidelines to prevent moisture problems in buildings in hot, humid areas. There should be a home modification and maintenance service as well as assistance with home cleaning brought into homes for senior people. Policy makers should encourage industries to produce allergen proof products at affordable costs. The quality of home indoor air depends on the quality of outdoor air; therefore, outdoor air pollution should be controlled seriously. 


\section{Recommendations}

The following recommendations were proposed for designers, builders, educators as well as allergy sufferers. The recommendations derived from literature reviews and observations in the study. The recommendations include design recommendations, home maintenance recommendations, and lifestyle practice recommendations. The recommendations focus only on problematic areas found in hot, humid climate. This study also focused on Thai lifestyle because Thai lifestyle differs from western lifestyle. Thus, the recommendations are tailored and are prioritized to fit Thai lifestyle.

\section{Design Recommendations}

The design recommendations provide appropriate guidelines for designing and modifying home environments for allergy sufferers in a hot, humid climate, particularly urban areas in Thailand.

1. Use closed cabinets instead of open shelves in bedrooms.

2. Use easy to wash curtains instead of drapes and horizontal blinds in bedrooms.

3. Furniture in bedrooms should be wood, leather, plastic, or metal. Avoid upholstered furniture in bedrooms.

4. Provide enough storage spaces and enough closed cabinets to store items in homes.

5. Seal exterior doors with weather stripping to prevent cockroaches from entering the home.

6. Place fine mesh screening over crawl space vents and floor drain and apply caulking around pipes.

7. Seal kitchen cabinet doors to prevent cockroaches.

8. Provide an exhaust fan near a shower area in a bathroom.

9. Provide an exhaust fan over a stove in a kitchen.

10. Use mold-inhibiting paints.

\section{Home Maintenance Recommendations}

1. Routinely inspect the home. Look for cockroach evidences, moldy areas, dripping faucets, and leaky pipes.

2. Routinely use cockroach traps in kitchens and bathrooms to monitor cockroaches. 
3. Use bait stations, gel bait, or insect growth regulators to eliminate cockroaches instead of using insecticide spray.

\section{Lifestyle Practice Recommendations}

1. Use allergy-proof pillowcases and sheets.

2. Wash all bedding in hot water weekly.

3. Wear a particle mask when vacuuming.

4. Wash pets every week.

5. Routinely clean stovetops, cooking surfaces, and kitchen floors with a household cleaner containing chlorine bleach.

6. Routinely clean bathrooms with bathroom cleaner containing chlorine bleach.

7. Use hypoallergenic pillows instead of foam rubber pillows.

\section{Recommendations for Further Research}

Based on the findings of this study, the following topics are recommended for further research.

1. The sample in this study was representative of only female patients who visited a leading allergy clinic in a government hospital in Bangkok. In order to represent a larger group of allergy sufferers, the sample should include male allergy sufferers, patients from other regions of Thailand, and patients who visit other types of healthcare facilities, such as private hospitals and private allergy clinics.

2. The data were collected during the month of June, July, and August only. Levels of allergens such as dust mite allergens or pollen vary by season; therefore, the data should be collected throughout the year.

3. This study focuses on residents who are users of home interior spaces. Further study should focus on design professionals and homebuilders. Further research should explore problems that influence healthy houses being designed and built.

4. In order to provide convincing scientific evidence that healthy houses can help in reducing allergy symptoms, research on cost effectiveness of allergen-free home environments and healthy houses should be conducted.

5. In order to provide more useful education programs for allergy sufferers, designers, and design students, research should be done on the effectiveness of allergen-free environments educational programs. 


\section{References}

Al-Najadah, A. S. (1996). The impact of oil-related pollution on housing satisfaction of Kuwaiti households. Unpublished doctoral dissertation, Virginia Polytechnic Institute and State University, Blacksburg.

Alvarez, M. J., Olaguibel, J. M., Acero, S., Quirce, S., Garcia, B. E., Carrillo, T., Cortes, C., \& Tabar, A. I. (1997). Indoor allergens and dwelling characteristics in two cities in Spain. Journal of Investigational Allergology \& Clinical Immunology, 7, 572-577.

American Academy of Allergy, Asthma, and Immunology. (2001a). Fast Facts: Allergies. AAAAI Patient/Public Resource Center. Retrieved March 26, 2001, from http://www.aaaai.org/public/fastfacts/allergies.stm

American Academy of Allergy, Asthma, and Immunology. (2001b). Tips to remember: What is allergic reaction? AAAAI Patient/Public Resource Center. Retrieved March 26, 2001, from http://www.aaaai.org/public/publicedmat/tips/whatisallergicreaction.stm

American Academy of Allergy, Asthma, and Immunology. (2001c). Tips to remember: Rhinitis. AAAAI Patient/Public Resource Center. Retrieved March 26, 2001, from http://www.aaaai.org/public/publicedmat/tips/rhinitis.stm

American Academy of Allergy, Asthma, and Immunology. (2001d). Tips to remember: What are allergy shots? AAAAI Patient/Public Resource Center. Retrieved March 26, 2001, http://www.aaaai.org/public/publicedmat/tips/whatareallergyshots.stm

American Lung Association Asthma Advisory Group \& Edelman, N. H. (1997). American Lung Association family guide to asthma and allergies. New York: Little, Brown \& Company.

American Thoracic Society. (1997). Achieving healthy indoor air. American Journal of Respiratory and Critical Care Medicine, 156 (3), S33-S64.

Andes, G. G. (2000). The effect of carpet fiber on the growth of Dermtophagiodes farinae in a controlled environment. Unpublished master's thesis, Virginia Polytechnic Institute and State University, Blacksburg.

Baggs, S. \& Baggs J. (1996). The healthy house. London: Thames and Hudson.

Baratawidjaja, I. R., Baratawidjaja, P. P., Darwis, A., Soo-Hwee, L., Fook-Tim, C., \& Bee-Wah, L., (1999). Prevalence of allergic sensitization to regional inhalants among allergic patients in Jakarta, Indonesia. Asian Pacific Journal of Allergy and Immunology, 17 (1), 9-12.

472.

Beck, H. I. \& Bjerring P. (1987). House dust mites and human dander. Allergy, 42, 471- 
Beck, A. M. \& Meyers, N. M. (1996). Health enhancement and companion animal ownership. Annual Review of Public Health, 17, 247-257.

Bellanti, J. A., Azem, M., MacDowell-Carneiro, A. L., Tutunchuoglu, S. O., Wallerstedt, D. B. (2000). Possible mechanisms of late-life-onset allergic diseases and asthma in the senior citizen. Allergy and Asthma Proceedings, 21 (5), 267-270. Minds.

Berger, W. E. (2000). Allergies and asthma for dummies. Foster City, CA: Hungry

de Blay, F., Chapman, M. D., Platts-Mills, T. A. E. (1991). Airborne cat allergen (Fel d 1): Environmental control with cat in situ. American Review of Respiratory Diseases, 143, 13341339.

de Blay, F., Fourgaut, G., Lieutier-Colas, F., Ott, M., Touron, D., Rolland, C., Pauli, G., Michel, F. (2001). Mite allergen reduction: Role of an indoor technician in patients' compliance and allergen exposure. The Journal of Allergy and Clinical Immunology, 107 (2), S218.

Bousquet, J., Bullinger, M., Fayol C., Marquis, P., Valentin, B., \& Burtin, B. (1994). Assessment of quality of life in patients with perennial allergic rhinitis with the French version of the SF-36 health status questionnaire. The Journal of Allergy and Clinical Immunology, 94, $182-188$.

Brody, J. E. (1997). Jane Brody's allergy fighter. New York: W. W. Norton \& Company.

Brown, C. W. \& Hawkins, L. (1999). Allergy prevalence and causal factors in the domestic environment: Results of a random population survey in the United Kingdom. Annals of Allergy, Asthma, \& Immunology, 83, 240-244.

Bunnag, C., Dhorranintra, B. \& Limsuvan, S. (1985). Airborne pollen in Bangkok metropolis: Incidence and seasonal variation. Siriraj Hospital Gazette, 38, 773-781.

Bunnag, C. Joroencharsri, P., Voraprayoon, S., Prasansak, S. (1995). A survey of allergic rhinitis in Thais. Siriraj Hospital Gazette, 47, 1027-1031.

Callahan, K. A., Eggleston, P. A., Rand, C. S., Wood, R. A., Kanchanaraksa, S., Swartz, S., Lukk, P., Deitchman, C. (2001). Knowledge and implementation of dust mite control behavior by specialty care. The Journal of Allergy and Clinical Immunology, 107 (2), S68. Brook/Cole.

Cavanaugh, J. C. (1997). Adult development and aging ( $3^{\text {rd }}$ ed.). Pacific Grove, CA:

Chandra, S., Codina, R., Beal, D., \& Lockey, R. F. (1999). Dust mite allergen prevention in new homes in hot, humid climates using thorough vacuum cleaning and central air 
conditioning and dehumidification. The Journal of Allergy and Clinical Immunology, 105 (1), S269.

Chanyeung, M., Becker, A., Lam, J., Dimichward, H., Ferguson, A., Warren, P., Simons, E., Broder, I., \& Manfred, J. (1995). House-dust mite allergen levels in 2 cities in Canada effects of season, humidity, city, and home characteristics. Clinical and Experimental Allergy, 25 (3), 240-246.

Charpin, D., Vervloet, D., Lanteaume, A. Kleisbauer, J. P., Kulling, G., Razzouk, H., Charpin, J. (1989). Respiratory allergy and domestic animals: Survey in a sample of the general population. Rev Mal Respir, 6 (4), 325-328. Abstract retrieved March 30, 2001 from Medline database

http://www.ncbi.nlm.nih.gov/entrez/query.fcgi?cmd=Retrieve\&db=PubMed\&list_uids=2799044 \&dopt $=$ Abstract

Cheple, M. \& Yust, B. L. (1999). Moisture problems in houses built in 1991 and 1992 in Minnesota. Housing and Society, 26 (1-3), 26-40.

Chew, G. L., Higgins, K. M., Gold, D. R., Muilenberg, M. L., \& Burge, H. A. (1999). Monthly measurements of indoor allergens and the influence of housing type in a northeastern US city. Allergy, 54, 1058-1066.

Corren, J. (2000). Allergic rhinitis: Treating the adult. The Journal of Allergy and Clinical Immunology, 105 (6), S610-615.

Creswell, J. W. (1994). Research design: Qualitative \& quantitative approaches. Thousand Oaks, CA: Sage Publications.

Crystal-Peters, J., Crown, W. H., Goetzel, R. Z. \& Schutt, D. C. (2000). The cost of productivity losses associated with allergies rhinitis. The American Journal of Managed Care, 6 (3), 373-378.

Cuffel, B. Wamboldt, M, Borish, L., Kennedy, S., \& Crystal-Peters, J. (1999). Economic consequences of comorbid depression, anxiety, and allergic rhinitis. Psychosomatics, 40, 491496.

Custovic A., Simpson, A., Pahdi, H., Green, R. M., Chapman, M. D., \& Woodcock, A. (1998). Distribution, aerodynamic characteristics, and removal of the major cat allergen Fel d 1 in British homes. Thorax, 53 (1), 33-38.

Delmar.

Cutler, E. W. (1998). Winning the war against asthma \& allergies. Albany, NY:

Dillman, D. A. (2000). Mail and internet survey: The tailored design method. New York: John Wiley \& Sons. 
Eggleston, P.A., Wood, R. A, Rand, C., \& Lukk, P. (2000). Cockroach allergen abatement with sodium hypochlorite in inner-city homes. The Journal of Allergy and Clinical Immunology, 105(1), S270.

Eggleston, P.A., Wood, R. A, Rand, C., Nixon, W. J., Chen, P. H., \& Lukk, P. (1999). Removal of cockroach allergen from inner-city homes. The Journal of Allergy and Clinical Immunology, 104, 842-846.

Egmar, A. C., Emenius, G., Almqvist, C., \& Wickman, M. (1998). Cat and dog allergen in mattresses and textile covered floors of homes which do or do not have pets, either in the past or currently. The Journal of Pediatric Allergy and Immonology, 9(1), 31-35.

European Academy of Allergology and Clinical Immunology. (1998). The impact of allergic rhinitis on quality of life and other airway diseases: Summary of a European conference. Allergy, 53(Suppl. 41), 7-31.

Greisner, W. A., Settipane R. J., Settipane, G. A. (1998). Natural history of hay fever: A 23-year follow-up study of college students. Allergy and Asthma Proceedings, 19(5), 271-275.

Goldfarb, S. (2000). Allergy relief. New York: Avery.

Hunter, L. M. (1989). The healthy home: An attic-to-basement guide to toxin-free living. New York: Pocket Books.

Jelks, M. L. \& Solomon, W. R. (1985). Airborne allergens. In A. P. Kaplan (Eds.), Allergy (pp. 255-320). New York: Churchill Livingstone.

Johnson, P. J. \& Abernathy, T. J. (1983). Sources of urban multifamily housing satisfaction. Housing and Society, 10, 36-42.

Juniper, E. F. (1997). Measuring health-related quality of life in rhinitis. The Journal of Allergy and Clinical Immunology, 99, S742-749.

Kramer, U., Koch, T., Ranft, U., Ring, J., \& Behrendt, H. (2000). Traffic-related air pollution is associated with atopy in children living in urban areas. Epidemology, 11(1), 64-70.

Krohn, J., Taylor, F. A., \& Larson, E. M. (1996). The whole way to allergy relief \& prevention (Rev. ed.). Point Roberts, WA: Hartley \& Marks.

Kulczycki, A. (1992). Environmental control. In P. E. Koren blat \& H. J. Wedner (Eds.), Allergy: Theory and practice (pp. 267-278). Philadelphia, PA: W. B. Saunders.

Kutintara, B. (1997). Residential interior environments of retired government employees in Thailand. Unpublished master's thesis, Virginia Polytechnic Institute and State University, Blacksburg. 
Kuwahara, Y., Kondon, J., Tatara, K., Azuma, E., Nakajima, T., Hashimoto, M., Komachi, Y. (2001). Involvement of urban living environments in atopy and enhanced eosinophil activity: potential risk factors of airway allergic symptoms. Allergy, 56(3), 224-230.

Lee, S., Brandt, J., \& McFadden, J. (1994). Effects of conditions and satisfactions related to housing on propensity to move at retirement. Housing and Society, 21(3), 34-51.

Leslie, G. B. \& Lunau, F. W. (1992). Indoor air pollution: Problems and priorities. Cambridge: Cambridge University Press.

Leung, R. \& Lai, C. K. W. (1997). The important of domestic allergens in a tropical environment. Clinical and Experimental Allergy, 27, 856-859.

Lewis, B. D., Kunkel, A., Wright, S. J., \& Olson, N. Y. (2000). Allergy and asthma patient knowledge base questionnaire. The Journal of Allergy and Clinical Immunology, 105(1), S9.

Linneberg, A., Nielsen, N. H., Madsen, F., Frolund, L., Dirksen, A., \& Jorgensen, T. (1999). Increasing prevalence of allergic rhinitis symptoms in an adult Danish population. Allergy, 54, 1194-1198.

Malainual, N., Chairat, P., Chapman, M. D. \& Vichyanond, P. (1994). House dust mites distribution in Thailand. Journal of Allergy and Clinical Immunology, January, 254.

Malainual, N., Vichyanond, P., Phan-urai, P. (1995). House dust mite fauna in Thailand. Clinical and Experimental Allergy, 25, 554-560.

Malainual, A., Vichyanond, P., Tuchinda, M., Chansang, U., Tavatsin, C., \& Phan-Urai, P. (1992). The significance of house dust mites in the house of Thai asthmaics. Abstracts of the First Asian Pacific Congress of Allergology and Immunology, Bangkok, Thailand, 82. 99, S807.

Meltzer, E. O. (1997). Introduction. The Journal of Allergy and Clinical Immunology,

Meltzer, E. O., Nathan, R. A., Selner, J. C., \& Storms, W., (1997). Quality of life and rhinitic symptoms: Results for a nationwide survey with the SF-36 and RQLQ questionnaire. The Journal of Allergy and Clinical Immunology, 99, S815-819.

Miller, J.D. \& Miller, A. (1996). Ten minutes in a dryer kills all mites in blankets. The Journal of Allergy and Clinical Immunology, 97, 423.

Miller, D. (2001). Cockroach integrated pest management. Unpublished manuscript.

Ministry of Public Health. (1999). Mahidol Population Gazette. Retrieved March 8, 2001, http://www.moph.go.th/OTHER/inform/mahidol/mahidol.htm 
Morris, E. W., Crull, S. R., \& Winter, M. (1976). Housing norms, housing satisfaction, and the propensity to move. Journal of Marriage and the Family, 38, 309-320.

Morris, E. W. \& Winter, M. (1978). Housing, family, and society. New York: John Wiley \& Sons.

Munir, A. K. M., Bjorksten, B., Einarsson, R., Ekstrandtobin, A., Moller, C., Warner, A., \& Kjellman, N. I. M. (1995). Mite allergens in relation to home conditions and sensitization of asthmatic-children from 3 climatic regions. Allergy, 50, 55-64.

Murphy, A. D., Finsten, L. M., Morris, E. W., Pettit, S. K.. \& Winter, M. (1997). Household adaptations to government housing designs in Oaxaca, Maxico. Housing and Society, 24(2), 1-21.

Murray, A. B. \& Zuk, P. (1979). The seasonal variation in a population of house dust mites in a North American city. Journal of Allergy and Clinical Immunology, 64, 266-269.

von Mutius, E. (2000). The environmental predictors of allergic disease. The Journal of Allergy and Clinical Immunology, 105, 9-19.

Nathan, R. A., Meltzer, E. O., Selner, J. C., \& Storms, W., (1997). Prevalence of allergic rhinitis in the United States. The Journal of Allergy and Clinical Immunology, 99, S808-814.

National Housing Authority. (1984). Housing information, Bangkok metropolitan and regional development studies, Research Report No 10.

National Housing Authority. (1999). Housing data in 1999. Retrieved April 29, 2001, from http://www.nhanet.or.th/chs/housing.html

National Institute of Allergy and Infections Diseases. (1998). Airborne allergens. Bethesda, MD: National Institute of Health.

National Statistical Office. (2000). Population and housing census 2000. Retrieved March 8, 2001, from http://nso.go.th/pop2000/pop2000.htm

Office of the Prime Minister, Royal Thai Government. (1991). Thailand in the 90s. Bangkok, Thailand: The National Identity Office of the Prime Minister.

Ogren, T. L. (2000). Allergy-free gardening: The revolutionary guide to healthy landscaping. Berkeley, CA: Ten Speed Press.

Parrott, K. (1993). The role of housing characteristics in the home-remodeling process. Housing and Society, 20(3), 73-86. 
Parrott, K. (1997). Indoor air quality: Reducing health risks and improving the air you breathe. In D. Eagan (Ed.), Home*A* Syst: An environmental risk-assessment guide for the home (pp.85-95). Ithaca, NY: Northeast Regional Agricultural Engineering Service.

Parrott, K. (2000). Sustainable consumption as a housing adjustment behavior. Unpublished manuscript.

Pearson, D. (1998). The new natural house book: Creating a healthy, harmonious, and ecologically sound home. New York: Fireside.

Peat, J. K. (1994). The rising trend in allergic illness: Which environmental factors are important? Clinical and Experimental Allergy, 24, 797-800.

Pedigo, L. (1999). Entomology and pest management ( $3^{\text {rd }}$ ed.). Upper Saddle River, NJ: Prentice Hall.

Petchurai, R. \& Wiriyawachkul, A. (Eds.). (1995). Older people in Thailand. Bangkok, Thailand: Mahidol University.

Platts-Mills, T. A. E. \& Chapman, M. D. (1987). Dust mites: Immunology, allergic disease, and environmental control. Journal of Allergy and Clinical Immunology, 80, 755-775.

Platts-Mills, T. A. E., Vaughan, J. W., Carter, M. C., \& Woodfolk, J. A. (2000). The role of intervention in established allergy: Avoidance of indoor allergens in the treatment of chronic allergic disease. The Journal of Allergy and Clinical Immunology, 106, 787-804.

Pope, A.M., Patterson, R. \& Burge, H. (Eds.). (1993). Indoor allergens: Assessing and controlling adverse health effects. Washington, D.C.: National Academy Press. Hospital.

Pramongkutklao Hospital. (1996). Annual report. Bangkok, Thailand: Pramongkutklao

Pumhirun, P., Towiwat, P., \& Mahakit, P. (1997). Aeroallergen sensitivity of Thai patients with allergic rhinitis. Asian Pacific Journal of Allergy and Immunology, 15(4), 183-185.

Purohit, A. \& de Blay, F. (1999). Cat allergen eviction with the cat in situ - Is it worthwhile? Allergy and Clinical Immunology International, 11(6), 207-210.

Quadagno, J. (1999). Aging and the life course: An introduction to social gerontology. Boston, MA: McGraw-Hill College.

Rousseau, D. \& Wasley, J. (1997). Healthy by design: Building and remodeling solutions for creating healthy homes. Point Roberts, WA: Hartley \& Marks.

Samir, M., Magdy, S., el Fetoh, A. A. (1997). Air pollution in relation to allergic and nonallergic rhinitis. Archives of Otolaryngology, Head, and Neck Surgery, 123, 746-748. 
Sarpong, S. B., Hamilton, R. G., Eggleston, P. A., \& Adkinson, N. F. Jr. (1996). Socioeconomic status and race as risk factors for cockroach allergen exposure and sensitization in children with asthma. The Journal of Allergy and Clinical Immunology, 97, 1393-1401.

Sarpong, S., Wood, R., \& Eggleston, P. (1996). Short term effects of extermination and cleaning on cockroach allergen Bla g 2 in settled dust. Annuls of Allergy, Asthma, and Immunology, 76, 257-260.

Sastre, J., Ibanez, M. D., Lombardero, M., Laso, M. T., \& Lehrer, S. (1996). Allergy to cockroaches in patients with asthma and rhinitis in an urban area (Madrid). Allergy, 51, 582586.

Scadding,G. K., Richards, D. H., \& Price, M. J. (2000). Patient and physician perspectives on the impact and management of perennial and seasonal allergic rhinitis. Clinical Otolaryngology and Allied Science, 25, 551-557.

Schoenwetter, W. F. (2000). Allergic rhinitis: epidemiology and natural history. Allergy and Asthma Proceedings, 21 (1), 1-6.

Settipane R. J., Hagy, G. W., Settipane, G. A. (1994). Long-term risk factors for developing asthma and allergic rhinitis: A 23-year follow-up study of college students. Allergy Proceedings, 15(1), 21-25.

Shida, T., Akiyama, K., Hasegawa, M., Maeda, Y., Taniguchi, M., Mori, A., Tomita, S., Yamamoto, N., Ishii, T., Saito, A., \& Yasueda, H. (2000). Change in skin reactivity to common allergens in allergic patients over a 30-year period: Association with aeroallergen load. Arerugi, 49, 1074-1086. Abstract retrieved March 28, 2001 from Medline database http://www.ncbi.nlm.nih.gov:80/ent...d\&list_uids=11193459\&dopt=Abstract

Sih, T. (1999). Correlation between respiratory alterations and respiratory diseases due to urban pollution. International Journal of Pediatric Otorhinolaryngology, 49(Suppl. 1), S261267.

Simoni, M., Biavati, P., Carrozzi, L., Viegi, G., Paoletti, P., Matteucci, G., Ziliani, G. L., Ioannilli, E., Sapigni, T. (1998). The Pl River Delta (North Italy) indoor epidemiological study: Home characteristics, indoor pollutants, and subjects' daily activity pattern. Indoor Air, 8(2), 7079.

Sly, R. M. (1999). Changing prevalence of allergic rhinitis and asthma. Annals of Allergy, Asthma, \& Immunology, 82, (233-248).

Stadtner, D. A. (2000). Foreword. In T. L. Ogren, Allergy-free gardening: The revolutionary guide to healthy landscaping (pp. xiii-xv). Berkeley, CA: Ten Speed Press. 
Stauder, A. Szedmak, S., \& Kopp, M. (2001). Psychosocial characteristics of people reporting allergic symptoms in a representative population survey. Allergy and Clinical Immunology International, 13(1), 18-22.

Storms, W., Meltzer, E. O., Nathan, R. A., \& Selner, J. C. (1997a). The economic impact of allergic rhinitis. The Journal of Allergy and Clinical Immunology, 99, S820-824.

Storms, W., Meltzer, E. O., Nathan, R. A., \& Selner, J. C. (1997b). Allergic rhinitis: The patient's perspective. The Journal of Allergy and Clinical Immunology, 99, S825-828.

van Strien, R. T., Verhoeff, A. P., Brunekreef, B., \& van Wijnen, J. H. (1994). Mite antigen in house dust: Relationship with different housing characteristics in The Netherlands. Clinical and Experimental Allergy, 24, 843-853.

Sundell, J., Wickman, M., Pershagen, G., \& Nordvall, S. L. (1995). Ventilation in homes infested by house-dust mites. Allergy, 50, 105-112.

Swartz, L. J., Callahan, K. A., Eggleston, P. A., Kanchanaraksa, S., Rand, C. S., Wood, R. A., Lukk, P., Voegtlin, R. (2001). Barriers to home allergen avoidance. The Journal of Allergy and Clinical Immunology, 107(2), S68-69.

Tawatsin, A., Thavara, U., Chompoosri, J., Kong-ngamsuk, W., Chansang, C., \& Paosriwong, S. (2001). Comparative efficacy of cockroach traps and cockroach fauna in Thailand. Manuscript submitted for publication, National Institute of Health.

Tettoni, L. I. \& Warren, W. (1988). Thai style. Bangkok, Thailand: Asia Books.

Titapunkul, S. \& Bunnag, S. (1997). Ageing in Thailand. Bangkok, Thailand: Thai Society of Gerontology and Geriatric Medicine.

Tovey, E., \& Marks, G. (1999). Methods and effectiveness of environmental control. The Journal of Allergy and Clinical Immunology, 103, 179-191.

Tuchinda (1978). Prevalence of asthma, rhinitis, and eczema in students at Mahidol University. Siriraj Journal, 30, 1285-1298.

Ukoha, O. M. (1995). Satisfaction with public housing: A case of Abuja, Nigeria. Unpublished doctoral dissertation, Virginia Polytechnic Institute and State University, Blacksburg.

Ulean, A. (1999, May). How to outsmart your allergies. Vegetarian Times, 81-87.

U.S. Bureau of the Census. (1990). American housing survey for the United States in 1987 (Housing Reports, H-150-87). Washington, DC: Government Printing Office.

U.S. Environmental Protection Agency. (2001a). An introduction to indoor air quality. Retrieved April 21, 2001, from http://www.epa.gov/iaq/ia-intro.html 
U.S. Environmental Protection Agency. (2001b). Biological pollutants in your home. Retrieved April 21, 2001, from http://ww.epa.gov/iaq/pubs/bio_1.html

U.S. Environmental Protection Agency. (2002). A brief guide to mold, moisture, and your home. Retrieved May 23, 2002, from http://www.epa.gov/iad/molds/moldguide.html

Verhoeff, A. P., van Strien, R. T., van Wijnen, J. H., \& Brunekreef, B. (1995). Damp housing and childhood respiratory symptoms: The role of sensitization to dust mites and molds. American Journal of Epidemiology, 141 (2), 103-110.

Vichyanond, P., Jirpongsananuruk, O., Visitsuntorn, N., \& Tuchinda, M. (1998). Prevalence of asthma, rhinitis, and eczema in children from the Bangkok area using the ISAAC questionnaires. Journal of the Medical Association of Thailand, 81, 175-184.

Vichyanond, P., Pothikamjorn, S., \& Raxrungtham, K. (Eds.). (2000). Allergy 2000's. Bangkok, Thailand: The Allergy and Immunology Society of Thailand.

Virginia Cooperative Extension. (2001a). German Cockroach. Retrieved March 31, 2001, from http://www.ext.vt.edu/departments/entomology/factsheets/germanco.html

Virginia Cooperative Extension (2001b). American Cockroach. Retrieved March 31, 2001, from http://www.ext.vt.edu/departments/entomology/factsheets/amercock.html

Wallace, L., Pellizzri, E., Sheldon, L., Hartwell, T., Sparacino, C., \& Zelon, H. (1986). The total exposure assessment methodology (TEAM) study: Direct measurement of personal exposures through air and water for 600 residents of several U.S. cities. In Y. Cohen (Ed.). Pollutants in a multimedia environment (pp. 289-315). New York: Plenum Press.

Wangwongwattana, S. (1995). Traffic-generated air pollution. In State of the Thai environment: 1995. Bangkok, Thailand: Amarin Printing.

Wickman M., Paues S., \& Emenius G. (1997). Reduction of the mite-allergen reservoir within mattresses by vacuum-cleaning: A comparison of three vacuum-cleaning system. Allergy, 52, 1123-1127.

Windley, P.G. \& Scheidt, R. J. (1983). Housing satisfaction among rural small-town elderly: A predictive model. Journal of Housing for the Elderly, 1, 57-68.

Wongsathuaythong, S., Fuangtong, R., \& Ketavan, C. (1977). Insect and archid allergy in Thailand. Journal of the Medical Association of Thailand, 60, 274-278.

Wongsekiarttirat, W. (1991). Indoor air pollution in Bangkok. Bangkok, Thailand: Chulalongkorn Social Research Institute.

Young, S. H., Dobozin, B. S., \& Miner, M. (1999). Allergies: The complete guide to diagnosis, treatment, and daily management (Rev. ed.). New York: A Plume Book. 
Zellerbach, M. (1995). Allergy sourcebook: Everything you need to know (2 ${ }^{\text {nd }}$ ed.) Los Angeles, CA: Lowell House. 
Appendix A

Screening Questions: English Version 


\section{Survey Questionnaire}

The purpose of the study is to examine home environments of people with allergic rhinitis. Your answers will assist us to design suitable dwellings for people with allergic rhinitis in the future. Please take a few minutes to answer all questions. I really appreciate your help.

\section{Please answer the following questions or mark $X$ in front of your responses.}

1. How old are you? years old

2. What is your marital status? 1. Single 2. Married 3. Widow 4. Divorced

3. How long have you had nasal allergy (hay fever)?

4. Do you know what you are allergic to? (Please check all that apply) Yes No

1. Dust mites 2. Cockroaches 3. Cats 4. Dogs 5. Mold 6 . Pollen (specify plants)

7. Others (specify)

5. How long have you received allergy treatments?

6. Did your doctor suggest how to improve your home in order to reduce your allergic symptoms?

$$
\text { _ Yes _ No }
$$

7. What kind of residence do you live? 1. House

2. Townhouse

3. Shophouse

4. Apartment

5. Others (specify)

8. How long have you lived in your home? year(s)

9. How old is your home?

10. Do you own or rent your home? 1. Owned by yourself 2. Owned by a family member 3. Rent 4. Others (specify)

\section{A Free Home Improvement}

Consultation

I am conducting a study on homes of allergy patients. I would like to visit your home and take pictures of home interiors. Each participant will receive free advice and information on home improvements in order to reduce allergic symptoms.

Would you like me to visit your home and to suggest how to improve your home in order to reduce your allergic symptoms? If so please give me your name, address, a telephone number, and your available time.

Name

Address

Phone

Available Date

Available Time

Please draw a map to your home on the back of this questionnaire.

\section{THANK YOU VERY MUCH}


Appendix B

Screening Questions: Thai Version 
แบบสอบถามนี้จัดทำขึ้นเพื่อต้องการทราบถึงสภาพที่อยู่อาศัยของผู้ปวยโรคภูมิแพ้ คำตอบของ ท่านจะเป็นประโยซน์ต่อการวิจัยเพื่อนำไปสูการแก้ไขปัญหาสภาพแวดล้อมในที่อยู่อาศัยของผู้ปวยยรคค ภูมิแพ้ในอนาคต จึงขอความกรุณาท่านตอบแบบสอบถาม และให้ข้อคิดเห็นในแบบสอบถามนี้ด้วย แบบสอบถามประกอบด้วย 2 ส่วน ส่วนที่1 ข้อมูลทั่วไป และ ส่วนที่2 แบบสอบถามความคิดเห็น ขอขอบคุณ อาจารย์ เบญจมาศ กุฏอินทร์ คณะสถาปัตยกรรมศาสตร์ สถาบันเทคโนโคยีพระจอมเกล้าบ ลาดกระบัง

1. จายุ — ปี

2. สถานภาพสมรส

1. โกด

2. แต่งงาน

3. ม่าย

4. หย่า

3. ท่านเป็นโรคภูมิแพ้มานานประมาณ - ปี

4. ท่านเป็นภูมิแพ้ต่อ

1. ไรฝุ่น

2. แมลงสาบ

3. แมว

4. เุนัข

5. รา

6. เกสรดอกไม้, พืช, หญ้า

(โปรดระบุ)

7. อื่นๆ (โปรดระบุ)

5. ท่านรับการรักษาโรคภูมิแพ้มานาน ประมาณ

6. แพทย์แนะนำให้ปรับปรุงที่อยู่อาศัยเพื่อลด อาการของภูมิแพ้หรือไม่ แนะนำ ไม่แนะนำ

7. ประเภทของบ้านของท่าน
1. บ้านเดี่ยว

2. ทาวน์เฮาส

3. ตึกแถว

4. ห้องชุด

5. อื่นๆ โปรดระบุ

8. ท่านอยู่บ้านนี้มาเป็นเวลา

9. บ้านที่ท่านอยู่สร้างมาแล้วประมาณ__ป ปี

10. บ้านที่ท่านอยู่ท่านเป็นเร้าของหรือเช่า

1. เป็นเจ้าของบ้าน

2. สมาชิกในป้านเป็นเจ้าของ

3. เช่า

4. อื่นๆ (โปรดระบุ)

ผู้วิจัยกำลังศึกษาเรื่องสภาพภายในบ้านของผู้ ป่วยโรกภูมิแพ้ หากท่านยินดีที่จะให้ผู้วิจัยไป สัมภาษณ์และเก็บข้อมูลที่บ้านของท่าน โปรด กรุณากรอกซื่อ -ที่อยู่ ทั้งนี้ผู้วิจัยจะให้คำ ปรึกษาและเอกสารแนะนำเกี่ยวกับการปรับปรุง บ้านเพื่อลดอาการภูมิแพ้ด้วย ชื่อ ที่อยู่

โทรศัพท์ 
Appendix C

Questionnaire: English Version 


\section{Please answer the following questions or mark $\mathrm{X}$ in front of your responses.}

1. How old are you?

2. How long have you lived in your home?

3. How old is your home?

4. Do you own or rent your home?
Own
Rent
Owned by a family member
Others (specify)

5. Was your home designed or decorated by an architect or an interior designer? No Yes

6. Do you smoke?

No Yes

7. Does anybody else in your home smoke?

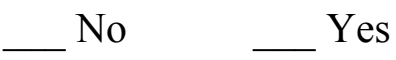

8. Do you have pets?

No, skip to question 11

Yes, I have Cat

Dog__ Others (specify)

9. Do you or someone in your household let your pets inside your home? No.

10. How often do you wash you pets?

Bedroom

Living room

Every week

Every month Less than once a month

11. Do you or someone in your household use insecticide spray to control cockroaches in your home?

No__ Yes

12. Do you have the following items in your bedroom? (Please check all that apply)

Carpet flooring

Open shelves or bookcases

Drapes or horizontal blinds

Upholstered furniture

Kapok pillows

Feather pillows

Foam rubber pillows

Indoor plants

13. Do you have the following problems in your home? (Please check all that apply) Molds in a bedroom

Molds in bathrooms

Molds in a kitchen

Cockroaches

Leaks and moisture damage

Others (specify) 
Would you tell us how satisfied or dissatisfied you are with the following aspects of your home? Please mark $(X)$ on your level of satisfaction: 1 = Very Dissatisfied, 2 = Somewhat Dissatisfied, $3=$ Somewhat satisfied, and $4=$ Very Satisfied.

$\begin{array}{cccc}1 & 2 & 3 & 4 \\ \text { Very } & \text { Somewhat } & \text { Somewhat } & \text { Very } \\ \text { Dissatisfied } & \text { Dissatisfied } & \begin{array}{c}\text { Satisfied } \\ \text { Satisfied }\end{array}\end{array}$

14. Are you satisfied that your home is a healthy place to live? .................... .1

2

3

4

15. Are you satisfied that your home is an allergy-free place to live? ..1

2

3

4

16. Are you satisfied that your home does not contribute to allergy problems?

3

4

17. Are you satisfied that you have controlled allergens in your home? $\ldots 1$

2

3

4

18. Do you get any professional help in order to control allergens in your home?

$\begin{array}{ll}\text { Yes, from } & \text { No, skip to question } 20 \\ & \text { Doctor } \\ \text { Interior designer or architect } & \text { Architect } \\ & \text { Builder } \\ & \text { Salesperson } \\ & \text { Others (specify) }\end{array}$

19. What type of help do you get?

Product selection

Construction technique

Others (specify)

20. Please check all items that you did or plan to do in the future.

\begin{tabular}{|l|c|c|c|c|}
\hline Practice & N/A & I did this. & $\begin{array}{l}\text { I plan to } \\
\text { do this in } \\
\text { the future. }\end{array}$ & $\begin{array}{l}\text { I don't } \\
\text { plan to do } \\
\text { this. }\end{array}$ \\
\hline Remove carpet from your bedroom. & $\square$ & $\square$ & $\square$ & $\square$ \\
\hline $\begin{array}{l}\text { Replace drapes and horizontal blinds } \\
\text { with washable curtains. }\end{array}$ & $\square$ & $\square$ & $\square$ & $\square$ \\
\hline $\begin{array}{l}\text { Remove upholstered furniture from } \\
\text { your bedroom. }\end{array}$ & $\square$ & $\square$ & $\square$ & $\square$ \\
\hline Remove plants from your bedroom. & $\square$ & $\square$ & $\square$ & $\square$ \\
\hline Give your pet away. & $\square$ & $\square$ & $\square$ & $\square$ \\
\hline
\end{tabular}


21. Please check all practices that you do and plan to do in the future.

\begin{tabular}{|l|c|l|c|}
\hline Practice & $\begin{array}{l}\text { I do this } \\
\text { now. }\end{array}$ & $\begin{array}{l}\text { I would like } \\
\text { to do this, but } \\
\text { I really don't } \\
\text { do it now. }\end{array}$ & $\begin{array}{l}\text { I don't do } \\
\text { this and I } \\
\text { don't plan } \\
\text { to do this. }\end{array}$ \\
\hline Use allergen-proof pillowcases. & $\square$ & $\square$ & $\square$ \\
\hline Use allergen-proof sheets. & $\square$ & $\square$ & $\square$ \\
\hline Use polyester-fiber-filled pillows & $\square$ & $\square$ & $\square$ \\
\hline $\begin{array}{l}\text { Use a vacuum cleaner with a high } \\
\text { efficiency filter or allergen-controlling } \\
\text { bags. }\end{array}$ & $\square$ & $\square$ & $\square$ \\
\hline Use lidded garbage containers. & $\square$ & $\square$ & $\square$ \\
\hline
\end{tabular}

22. Please check all practices that you do and plan to do in the future.

\begin{tabular}{|l|c|c|l|c|}
\hline Practice & $\begin{array}{l}\text { I do this } \\
\text { regularly }\end{array}$ & $\begin{array}{l}\text { I do this } \\
\text { sometimes }\end{array}$ & $\begin{array}{l}\text { I would } \\
\text { like to do } \\
\text { this, but I } \\
\text { really } \\
\text { don't do it } \\
\text { now. }\end{array}$ & $\begin{array}{l}\text { I don't } \\
\text { do this } \\
\text { and I } \\
\text { don't } \\
\text { plan to } \\
\text { do it. }\end{array}$ \\
\hline Wash pillowcases and sheets weekly. & $\square$ & $\square$ & $\square$ & $\square$ \\
\hline Wash pillowcases and sheet in hot water. & $\square$ & $\square$ & $\square$ & $\square$ \\
\hline $\begin{array}{l}\text { Clean your bedroom with a damp cloth } \\
\text { weekly. }\end{array}$ & $\square$ & $\square$ & $\square$ & $\square$ \\
\hline $\begin{array}{l}\text { Wet mop or vacuum your bedroom floor } \\
\text { weekly. }\end{array}$ & $\square$ & $\square$ & $\square$ & $\square$ \\
\hline Vacuum your bedroom weekly. & $\square$ & $\square$ & $\square$ & $\square$ \\
\hline Wear a particle mask when vacuuming & $\square$ & $\square$ & $\square$ & $\square$ \\
\hline Use cockroach traps & $\square$ & $\square$ & $\square$ & $\square$ \\
\hline Use an exhaust fan in a kitchen & $\square$ & $\square$ & $\square$ & $\square$ \\
\hline Use an exhaust fan in bathrooms & $\square$ & $\square$ & $\square$ & $\square$ \\
\hline Use an air conditioner in your bedroom & $\square$ & $\square$ & $\square$ & $\square$ \\
\hline $\begin{array}{l}\text { Clean a filter in an air conditioner } \\
\text { monthly }\end{array}$ & $\square$ & $\square$ & $\square$ & $\square$ \\
\hline Use a dehumidifier & $\square$ & $\square$ & $\square$ & $\square$ \\
\hline Use an air cleaner & $\square$ & $\square$ & $\square$ & $\square$ \\
\hline Use a cloth dryer & $\square$ & $\square$ & $\square$ & $\square$ \\
\hline
\end{tabular}


23. What obstructs you from improving your home in order to avoid allergens? (Please check all that apply)

Never get advice from anyone

Not sure what to do

Not have enough time to do it

Not sure changes will help

Procrastination

No need to make changes

Cost of products

Not want to give pets away

It is hard to hire someone to do a home modification.

No house keeper

Aesthetic

Other reasons (specify)

24. Please list 3 things that you plan to change in your home to reduce your allergy symptoms.

25. Please make other comments or suggestions that will help to improve indoor air quality in homes. (Please describe)

THANK YOU VERY MUCH 
Appendix D

\section{Questionnaire: Thai Version}


แบบสอบถามนี้จัดทำขึ้นเพื่อต้องการทราบถึงสภาพที่อยู่อาศัยของผู้ปวยโรคภูมิแพ้ คำตอบของ ท่านจะเป็นประโยชน์ต่อการแก้ไขปัญหาสภาพแวดล้อมในที่อยู่อาศัยของผู้ปวยโรคภูมิแพ้ในอนาคต ดั้ง นั้นจึงขอความกรุณาจากท่านช่วยตอบแบบสอบถาม ถ้าท่านมีข้อคิดเห็นประการใดโปรดเขียนข้อคิด เห็นของท่านลงบนที่ว่างในแบบสอบถามนี้ด้วย

$$
\begin{aligned}
& \text { ขอขอบคุณ } \\
& \text { นางศาวเบญจมาศ กฎอินทร์ } \\
& \text { อาจารย์ประจำคณะสถาปัตยกรรมศาสตร์ } \\
& \text { สถาบันเทคโนโลยีพระจอมเกล้าบลาดกระบัง }
\end{aligned}
$$

กรุณาบอกถึงความพอเ์และความไม่พอใจเกี่ยวกับบ้านของท่านโดยกากบาทตามระดับความ พอใด คือ ระนับ1 1 = ไม่พอใจมาก ระดับ 2 = ค่อนข้างไม่พอใด ระดับ $3=$ ค่อนข้างพอใด ระดับ $4=$ พจใจมาก

ไม่พอใจ ค่อนข้าง ค่อนข้าง พอใจ มาก ไม่พอใจ พอใจ มาก
1. ท่านพอใจที่บ้านของท่านถูกสุขลักษณะและน่าอยู่อาศัย

1

23
4
2. ท่านพอใจที่บ้านของท่านปราศจากเส่งที่ทำให้เกิดภมิแพ้
1
2

3
3. ท่านพอใจที่ร้านของท่านไม่ก่อให้เกิดปัญหาภูมิแห้แก่ท่าน

1
4. ท่านพอใจที่สามารถควบคุมสิ่งที่ทำให้เกิดภูมิแพ้ในบ้านของท่านได้ 1

$\begin{array}{lll}2 & 3 & 4 \\ 2 & 3 & 4\end{array}$

5. ท่านสูบบุหรี่หรือไม่

6. มีคนในบ้านของท่านสูบบุหรี่หรือไม่

7. ท่านมีสัตว์เลี้ยงหรือไม่

ไม่มี หากตอบข้อนี้กรุณาข้ามไปตอบข้อ 10

—มี โปรดระบุ —แมว —อื่น ๆโปรดระบุ - กุนัข

8. สัตว์เลี้ยงของท่านได้เข้ามาภายในตัวบ้านหรือไม่

— ได้เข้ามาที่ ห้องนอนของท่าน ห้องนอนของผู้อี่น ห้องพักผ่อน / ห้องนั่งเล่น

9. มีการอาบน้ำสัตว์เลี้ยงบ่อยแค่ไหน —ทุกสัปดาห์ ทุกเดือน น้อยกว่าเดือนละครั้ง 
น้องนอนของท่านมีสิ่งใดดังต่อไปนี้ (กรุณากากบาทx ข้อที่ท่านมี)

-11. พรมปูพพื้นในห้องนอน

12. ชั้นวางของหรือตู้หนังสือ (แบบเปิดโล่ง) ในห้องนอน

13. ม่านผ้าที่ถอดชักยากหรือม่านปรับแสง(มู่ลี่พลาสติก)ในห้องนอน

14. เฟอร์นิเจอร์นุ้มด้วยผ้าในห้องนอน

15. หมอนนุ่น

16. หมอนขนเป็ด

-17. หม อนฟองน้ำ

— 18. ต้นไม้ในน้องนอน

ไม่มีสิ่งของดังกล่าว

ท่านพบสิ่งใดต่อไปนี้บ้างในบ้านของท่าน (กรุณากากบาท $\times$ หน้าข้อที่ท่านพบ)

19. ราในห้องนอน (เช่น มีราขึ้นในช่องแอร์, ราบนผนังห้อง)

20. ราในห้องน้ำ (เช่น มีราขึ้นที่ผนังในบริเวณที่อาบน้ำหรืออ่างล้างหน้า)

21. ราในห้องครัว (เช่น มีราขึ้นที่บริเวณอ่างล้างจาน)

22. แมลงสาป

_ 23 . มีการรั่วซึม น้ำรั่ว ปัญหาเรื่องความชื้น

24. อื่นๆ (โปรดระบุ)

ท่านได้ทำสิ่งเหล่านี้หรีอคิด (อยาก) จะทำในอนาคต โปรดกากบาทในช่องที่เป็นคำตอบของ ท่าน

\begin{tabular}{|l|c|c|c|c|}
\cline { 2 - 5 } \multicolumn{1}{c|}{} & ไม่มีลิ่งนี้ & ทำแล้ว & $\begin{array}{c}\text { อยากท่า } \\
\text { ในอนาคต }\end{array}$ & $\begin{array}{c}\text { ไม่คิดที่จะ } \\
\text { ทำใน } \\
\text { อนาคต }\end{array}$ \\
\hline 25. เอาพรมออกไปจากห้องนอน & $\square$ & $\square$ & $\square$ & $\square$ \\
\hline 26. ใช้ม่านที่ทำความสะอาดได้แทนม่านบังตา & $\square$ & $\square$ & $\square$ & $\square$ \\
\hline 27. ย้ายเฟอร์นิเจอร์ต่างๆ ออกจากห้องนอน & $\square$ & $\square$ & $\square$ & $\square$ \\
\hline 28. ย้ายต้นไม้ที่ปลูกไร้ในห้องนอนออกไป & $\square$ & $\square$ & $\square$ & $\square$ \\
\hline 29. เลิกเลี้ยงสัตว์เลี้ยง & $\square$ & $\square$ & $\square$ & $\square$ \\
\hline
\end{tabular}


ท่านใช้สิ่งของเหล่านี้หรือไม่ โปรดกากบาทในช่องที่เป็นคำตอบของท่าน

\begin{tabular}{|l|c|c|c|}
\cline { 2 - 4 } \multicolumn{1}{c|}{} & $\begin{array}{c}\text { ใช้อยู่ใน } \\
\text { ปัจจุบัน }\end{array}$ & $\begin{array}{c}\text { อยากใช้แต่ยัง } \\
\text { ไม่ได้ใช้ }\end{array}$ & $\begin{array}{c}\text { ไม่ได้ใช้และ } \\
\text { ไม่คิดจะใช้ }\end{array}$ \\
\hline 30. ใช้ปลอกหมอนป้องกันการแพ้ & $\square$ & $\square$ & $\square$ \\
\hline 31. ใช้ผ้าปุที่นอนป้องกันการแพ้ & $\square$ & $\square$ & $\square$ \\
\hline 32. ใช้นมอนที่บรรรุด้วยใยสังเคราะห์ & $\square$ & $\square$ & $\square$ \\
\hline $\begin{array}{l}\text { 33. ใช้เครื่องดูดฝู่นที่มีประสีทธิภาพในการควบ } \\
\text { คุม สารก่อภูมิแพ้ }\end{array}$ & $\square$ & $\square$ & $\square$ \\
\hline 34. ใช้ถังขยะที่มีฝาปิด & $\square$ & $\square$ & $\square$ \\
\hline
\end{tabular}

ท่านทำสิ่งต่อไปนี้บ่อยแค่ไหน โปรดกากบาทในช่องที่เป็นคำตอบของท่าน

\begin{tabular}{|c|c|c|c|c|}
\hline & สม่ำเสมอ & บางครั้ง & $\begin{array}{l}\text { ต้องการ } \\
\text { ทำแต่ยัง } \\
\text { ไม่ได้ทำ }\end{array}$ & $\begin{array}{l}\text { ไม่ได้ทำ } \\
\text { และไม่ } \\
\text { อยากทำ }\end{array}$ \\
\hline 35. ขักปลอกหมอนและผ้าปู่ที่นอนทุกสัปดาห์ & $\square$ & $\square$ & $\square$ & $\square$ \\
\hline 36. ชักปลอกหมอนและผ้าปู่ที่นอนด้วยน้ำร้อน & $\square$ & $\square$ & $\square$ & $\square$ \\
\hline 37. เช็ดฝุนในห้องนอนด้วยผ้าหมาดๆ ทุกสัปดาห์ & $\square$ & $\square$ & $\square$ & $\square$ \\
\hline 38. ดูดผู่นห้องนอนทุกสัปดาห์ & $\square$ & $\square$ & $\square$ & $\square$ \\
\hline 39. ถูพื้นหรีอดูดฝู่นพื้นห้องนอนทุกสัปดาห์ & $\square$ & $\square$ & $\square$ & $\square$ \\
\hline 40. สวมที่ครอบจมูกและปากกันผุ่นขณะดูดฝู่น & $\square$ & $\square$ & $\square$ & $\square$ \\
\hline 41. ใช้กับดักแมลงสาบ & $\square$ & $\square$ & $\square$ & $\square$ \\
\hline 42. ใช้พัดลมดูดอากาศในห้องครัว & $\square$ & $\square$ & $\square$ & $\square$ \\
\hline 43. ใช้พัดลมดูดอากาศในห้องน้ำ & $\square$ & $\square$ & $\square$ & $\square$ \\
\hline 44. ใช้เครื่องปรับอากาศในห้องนอน & $\square$ & $\square$ & $\square$ & $\square$ \\
\hline $\begin{array}{l}\text { 45. ทำความสะอาดที่กรองผุ่นในเครื่องปรับ } \\
\text { อากาศทุ่กเดือน }\end{array}$ & $\square$ & $\square$ & $\square$ & $\square$ \\
\hline 46. ใช้เครื่องลดความชื้น & $\square$ & $\square$ & $\square$ & $\square$ \\
\hline 47. ใช้เครื่องฟอกอากาศ & $\square$ & $\square$ & $\square$ & $\square$ \\
\hline 48. ใช้เครื่องอบผ้า & $\square$ & $\square$ & 0 & $\square$ \\
\hline
\end{tabular}


49. บ้านของท่านได้รับการออกแบบหรีอตกแต่งโดยสถาปนิกหรีอมัณทนากรหรือไม่

ใช่ ไม่ใช่

50. ท่านได้รับความช่วยเหลือในการหลีกเลี่ยงสิ่งที่ทำให้เกิดภูมิแพ้ในบ้านท่านหรือไม่ ได้รับ จาก

—1. แพทย์

-2. มัณฑนากร

- 3. สถาปนิก

-4. ผู้รับเหมาก่อสร้าง

5. พนักงานขาย

6. อื่น (โปรดระบุ)

_. แม้ได้รับ (หากตอบข้อนี้กรุณาข้ามไปตอบข้อ 52

51. ท่านได้ความช่วยเหลือในลักษณะใด 1. การเลือกผลิตภัณฑ์

2. เทคนิคการก่อสร้าง(เช่นการออกแบบที่เหมาะสม การติดตั้งพัดลมดูดอากาศ) 3. อิ่นๆ (โปรดระบุ)

52. ข้อใดที่เป็นอุปสรรคในปรับปรุงบ้านของท่านเพื่อหลีกเลี่ยงสิ่งที่ทำให้เกิดภมิแพ้ 1. ไม่เคยได้รับคำแนะนุมากผู้ใด

2. ไม่แน่ใจว่าจะปรัปปรุงอย่างไร

3. ไม่มีเวลาเพียงพอที่จะทำ

4. ไม่แน่ใจว่าการปรับปรุงจะช่วยได้

5. ผัดวันประกันพรุ่ง

6. ไม่ต้องการปรับปรุงเปลี่ยนแปลง

7. ผลิตภัณฑ์สำหรับผู้ป๋วยโรครูมิแพ้มีราคาสูง

8. ไม่อยากเลิกเลี้ยงสัตว์เลี้ยง

9. ไม่สามารถจ้างใครให้มาปรับปรุงแก้ไขให้

เนื่องจาก

10. ไม่มีคนดูแลทำความสะอาดบ้าน

11. กลัวว่าจะทำลายความสวยงาม

12. อื่น ๆ (โปรดระบุ) 
53. โปรดระบ ลิ่งที่ท่านอยากจะเปลี่ยนแปลงในบ้านเพื่อลดอาการภูมิแพ้ของท่าน (ประมาณ 3 ข้อ) $=$

-

-

54. กรุณาให้ข้อเสนอแนะที่จะช่วยในการปรับปรุงคุณภาพอากาศภายในบ้านของท่าน

ขอขอบคุณที่กรุณาสละเวลาตอบแบบสอบถาม เบญจมาศ กุฏอินทร์ 


\section{Appendix E}

\section{Things That the Respondents Planned to Change in Their Homes}

\begin{tabular}{|c|c|c|}
\hline & & \\
\hline Home Furnishing & $\begin{array}{l}\text { Rearrange furniture and equipment and eliminate unused } \\
\text { furniture and belongings }\end{array}$ & $\frac{\mathrm{n}}{6}$ \\
\hline & Use allergen proof bedding & 2 \\
\hline & Use washable curtains & 1 \\
\hline & Use trash cans with lids & 1 \\
\hline & $\begin{array}{l}\text { Replace the wooden bathroom door with a plastic bathroom } \\
\text { door in order to avoid molds }\end{array}$ & 1 \\
\hline & Replace mosquito screens with glass windows & 1 \\
\hline Structure & Build a new house & 3 \\
\hline & Build a library in the house to keep books & 1 \\
\hline & Build a walk-in closet to keep clothes & 1 \\
\hline & Remodel a bathroom & 1 \\
\hline & Install more windows & 1 \\
\hline & Elevate the ground floors & 1 \\
\hline & Fix the damaged ceiling & 1 \\
\hline Cleaning & Clean home frequently & 4 \\
\hline & Clean mosquito screens frequently & 1 \\
\hline & Arrange belongings in order & 1 \\
\hline Laundering & Wash bedding in hot water & 1 \\
\hline & Wash curtains every month & 1 \\
\hline & Dry the mattress to the sun & 1 \\
\hline Ventilation & Install an air cleaner & 3 \\
\hline & Install an exhaust fan (in the kitchen or in the bathroom) & 4 \\
\hline Landscaping & Plant more trees around the house & 1 \\
\hline & Cut trees down & 1 \\
\hline Pest Management & Use cockroach traps & 1 \\
\hline Pets & Give dogs away & 2 \\
\hline
\end{tabular}




\section{Appendix F}

\section{Suggestions from the Respondents about Improving Home Indoor Air Quality}

\begin{tabular}{|l|l|r|}
\hline \multirow{5}{*}{ Ventilation } & & $\underline{n}$ \\
\hline \multirow{5}{*}{ Home Furnishing } & Have good ventilation in the home & 4 \\
\cline { 2 - 3 } & Install an air cleaner & 2 \\
\cline { 2 - 3 } & Open all windows to get more wind & 2 \\
\cline { 2 - 3 } & Change locations of windows to get more wind & 1 \\
\cline { 2 - 3 } & Always keep doors closed to prevent dust from outside & 1 \\
\cline { 2 - 3 } & Have fewer belongings and furniture & 3 \\
\hline & Avoid upholstered furniture and kapok & 1 \\
\cline { 2 - 3 } & Relocate bookshelves & 1 \\
\hline \multirow{5}{*}{ Housekeeping } & Keep belongings in order & 1 \\
\cline { 2 - 3 } & Clean belonging and equipment frequently & 3 \\
\cline { 2 - 3 } & Wash bedding frequently & 1 \\
\cline { 2 - 3 } & Clean mosquito screens frequently & 1 \\
\hline \multirow{5}{*}{ Landscaping } & Plant trees and shrubs around a house to protect the house & 5 \\
\hline \multirow{5}{*}{ Pets } & from outside dust & 1 \\
\cline { 2 - 3 } & Plant trees without flowers. Avoid plants with flowers & 1 \\
\hline Others & Do not have pets in the house & 1 \\
\cline { 2 - 3 } & Wash pets frequently & 1 \\
\hline
\end{tabular}




\section{Appendix G}

Obstacles to the Improvement of the Homes in order to Avoid Allergens

\begin{tabular}{|c|c|c|c|}
\hline & & $\underline{\mathrm{n}}$ & Percent \\
\hline \multirow[t]{2}{*}{ Economic Reason } & Cost of products & 18 & $44 \%$ \\
\hline & Remodeling cost was expensive & 2 & $5 \%$ \\
\hline Emotional Reason & Not want to give pets away & 12 & $29 \%$ \\
\hline \multirow{2}{*}{$\begin{array}{l}\text { Time Management } \\
\text { Reason }\end{array}$} & Not have enough time to do it & 11 & $27 \%$ \\
\hline & Procrastination & 9 & $22 \%$ \\
\hline \multirow[t]{3}{*}{ Knowledge Reason } & Not sure what to do & 10 & $24 \%$ \\
\hline & Never get advice from anyone & 6 & $15 \%$ \\
\hline & Not sure changes will help & 4 & $10 \%$ \\
\hline \multirow[t]{2}{*}{ Labor Reason } & No house keeper & 10 & $24 \%$ \\
\hline & $\begin{array}{l}\text { It was hard to hire someone to do a home } \\
\text { modification }\end{array}$ & 9 & $22 \%$ \\
\hline \multirow[t]{2}{*}{ Architectural Reason } & Aesthetic & 2 & $5 \%$ \\
\hline & $\begin{array}{l}\text { It was hard to make changes because of limited } \\
\text { space }\end{array}$ & 1 & $2 \%$ \\
\hline \multirow[t]{3}{*}{ Outdoor Pollution } & Odor from a factory nearby & 1 & $2 \%$ \\
\hline & Insecticide from an orchid farm nearby & 1 & $2 \%$ \\
\hline & Dust from roads & 1 & $2 \%$ \\
\hline \multirow[t]{3}{*}{ Others } & No need to make changes & 2 & $5 \%$ \\
\hline & $\begin{array}{l}\text { Wanted to replace a vacuum cleaner when an } \\
\text { existing one is out of order }\end{array}$ & 1 & $2 \%$ \\
\hline & Had many toys which were full of dirt & 1 & $2 \%$ \\
\hline
\end{tabular}




\section{Appendix H}

Sources of Professional Help in Controlling Allergens in Homes

\begin{tabular}{lrr}
\hline & Percent & $\underline{\underline{n}}$ \\
\hline Doctor & $83 \%$ & 34 \\
Family member & $7 \%$ & 3 \\
Public health officer, radio, television, brochure, and seminar & $5 \%$ & 2 \\
Personal knowledge from nursing education & $2 \%$ & 1 \\
Did not get help & $15 \%$ & 6 \\
\hline
\end{tabular}

\section{Appendix I}

\section{Type of Help in Controlling Allergens in Homes}

\begin{tabular}{lrr}
\hline & Percent & $\underline{\underline{\mathrm{n}}}$ \\
\hline Suggestions about allergen avoidance practices & $32 \%$ & 13 \\
Product selection & $29 \%$ & 12 \\
Other specific suggestions reported & & \\
- Wear a mask when cleaning & $5 \%$ & 2 \\
- Exercise & $2 \%$ & 1 \\
- Wear eyeglasses & $2 \%$ & 1 \\
- Get enough sleep & $2 \%$ & 1 \\
- Drug (antihistamine) & $2 \%$ & 1 \\
- Home environmental arrangement & $2 \%$ & 1 \\
- Avoid pets, washing and grooming pets & $2 \%$ & 1 \\
- Give pets away & $2 \%$ & 1 \\
- House cleaning & $2 \%$ & 1 \\
- Use an air cleaner & $2 \%$ & 1 \\
- Do not keep books in the bedroom & $2 \%$ & 1 \\
Did not answer & $29 \%$ & 12 \\
\hline
\end{tabular}




\section{EDUCATION}

Ph.D. in Housing, Interior Design, and Resource Management Graduate Certificate in Gerontology

Virginia Polytechnic Institute and State University, Blacksburg, VA May, 2002

Dissertation: Home environments and allergen avoidance practices in a hot, humid climate

Advisor: Dr. Kathleen R. Parrott

M.S. in Housing, Interior Design, and Resource Management

Virginia Polytechnic Institute and State University, Blacksburg, VA

December, 1997

Thesis: Residential interior environments of retired government employees

Advisor: Dr. Julia O. Beamish

B.Arch. in Interior Architecture (Second Class Honor)

King Mongkut's Institute of Technology, Bangkok, Thailand

April, 1993 (Top in class)

Thesis (Creative Research): Museum of medicine and public health, Bangkok

\section{AWARDS}

Joel Posky Academic Achievement Award in Graduate Research, 1998

The American Society of Interior Designers

This is the only national competition for graduate research in interior design.

Student Research Paper Award, 1999, The Southern Gorontological Society

Graduate Student Assembly Travel Award, 2000, Virginia Tech

James D. Moran Memorial Dissertation Award, 2001, Virginia Tech

Graduate Student Assembly Research Development Award, 2001

Virginia Tech

\section{SCHOLARSHIPS}

1995 Royal Thai Government Scholarship for Graduate Studies

1989 King Mongkut's Institute of Technology Scholarship

\section{PROFESSIONAL EXPERIENCES}

Graduate Research Assistant, Department of Near Environments and Virginia Cooperative Extension, Virginia Tech

August 2001 - May 2002 
Project Assistant, Virginia Cooperative Extension, Virginia Tech August 1999 - March 2000

Instructor, Department of Interior Architecture, King Mongkut's Institute of Technology, Bangkok, Thailand October 1994 - Present

Instructor, Department of Interior Design, Bangkok University, Thailand January 1994 - October 1994

Interior Designer, Waranz Design Group Co., Ltd., Bangkok, Thailand April 1993 - January 1994

Interior Design Trainee, Casa Co., Ltd., Bangkok Thailand April - May 1992

Interior Design Trainee, Satian and Associates Co., Ltd., Bangkok, Thailand September - October 1989

\section{HONORS}

Sigma Phi Omega: National and Professional Honor Society in Gerontology Initiated: 1998, Virginia Polytechnic Institute and State University

Kappa Omicron Nu: National Home Economics Honor Society Initiated: 1996, Virginia Polytechnic Institute and State University

\section{SERVICES}

\section{Virginia Tech Building Committee}

Graduate student representative on the Virginia Tech Building Committee for the 20012002 academic year

Sigma Phi Omega: National and Professional Honor Society in Gerontology Secretary for the $2000-2001$ academic year

Kappa Omicron Nu: National Home Economics Honor Society

Treasurer for the1998 - 1999 academic year

\section{MEMBERSHIPS}

The American Association of Housing Educators

The Interior Design Educators Council

The Thai Interior Designers Association 